\title{
3-D FINITE ELEMENT ANALYSIS OF LATERALLY LOADED SHORT SHAFTS IN SOIL
}

\author{
by \\ Jasinthan Arulanantham, B.Eng. (Hons) \\ University of Moratuwa, 2001 \\ A thesis \\ presented to Ryerson University \\ in partial fulfillment of the \\ requirements for the degree of \\ Master of Applied Science \\ in the program of \\ Civil Engineering
}

Toronto, Ontario, Canada, 2015

(c) (Jasinthan Arulanantham) 2015 


\section{AUTHOR'S DECLARATION}

I hereby declare that I am the sole author of this thesis.

I authorize Ryerson University to lend this thesis to other institutions or individuals for the purpose of scholarly research.

Author's signature

Date

I further authorize Ryerson University to reproduce this thesis by photocopying or by other means, in total or in part, at the request of other institutions or individuals for the purpose of scholarly research.

Author's signature

Date 


\begin{abstract}
The objective of this research is to conduct an optimized design of drilled shaft foundation for noise barrier walls. A non-linear three-dimensional (3D) finite element method (FEM) program, Plaxis $3 \mathrm{D}$, is used to investigate the behaviour of laterally loaded shafts. Two published cases are used to calibrate the modelling method and validate the numerical results. In the case of a field test performed by Helmers (1997), FEM results agree very well with field tests in terms of ultimate load and deflection curves. In the laboratory test conducted by Uncuoglu \& Laman (2011) case, numerical results agree well with their results except the soil-shaft interface modelling part. The Plaxis 3D embedded pile model tends to overestimate the lateral load capacity of a smooth pile. Though it is satisfactory in modelling a pile with a "rough" surface. Two theoretical formulas in estimating lateral capacity of piles are also compared with the FEM results. It is found that Broms's (1964b) theory for cohesionless soils has underestimated the lateral load capacities and Brinch-Hansen's (1961) theory provides a more accurate estimation. In summary, 3-D FEM is able to accurately simulate the behaviour of laterally loaded drilled shafts in soil.
\end{abstract}




\section{ACKNOWLEDGEMENT}

Primarily, I would like to express my sincere thanks to my supervisor, Professor Jinyuan Liu for contributing and supporting in all aspects of this research. He was providing a continuous source of ideas relating to the technical approach, numerical modelling, and the practical applications of the research. I gratefully acknowledge his help and guidance in preparing this thesis. I also appreciate his caring and encouragement during the period of the research study. In addition, Prof. Liu conducted group discussions frequently on areas regarding this research and other areas of geotechnical engineering, which were very beneficial.

Secondly, thanks for the financial support for this research that was provided by NSERC Engage Program in conjunction with the support from Safe Roads Engineering Ltd. I wish to thank Mathews Forcelini for his support at the beginning of this research study.

Finally, I wish to thank my wife, and my daughter for their constant love and support throughout my educational career. 


\section{TABLE OF CONTENTS}

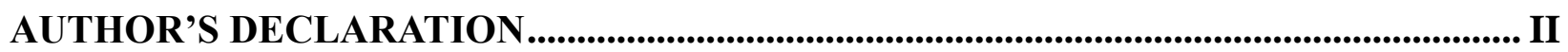

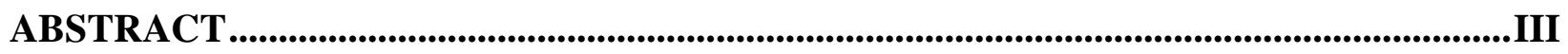

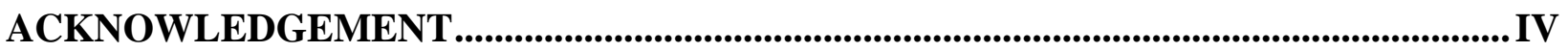

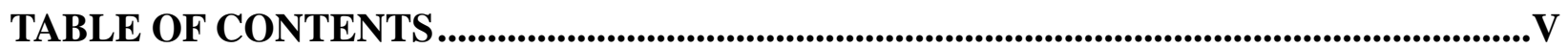

TABLE OF TABLES ......................................................................................................... VII

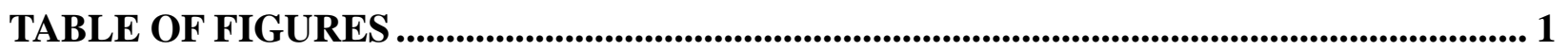

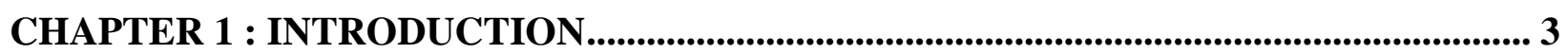

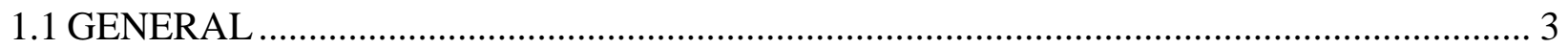

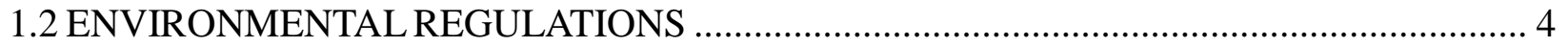

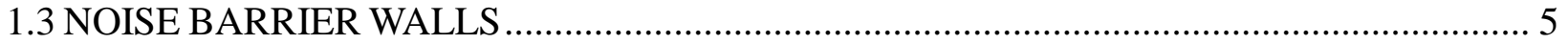

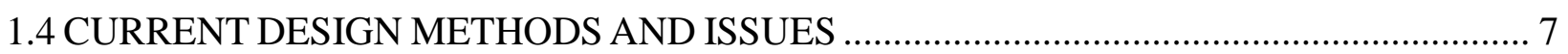

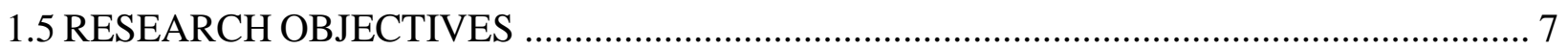

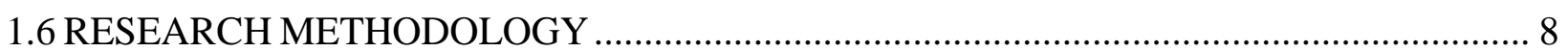

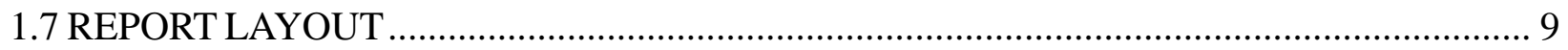

CHAPTER 2: CURRENT DESIGN OF NOISE BARRIER WALLS ..................................... 10

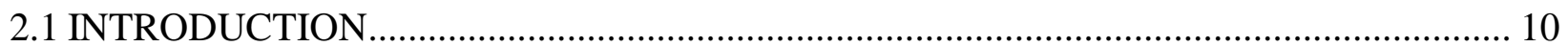

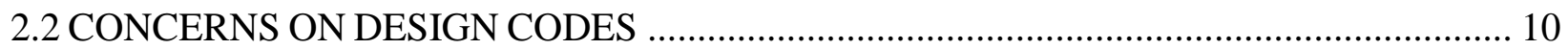

2.3 LATERALLY LOADED SHAFTS OR PILES ………..................................................11

2.4 WIND LOADS FOR DESIGN OF SOUND BARRIERS ………….................................. 15

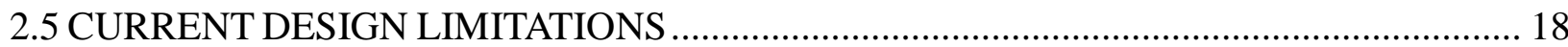

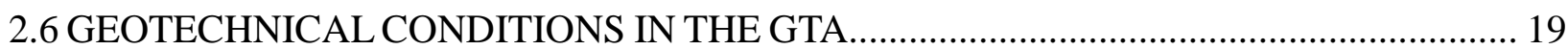

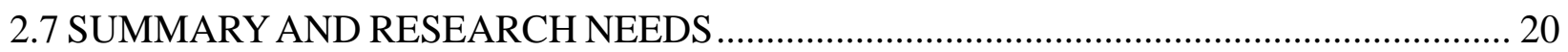

CHAPTER 3: ANALYSIS METHODS AND PROCEDURES............................................ 21

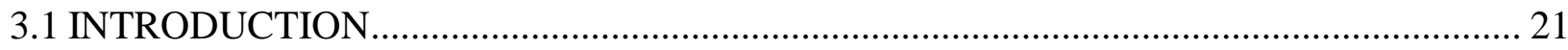

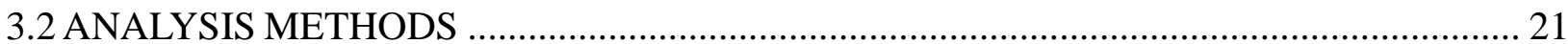

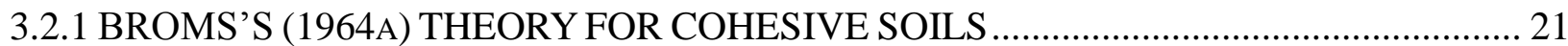

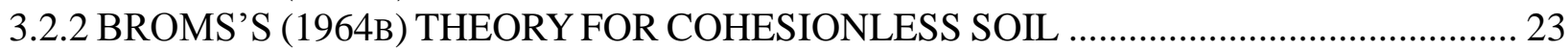

3.2.3 BRINCH-HANSEN'S (1961) THEORY FOR SOILS HAVING COHESION AND

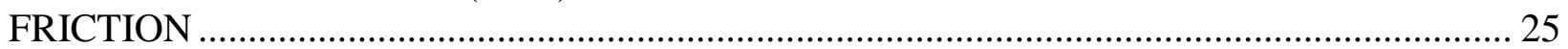

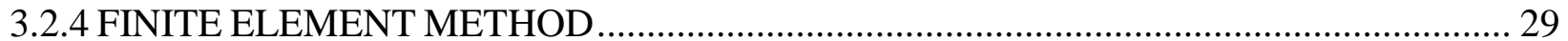

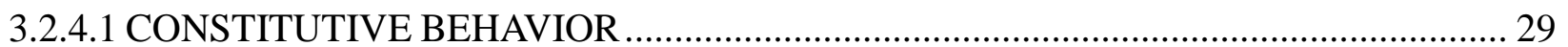

3.2.4.2 STEPS INVOLVED IN THE FINITE ELEMENT METHOD …..................................... 32

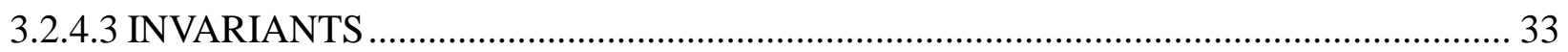

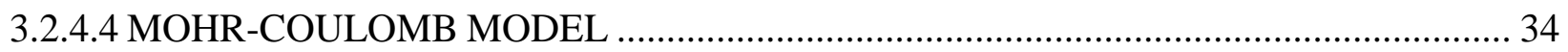

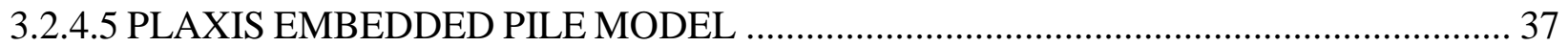


CHAPTER 4 : 3-D FEM ANALYSES AND RESULTS ........................................................ 42

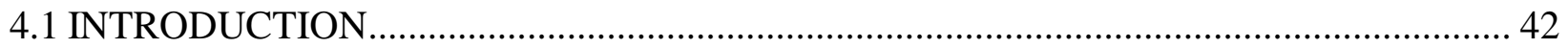

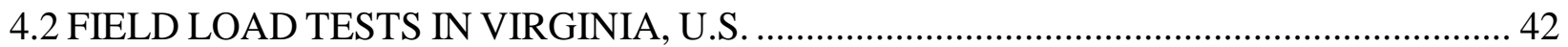

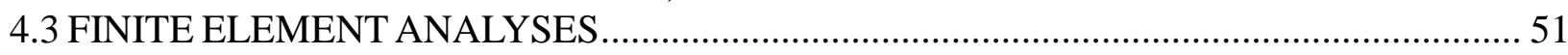

4.3.1 3-D FEM MODEL OF A LATERALLY LOADED PILE ................................................. 51

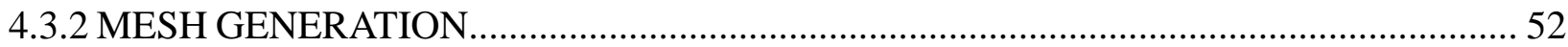

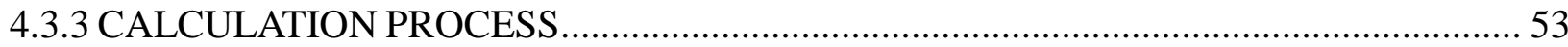

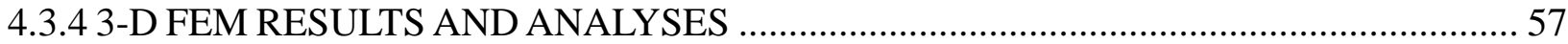

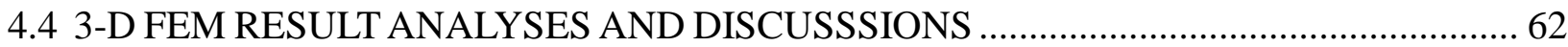

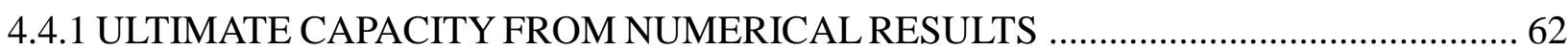

4.4.2 COMPARISON WITH FIELD MEASUREMENTS …………………………............... 75

4.4.3 COMPARISON WITH ULTIMATE LATERAL LOAD CAPACITY THEORIES............... 75

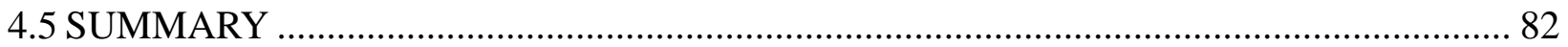

CHAPTER 5: PARAMETRIC STUDIES AND ANALYSES .................................................. 84

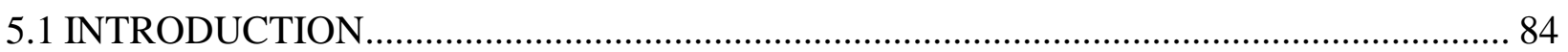

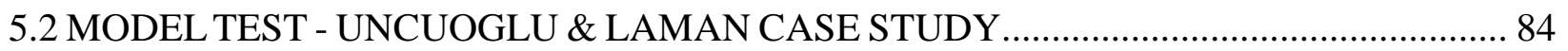

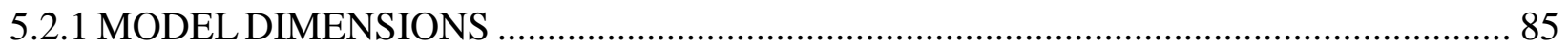

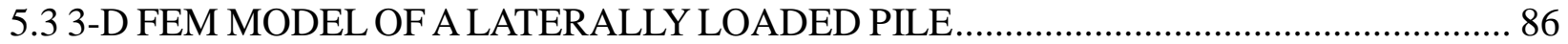

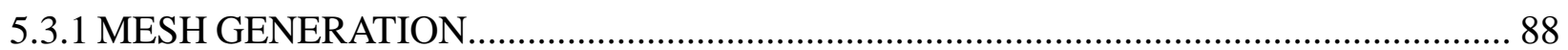

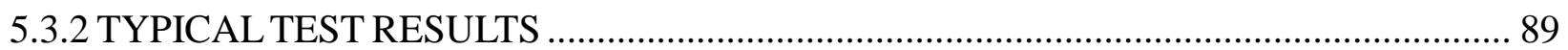

5.4 3-D FEM PARAMETRIC ANALYSIS OF A LATERALLY LOADED PILE IN SAND........ 90

5.4.1 EFFECT OF INCREASING ELASTICITY MODULUS WITH DEPTH ........................... 90

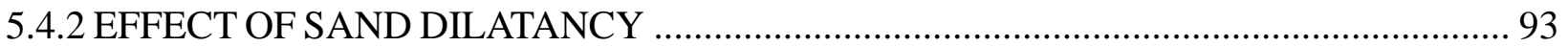

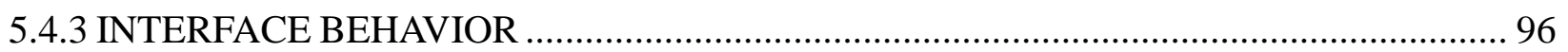

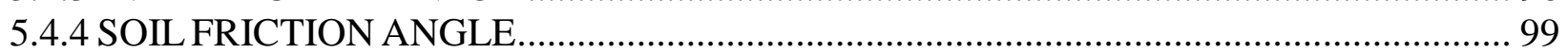

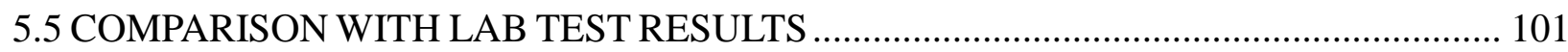

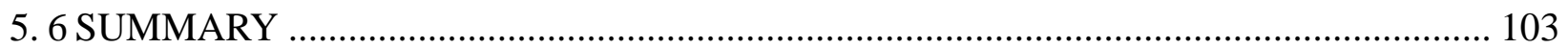

CHAPTER 6: CONCLUSION AND DISCUSSION..................................................... 104

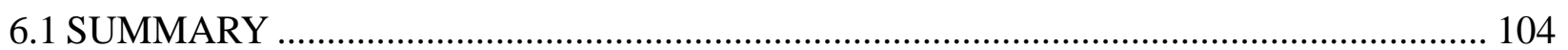

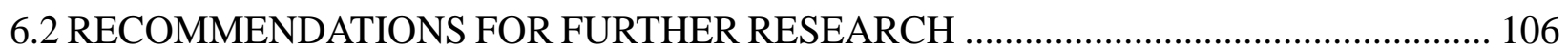

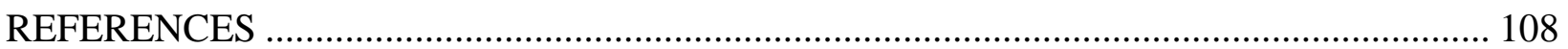




\section{TABLE OF TABLES}

Table 1.1 Layout of the thesis.

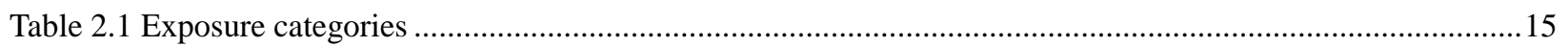

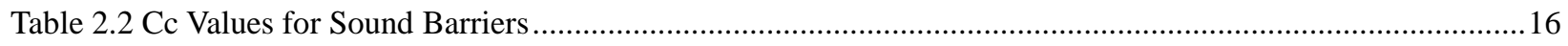

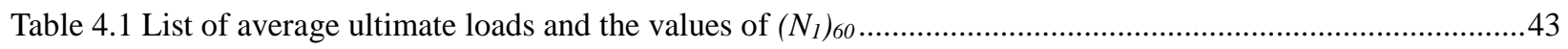

Table 4.2 Properties of the soil at the test sites ....................................................................................................4

Table 4.3 SPT - Based soil and rock classification systems (Skempton, 1986) .......................................................45

Table 4.4 Typical values of Young's modulus for granular materials (Kézdi \& Rétháti, 1974 \& Prat et al., 1995) .....45

Table 4.5 Typical values of Young's modulus for cohesive materials (Kézdi \& Rétháti, 1974 and Prat et al., 1995) .46

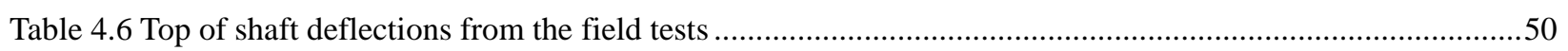

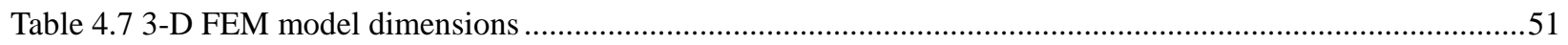

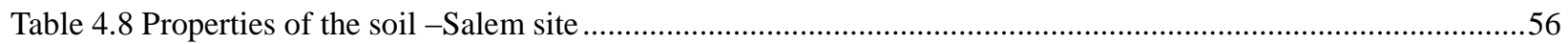

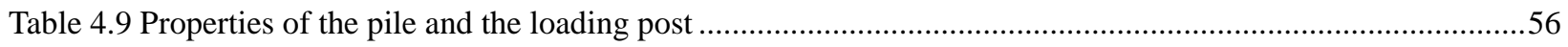

Table 4.10 Numbers of elements and nodes generated for different mesh coarseness conditions ...............................57

Table 4.11 The influence of mesh coarseness on the maximum pile head displacements at the end of analysis .........57

Table 4.12 3-D FEM simulation of field tests in Virginia, U.S.........................................................................62

Table 4.13 Comparison with field measurements on ultimate lateral load .............................................................75

Table 4.14 Comparison of 3-D FEM analyses \& Broms's (1964b) theory on ultimate lateral load ............................76

Table 4.15 Comparison with Brinch-Hansen's (1961) theory on ultimate lateral load................................................77

Table 4.16 Summary of ultimate lateral capacities of drilled shafts in Virginia along with predictions from FEM \&

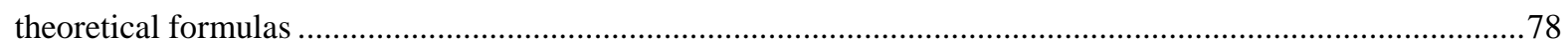

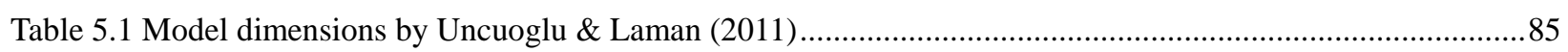

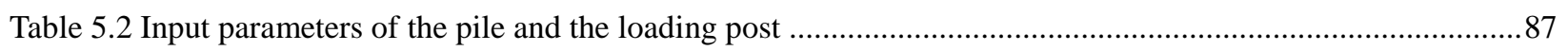

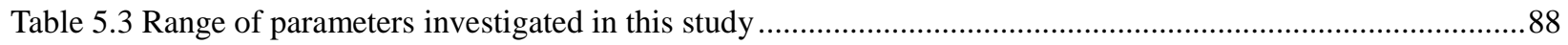

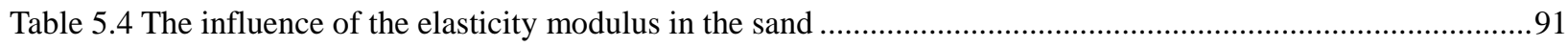

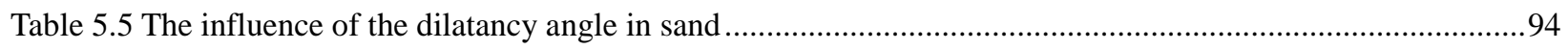

Table 5.6 The influence of the interface behaviour in sand ..............................................................................97

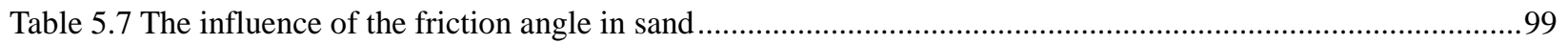

Table 5.8 Soil properties used for comparison study - Uncuoglu \& Laman case ......................................................101

Table 5.9 Comparison of the results - Uncuoglu \& Laman case ............................................................................ 102 


\section{TABLE OF FIGURES}

Figure 1.1 Picture of a typical noise barrier wall (Source-Florida Department of Transportation) ............................5

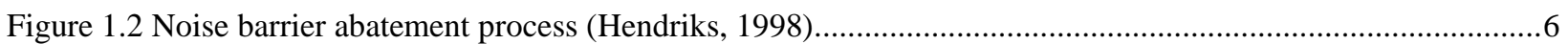

Figure 2.1 Pile response to a lateral load (Helmers, 1997) ................................................................................14

Figure 2.2 Loads on sound wall foundations due to wind (Helmers, 1997) …...........................................................17

Figure 2.3 Typical glacial till (Source- Mark Clark, http://free-stockillustration.com) ..............................................19

Figure 3.1 Soil reactions for Broms's method for cohesive soils (Helmers, 1997) .................................................22

Figure 3.2 Soil reaction for Broms's method for cohesionless soils (Helmers, 1997) ..............................................24

Figure 3.3 Soil reaction for Brinch-Hansen's theory (Helmers, 1997) ................................................................25

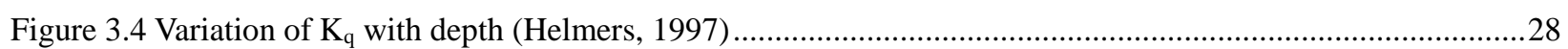

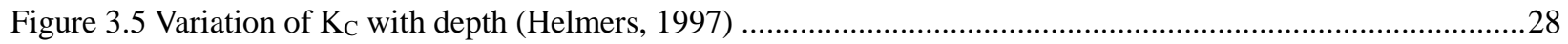

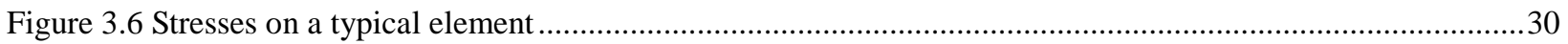

Figure 3.7 Mohr's circles of effective stress (Ports \& Zdravkovic, 2001) ............................................................35

Figure 3.8 Mohr - Coulomb yield surface in principal stress space (Ports \& Zdravkovic, 2001) ..............................36

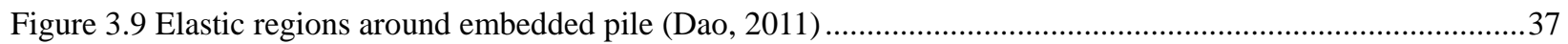

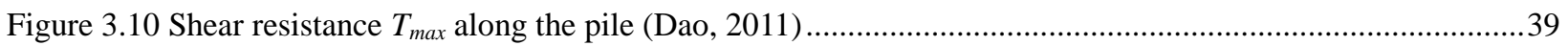

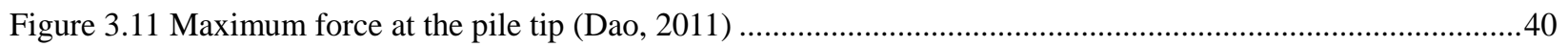

Figure 3.12 Node model for the soil-pile interaction (Dao, 2011) .........................................................................41

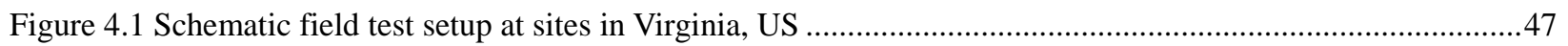

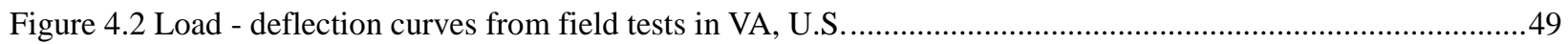

Figure 4.3 3-D finite element mesh used for model the soil .............................................................................53

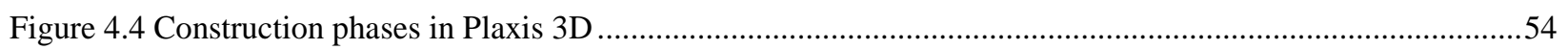

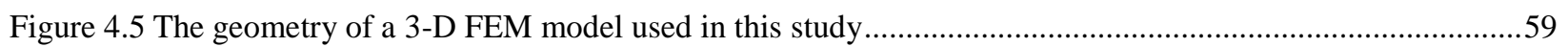

Figure 4.6 Typical mesh generation of the 3-D FEM model in Plaxis 3D ................................................................59

Figure 4.7 Typical deformed mesh after FEM analysis in Plaxis 3D ................................................................60

Figure 4.8 Total horizontal displacemet, $U x$, at the pile head after FEM analysis .....................................................60

Figure 4.9 Distribution of bending moment along the pile depth at the end of FEM analysis ..................................61

Figure 4.10 Distribution of shear force along the pile depth at the end of FEM analysis .........................................61

Figure 4.11 Total deflection of the shaft at the end of FEM analysis ..................................................................65

Figure 4.12 Distribution of bending moment along the depth at the end of FEM analysis ........................................65

Figure 4.13 Distribution of shear force along the depth at the end of FEM analysis................................................66

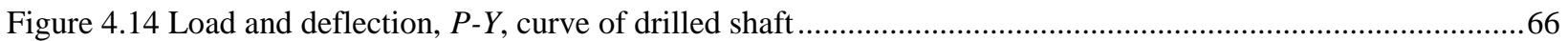

Figure 4.15 Total deflection of the shaft at the end of FEM analysis ..................................................................67 
Figure 4.16 Distribution of bending moment along the depth at the end of FEM analysis

Figure 4.17 Distribution of shear force along the depth at the end of FEM analysis.............................................68

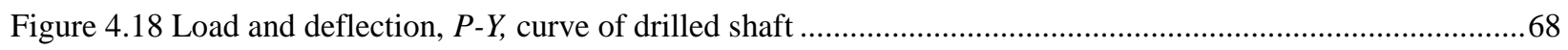

Figure 4.19 Total deflection of the shaft at the end of FEM analysis .............................................................69

Figure 4.20 Distribution of bending moment along the depth at the end of FEM analysis ..................................69

Figure 4.21 Distribution of shear force along the depth at the end of FEM analysis.............................................

Figure 4.22 Load and deflection, $P-Y$, curve of drilled shaft .........................................................................

Figure 4.23 Total deflection of the shaft at the end of FEM analysis ................................................................

Figure 4.24 Distribution of bending moment along the depth at the end of FEM analysis ..................................71

Figure 4.25 Distribution of shear stress along the depth at the end of FEM analysis .............................................72

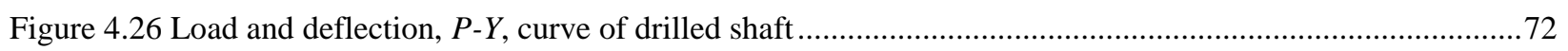

Figure 4.27 Total deflection of the shaft at the end of FEM analysis ..........................................................73

Figure 4.28 Distribution of bending moment along the depth at the end of FEM analysis ..................................73

Figure 4.29 Distribution of shear stress along the depth at the end of FEM analysis ...........................................74

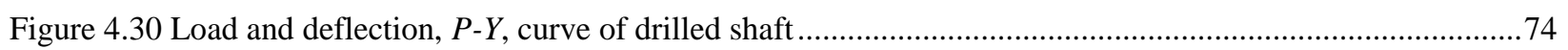

Figure 4.31 Comparison of the load-deformation curves for the Prices Fork site test..........................................79

Figure 4.32 Comparison of the load-deformation curves for the Salem Site test .............................................. 79

Figure 4.33 Comparison of the load-deformation curve for the Suffolk Site test .............................................. 80

Figure 4.34 Comparison of the load-deformation curve for the Fairfax Site test ...................................................80

Figure 4.35 Comparison of the load-deformation curve for the Roberts Road Site test ...................................... 81

Figure 5.1 The schematic view of the model test setup used by Uncuoglu \& Laman (2011) ................................85

Figure 5.2 A typical deformed mesh after FEM analysis- Uncuoglu \& Laman case ..........................................89

Figure 5.4 Influence on load - deformation curve from dilatation angle ...........................................................95

Figure 5.5 Influence on load-deformation curve from soil-shaft interface ...................................................98

Figure 5.6 Influence of load-deformation curve from friction angle ........................................................ 100

Figure 5.7 Comparison between FEM results and laboratory measurement .................................................. 102 


\section{CHAPTER 1 : INTRODUCTION}

\subsection{GENERAL}

The most effective method to mitigate roadway, railway, and industrial noise sources is constructing a noise barrier wall. Noise barrier walls are designed to protect residents of sensitive land use areas from noise pollution. Designers started to use noise barriers extensively in the United States (U.S.) after introducing noise regulations in the early 1970s. New highways are being built everyday through heavily populated residential areas. Therefore, the noise generated by high speed traffic has become an environmental concern. At the same time, the welfare of the surrounding population should also be considered seriously. In order to handle these problems effectively, noise barrier walls can be erected on both sides of a highway to reflect and absorb sound energy, and reduce the amount spread into residential and commercial zones.

For noise barrier walls, drilled shafts or piles are the most popular foundation types. Larger diameter short shafts or piles are also used to support other structures such as transmission towers, advertisement posts, overhead catenary systems in railway networks, and water towers. These types of structures are capable of withstanding significant lateral loads and overturning moments. Due to the relatively small vertical forces, the axial capacity of these shafts is normally guaranteed without much consideration.

When these foundations are designed, the wind load is considered as the main load. It leads to a complex soil-structure interaction problem; i.e. the lateral capacity of deep foundations. The analysis of laterally loaded piles is a complicated soil-pile interaction problem due to the fact that the soil reaction is dependent of the pile movement which, on the other hand, is dependent on soil response (Sun , 1994).

The interaction between the pile and the soil governs the behavior of piles subjected to lateral loads. In addition, this is a non-linear three-dimensional (3-D) soil-structure interaction problem. 
There are many influencing factors in the reaction of piles subjected to lateral loads, including the stress-strain behavior of the soil, shear strength, stiffness and volume change characteristics, as well as soil-pile interface. As a result, the load-transfer mechanism in pile foundations is so complicated and not yet fully understood.

During this research, a three-dimensional finite element method (FEM) is used to investigate the behaviour of a laterally loaded short shaft in soil. The results will be compared with a number of published case studies and the theories proposed by Broms and Birch-Hansen to better estimate its lateral capacity and deformation behaviour.

\subsection{ENVIRONMENTAL REGULATIONS}

Nowadays, there are many complex motorized transport systems in use for our daily needs such as railroads, automobiles and airplanes. Consequently, there is a need to reduce or prevent noise caused by such systems, or else it will affect the surrounding neighborhoods and businesses. Therefore, a number of devices and systems were produced which have been slightly effective in attenuating such noise.

A healthy young person's normal range of hearing is $20 \mathrm{~Hz}$ to $20 \mathrm{KHz}$. One Hertz (Hz) is equivalent to the number of pressure variations per second. Sound is the pressure variation in a medium like air, water, etc., that the human ear can hear. Sound pressure levels can be measured in $\mathrm{dB}$ (Decibel). The threshold of hearing is $0 \mathrm{~dB}$, and the threshold of pain is $140 \mathrm{~dB}$. Leq (equivalent sound level) is a measure of sound level over a period of time.

There are mandatory requirements which have been posed on noise abatements by many municipalities, if the noise level reaches a certain threshold. As stated by the Region of Halton Abatement Policy (2011), retrofitting noise mitigation barriers may be installed in existing residential areas, if the reception subject receives sound levels of $60 \mathrm{dBA}$ or higher. This is during the Leq day time 7:00 a.m. to 11:00 p.m. The traffic noise in outdoor living areas can be 
reduced to the extent that is technically, economically, and administratively practical toward the region's recognized sound level objectives for retrofit cases.

\subsection{NOISE BARRIER WALLS}

As specified by Knight (1997), a typical noise barrier wall has concrete footings, spaced around 15 feet or more apart; and a steel or concrete post in the general shape of an I-beam with lateral channels. The barrier wall is set in concrete and secured in a vertical position for fixing the absorbing and sound reflecting panels in the channels between adjacent posts.

It is also designed to withstand wind loads up to $70 \mathrm{mph}$. Fig. 1.1 shows a picture of a typical noise barrier wall.

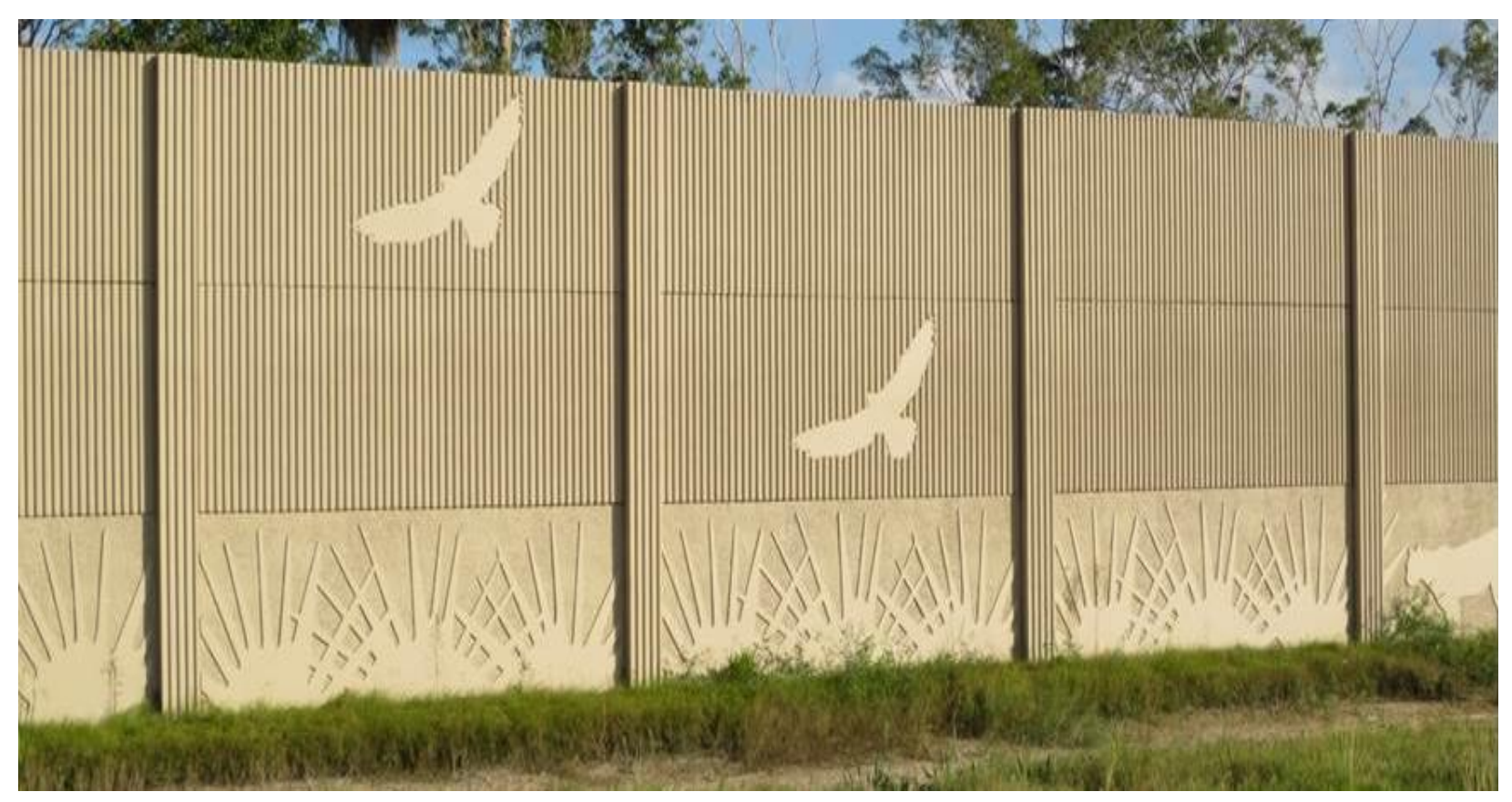

Figure 1.1 Picture of a typical noise barrier wall (Source-Florida Department of Transportation) 


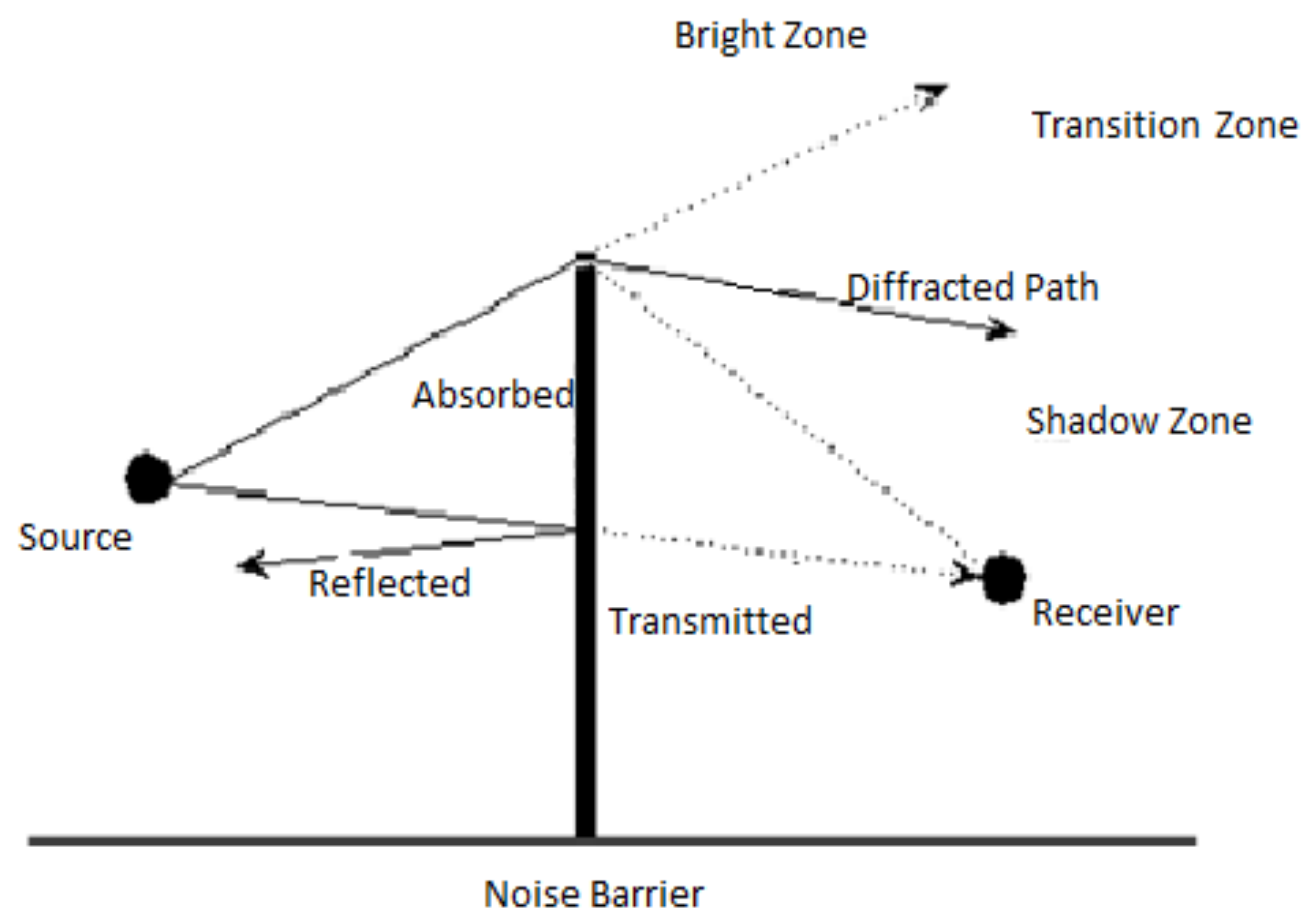

Figure 1.2 Noise barrier abatement process (Hendriks, 1998)

Fig. 1.2 describes the noise barrier abatement process. The sound propagated through a community from heavy highways can be reduced by the noise barrier wall. As shown in the Fig.1.2, the sound may be reflected back across the highway, absorbed, transmitted, or forced to take a diffracted path (i.e. a longer path). All frequencies are not bent uniformly by the diffraction because of the nature of sound waves. The barrier diffracts higher frequency waves to a lesser degree. In the meantime, the lower frequency waves are diffracted deeper into the "shadow zone" behind the barrier, which is closer to the receiver. Therefore, the higher frequency waves are attenuated more effectively by the barrier as compared with the lower frequency waves (Hendriks, 1998) 


\subsection{CURRENT DESIGN METHODS AND ISSUES}

It is important to analyze the load system when a noise barrier wall foundation is designed. The noise wall is considered to present the low magnitude dead load (due to the light weight material). There is no live load. The wind load is taken as the structural main load, which is a lateral load on the structure and a consequent lateral load on the foundation itself.

There are numerous methods available in the geotechnical literature for designing of foundations subjected to horizontal forces. There are some empirical methods (i.e. Broms; Brinch- Hansen), which are easy to handle but hard in physical understanding, leading to project uncertainties. Some methods have larger physical accuracies; however, there are complications in using them due to the complexity of the formulations presented.

\subsection{RESEARCH OBJECTIVES}

The objective of this research is to conduct an optimized design of drilled shaft foundations for noise barrier walls in order to achieve safe and cost-effective design solutions. The design guidelines for the foundations of noise barrier walls are provided in general by the agencies like FHWA (2000). However, the available theories are based on many simplifications, which may lead to improper design of foundations. This may be due to the many variables involved in the design. In addition, the lateral capacity of a drilled shaft is a three-dimensional (3-D) problem. Therefore, it is essential to analyse the problem using a non-linear 3D FEM.

The FEM program, Plaxis 3D, will be used to investigate real field studies by analysing various variables involved in the design of laterally loaded shafts. The findings will notify the issues related to soil properties, numerical modelling procedures, and design methods. The results shall be valuable to geotechnical community by providing safe and cost-effective solutions of drilled shaft foundations for noise walls. 


\subsection{RESEARCH METHODOLOGY}

Drilled shaft foundation for a noise barrier wall is generally considered as having a relatively high stiffness and a limited depth. Therefore, its lateral capacity is primarily controlled by the failure of the surrounding soil. It can be structurally designed based on its moment and shear forces after the ultimate lateral capacity is finalized.

In this research, Plaxis 3D embedded pile model will be used to investigate the ultimate lateral load capacity of the drilled shaft foundations. In the calibration stage, numerical simulations of published cases will be done to validate an appropriate modelling method.

The data from Matthew Justin Helmer's report (1997) of Virginia Polytechnic Institute and State University, United States is used to analyse the problem. Field load test results and the soil properties from five different sites such as Prices Fork, Salem, Fairfax County, Parkway Suffolk, and Roberts Road are used to perform the numerical analysis. Ultimate Lateral load capacities are also calculated using the conventional empirical theories proposed by Broms (1981) and Brinch-Hansen (1961).The results obtained from numerical analyses, experimental studies, and conventional theories will be compared to each other. The most appropriate theory can be selected and recommended among various earth pressure theories by comparing with numerical modelling results.

In addition, a parametric study will be performed using Plaxis 3D to analyse the effect of the elasticity modulus, dilatancy angle, friction angle, and interface behavior of the sandy soil on the lateral load capacity of short rigid piles. A case study from Uncuoglu \& Laman (2011) will be used to conduct these studies. 


\subsection{REPORT LAYOUT}

The detailed layout of this thesis is shown in Table 1.1.

Table 1.1 Layout of the thesis

\begin{tabular}{|l|l|l|}
\hline Chapter & Title & Contents \\
\hline Chapter 1 & Introduction & Introduction and research background \\
\hline Chapter 2 & $\begin{array}{l}\text { Current Design of } \\
\text { Noise Barrier Walls }\end{array}$ & Design challenges, methods and limitations \\
\hline Chapter 3 & $\begin{array}{l}\text { Analysis Methods and } \\
\text { Procedures }\end{array}$ & $\begin{array}{l}\text { Explanation about the different design methods } \\
\text { Finite element method }\end{array}$ \\
\hline Chapter 4 & $\begin{array}{l}\text { Numerical Studies and } \\
\text { Analyses }\end{array}$ & $\begin{array}{l}\text { Development of numerical models using 3D-finite } \\
\text { element method } \\
\text { Present the results and respective discussions }\end{array}$ \\
\hline Chapter 5 & $\begin{array}{l}\text { Parametric Studies and } \\
\text { Analyses }\end{array}$ & $\begin{array}{l}\text { Parametric studies by 3D- finite element method } \\
\text { Results and analyses }\end{array}$ \\
\hline Chapter 6 & Conclusion and & Discussion ,conclusion \& future research needs \\
\hline
\end{tabular}




\section{CHAPTER 2: CURRENT DESIGN OF NOISE BARRIER WALLS}

\subsection{INTRODUCTION}

The first theories on the subject of the ultimate load design for horizontally loaded foundations were developed in the 1960's.

These theories are:

$>$ Broms's (1964a) theory for cohesive soils (soils with cohesion $>0$, friction $=0$ )

$>$ Broms's (1964b) theory for cohesionless soils ( soils with cohesion $=0$, friction $>0$ )

$>$ Brinch-Hansen's (1961) theory for soils having both cohesion and friction (soils with cohesion $>0$ and friction $>0$ )

The shaft foundation is assumed to behave as a rigid body according to ultimate load theories. It is also assumed that bending deformations of the shaft are negligible when it is compared with movements due to the deformation of the soil around the shaft; i.e. the lateral load capacity calculated using the above methods is connected to failure of the soil.

\subsection{CONCERNS ON DESIGN CODES}

There are many theoretical approaches available to predict the lateral capacity of a deep foundation (Tomlinson \& Woodward, 2008). However, these theories can result in overdesign of foundations because they are based on many simplifications. This occurs also due to many variables involved in the practice.

Firstly, the soil properties vary largely in both regional and local scales. In particular, the overburden soils covering the Greater Toronto Area (GTA) are primarily glacial deposits. These overburden soils are characterized by their highly variable material properties and complex nonlinear stress-strain characteristics (Baker et al., 1998). The evaluation of the geotechnical 
variables for glacial tills is a subjective process. It can easily lead to conservative or unsafe estimations.

Secondly, analysing and designing of a shaft under lateral loading is a complex soil-pile interaction problem (Sun, 1994). Since the theories developed are based on empirical assumptions and correlations more than on physical principles, they may lead to uncertainty and subsequent overdesign.

Thirdly, although the lateral capacity of a drilled shaft is three-dimensional (3-D), the empirical methods stated above simplify this problem into a 2-D plane strain problem. There are significant differences that exist between 2-D and 3-D failure planes, and these require a detailed investigation about the effect on lateral capacity of shaft foundations (Ashour et al., 1998).

As this research is intended to conduct an optimized drilled shaft design for horizontal loads considering the 3-D affect, the 3-D FEM software, Plaxis 3D, will be used to predict the capacity of the shafts.

\subsection{LATERALLY LOADED SHAFTS OR PILES}

The Lateral load on the drilled shaft is vital for noise barrier walls in relation to the foundation design as stated before. It was proposed by Duncan et al (1994) that deep foundations subjected to lateral loads should be designed in order that they satisfy three conditions.

- The drilled shaft should be capable of carrying the imposed load with an adequate margin of safety against failure in bending;

- The deflection of the foundation under loading conditions should not be larger than the allowable deflection for the structure supported by the foundation;

- The soil surrounding the shaft should not be loaded so heavily that its ultimate loadcarrying capacity is reached; 
It is also stated by Duncan (1994) that the considerations of bending moments and deflections govern design, for the reason that the ultimate load-carrying capacity of the soil is reached only at very large deflections. Although the ultimate capacity of the soil around the shaft may not be fully mobilized, its response is nonlinear. Therefore, for laterally loaded deep foundations, the relationships among loads, moments and deflections are nonlinear, even in the safe working range of loads. This proves the importance of taking into account the nonlinear behavior of the soil-foundation system when designing the laterally loaded shafts.

There are two factors that contribute to the nonlinear response of the soil around the shaft:

1. The load-deflection behavior of the soil around the shaft is nonlinear. Because the load transferred from the shaft to the soil increases by a fraction of its value, the deflection increases by a greater fraction. Although the behavior of the shaft may continue to be linear, the soil-shaft behavior is nonlinear.

2. The strength of the soil around the upper part of the shaft becomes mobilized. Therefore, the additional load is transferred to a greater depth, where the strength of the soil will not be mobilized to the same extent. The pile in effect must span a greater distance, so as to transfer the loads to a greater depth, resulting that the moments increase more rapidly than the load at the top. It can be seen in Randolph, et al. (1984): the depth at which the greatest soil reaction occurs and the depth at which the maximum moment occurs are deeper for a load of $100 \mathrm{kN}$ than they are for a load of $20 \mathrm{kN}$.

In recent times, extensive theoretical approaches have been developed for predicting the ultimate load capacity of soil and the shaft's lateral deflection or moment. Many researchers such as Broms (1964), Birch-Hansen (1961), and Matlock and Reese (1960) have presented a number of methods, curves and tables for reference. However, they are based more on simplifications and correlations than on rational references. It means that there are many variables to be considered in the design. 
As shown in Fig. 2.1, when a lateral point load is applied to the shaft, the shaft rotates and displaces in the direction of the applied load. The shaft rotates around a center of rotation located somewhere above the bottom of the shaft. Passive pressures are developed on the front of the shaft above the center of rotation, and the active pressures are developed on the back. In addition, below the center of rotation, the passive pressures are developed on the back of the shaft, and the active pressures are developed on the front. The eccentricity of the applied load and the properties of the soil determine the location of the center of rotation.

Finally, when the full shear strength of the surrounding soil is mobilized, no further change in earth pressure is possible. Consequently, the shaft rotates and deflects freely, with no further increase in load. This state of the shaft is called the "ultimate load condition." The magnitude of the applied load necessary to reach this ultimate load condition can be determined by ultimate load theories. This applied load is named as the "lateral load capacity" of the foundation. The lateral load capacity depends on the foundation dimensions, soil properties, and the eccentricity of the applied load. 


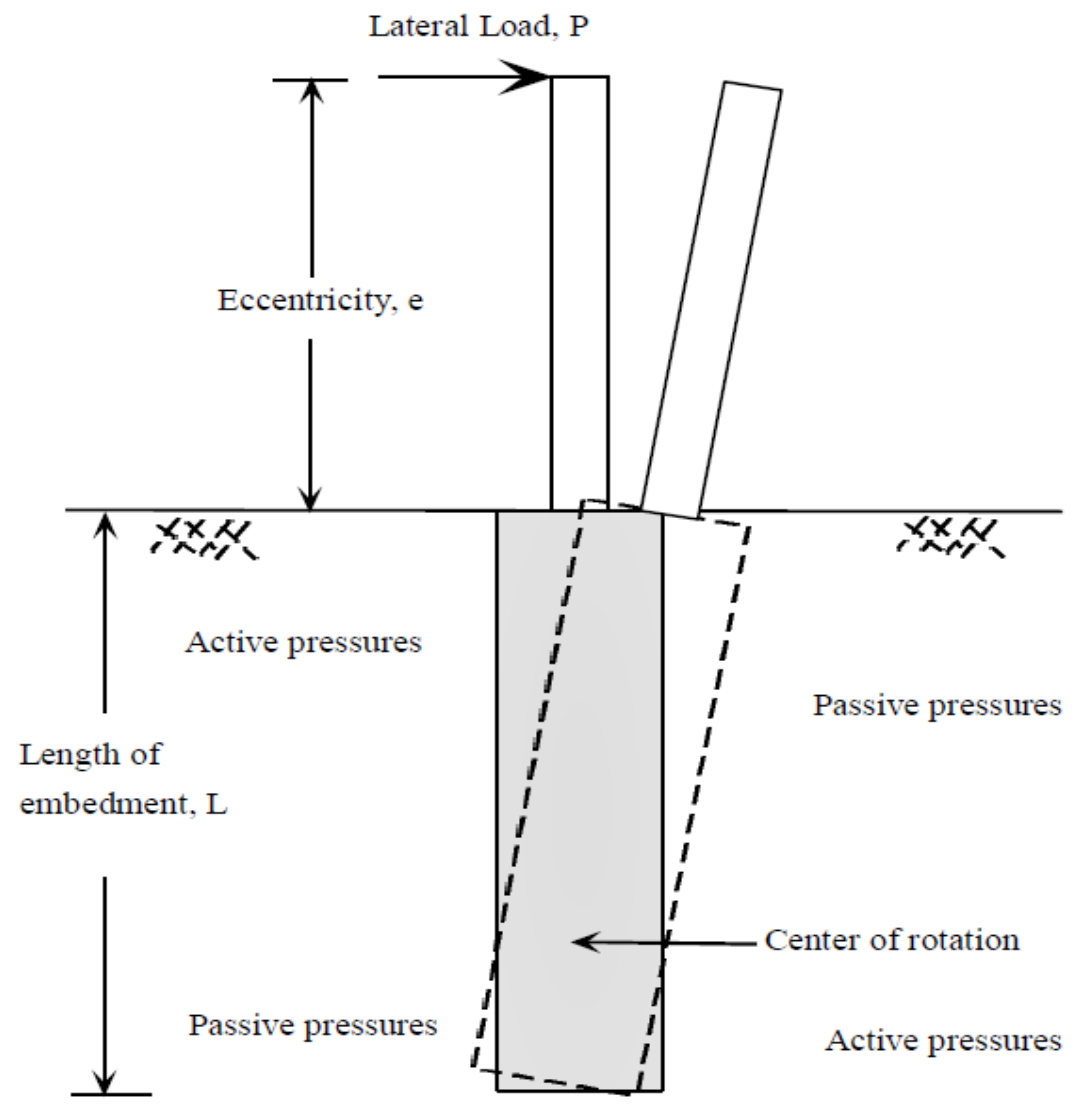

Figure 2.1 Pile response to a lateral load (Helmers, 1997)

According to Helmers (1997), the difference between active and passive earth pressures that resists movement of the shaft is larger than it would be calculated using conventional earth pressure theories, such as the Rankine theory. This is the most important characteristic of the interaction between a drilled shaft and surrounding soil.

The conventional earth pressure theories consider only 2-D conditions. This 2-D simplification corresponds to a long wall moving in the soil. In the case of a circular drilled shaft, larger passive pressures are possible due to three-dimensional (3D) effects: a zone within the soil that is wider than the face of the shaft is involved in resisting the movement of the shaft. Hence, it is necessary to use the methods that could consider 3-D effects of soil-shaft interaction. For this purpose, 3-D FEM is used in this study to model the complex 3-D soil-shaft interaction. 


\subsection{WIND LOADS FOR DESIGN OF SOUND BARRIERS}

In the design of sound walls, the critical important aspect is to get the right wind load. This wind load can be obtained based on the "Guide Specifications for Structural Design of Sound Barriers," 1989 and 1992 Revisions (AASHTO 1989, 1992).

\section{a) Wind Pressures}

Noise barrier walls are normally designed for wind pressures resultant from 50-year recurrence interval wind speeds. The wind pressure can be calculated using the following equation (Eq.2.1):

$$
P=0.00256(1.3 V)^{2} C_{d} C_{c}
$$

Where

$$
\begin{aligned}
& P \text { - Wind pressure (psf) } \\
& V \text { - Wind speed (mph) based on a } 50 \text { year mean recurrence interval } \\
& (1.3 \mathrm{~V})-30 \% \text { gust speed } \\
& C_{d} \text { - Drag coefficient ( } 1.2 \text { for sound barriers) } \\
& C_{c} \text { - Combined height, exposure, and location coefficient }
\end{aligned}
$$

The exposure categories of wind pressures are explained in Table 2.1.

Table 2.1 Exposure categories

\begin{tabular}{|l|l|}
\hline Exposure & Description \\
\hline B1 & $\begin{array}{l}\text { Urban and suburban areas with many closely spaced obstructions that prevail in } \\
\text { the upwind direction from the sound barrier for distance of a minimum } 1500 \text { feet }\end{array}$ \\
\hline B2 & Urban and suburban areas with more open terrain (not like exposure B1) \\
\hline C & $\begin{array}{l}\text { Open terrain with scattered obstructions. This is used for sound barriers located on } \\
\text { bridge structures, retaining walls, or traffic barriers }\end{array}$ \\
\hline D & $\begin{array}{l}\text { Unobstructed coastal areas open to wind flowing over large bodies of water, } \\
\text { extending inland from the coastline a distance of one half mile }\end{array}$ \\
\hline
\end{tabular}


Table 2.2 Cc Values for Sound Barriers

\begin{tabular}{|c|c|c|c|c|}
\hline $\begin{array}{c}\text { Distance from average level } \\
\text { of adjoining ground surface } \\
\text { to centroid of loaded area in } \\
\text { each height zone, } \mathrm{H}(\mathrm{ft} .)\end{array}$ & $\begin{array}{c}\text { Cc for } \\
\text { exposure } \\
\text { category B1 }\end{array}$ & $\begin{array}{c}\text { Cc for } \\
\text { exposure } \\
\text { category B2 }\end{array}$ & $\begin{array}{c}\text { Cc for } \\
\text { exposure } \\
\text { category C }\end{array}$ & $\begin{array}{c}\text { Cc for } \\
\text { exposure } \\
\text { category D }\end{array}$ \\
\hline $0<\mathrm{H} \leq 14$ & 0.37 & 0.59 & 0.80 & 1.20 \\
\hline $14<\mathrm{H} \leq 29$ & 0.59 & 0.75 & 1.00 & 1.37 \\
\hline $\mathrm{H} \geq 29$ & 0.59 & 0.85 & 1.10 & 1.49 \\
\hline
\end{tabular}

\section{b) Wind Loads}

For noise barrier walls, the loads are calculated by multiplying the wind pressure by the tributary area as follows (Eq.2.2):

$$
W_{t}=P_{1} A_{1}+P_{2} A_{2}+P_{3} A_{3}
$$

Where

$W_{t}$-Total wind load (lbs)

$P_{1}, P_{2}, P_{3}$ - Wind pressures for height zone 1, 2, and 3

$A_{1}, A_{2}, A_{3}$ - Areas for height zones 1,2 , and 3

The area for each height zone is calculated by multiplying the vertical distance from bottom to top of the height zone with the horizontal spacing between foundations (Eq.2.3).

$$
A=(\Delta Y) L
$$

Where

$\Delta Y$-Vertical distance from bottom to top of height zone (ft)

$L$-Horizontal distance (spacing) between foundations (ft) 

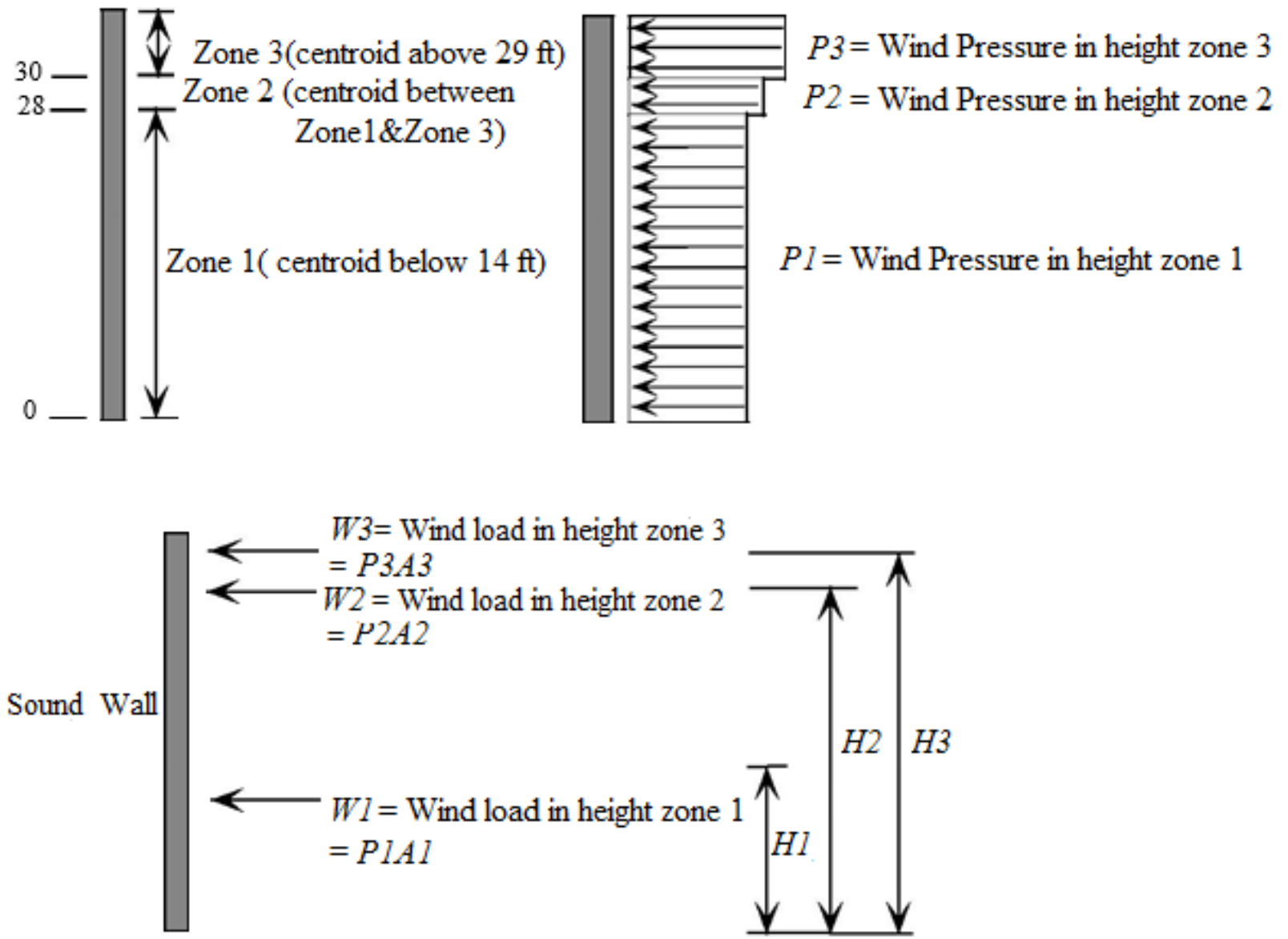

Figure 2.2 Loads on sound wall foundations due to wind (Helmers, 1997)

Figure 2.2 shows loads on sound wall foundations due to wind. The resultant eccentricity can be obtained from the total moment divided by the total horizontal load. (Eqs. 2.4, 2.5)

Total moment, $M_{t}=H_{1} W_{1}+H_{2} W_{2}+H_{3} W_{3}$

Total horizontal load, $W_{t}=W_{1}+W_{2}+W_{3}$ 


\subsection{CURRENT DESIGN LIMITATIONS}

The ultimate load theories are often used to determine the size of a drilled shaft sound wall foundation. The most commonly used theories are those developed by Broms (1964a \& 1964b) and Birch-Hansen (1961). In the ultimate load theories, the foundation is considered to behave as a rigid body. It represents an assumption for helping to promote the calculation but does not represent the pile-structure interaction that should be considered in an optimized design.

Furthermore, the use of these ultimate load theories does not cope with basic engineering problems easily; for example, the presence of a slope in the ground, groundwater table or soil strata with different layers of different soils can result in a much difficult calculation.

Since the laterally loaded shaft problem is 3-D in nature, it demands the use of 3-D numerical models to properly assess the soil-shaft interaction. According to the previous numerical studies, it is indicated that such a numerical approach is capable of providing a realistic assessment of soil-shaft behavior (Uncuoglu \& Laman, 2011). In this research, a 3-D FEM program, Plaxis 3D, is used to take into account the soil-pile deformation and to resolve the issues discussed above. 


\subsection{GEOTECHNICAL CONDITIONS IN THE GTA}

Unsorted glacial sediment is termed as glacial till. This kind of soil is derived due to the wearing away and entrainment of material as a result of the moving ice of a glacier. The biggest part of the GTA is covered by the glacial till. As shown in Fig. 2.3 below, this type of soil can be described as high variability materials in both horizontal and vertical axis, and it normally contains complex non-linear stress-strain characteristics (Baker et al., 1998).

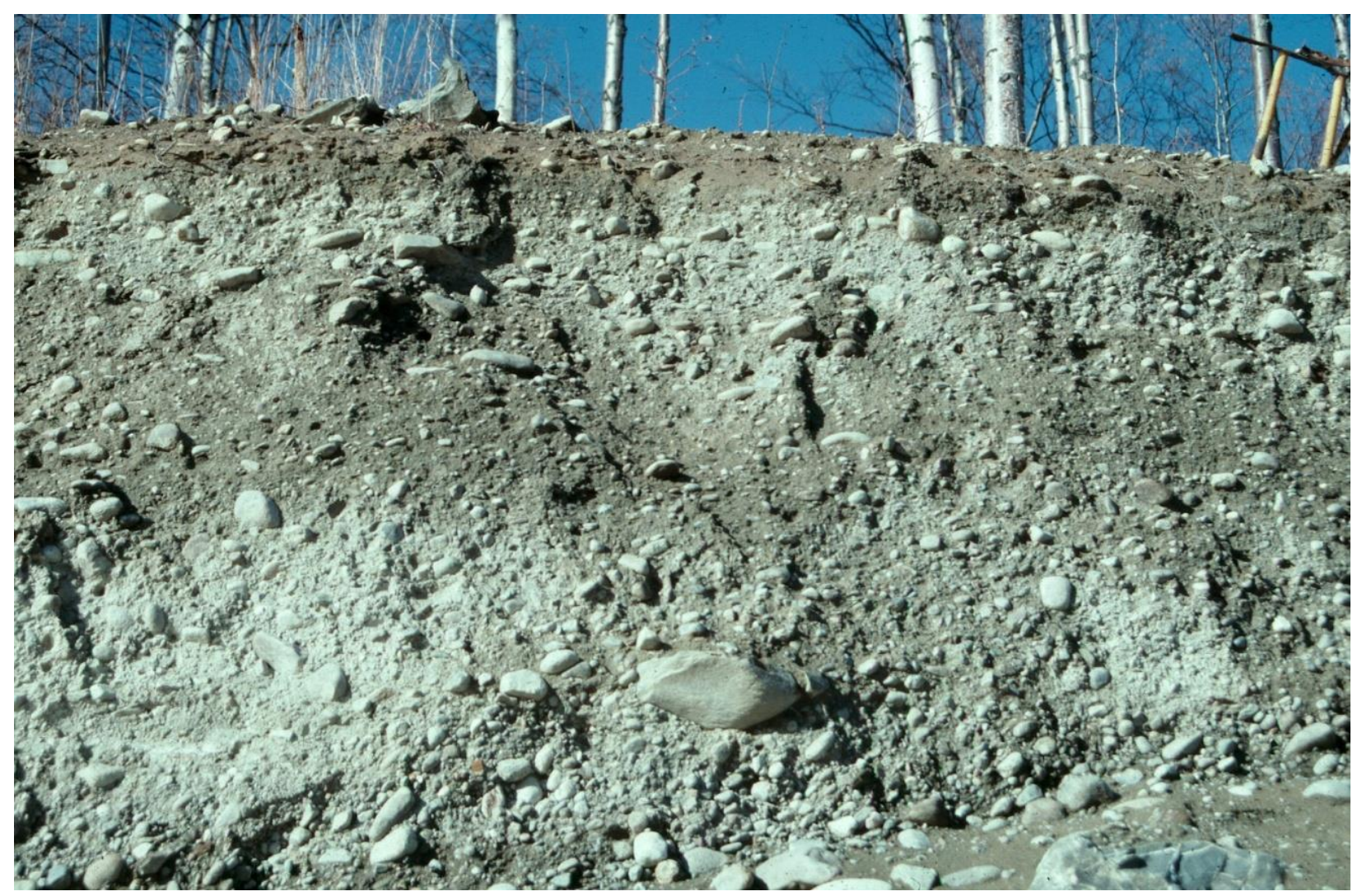

Figure 2.3 Typical glacial till (Source- Mark Clark, http://free-stockillustration.com)

The large disproportion of the particle sizes can be observed in Fig.2.3. It may include different soil types such as clays to mixture of clay, sand, gravel, and boulders. Due to the action of glacial plucking and abrasion, the bedrock can also be eroded. The resulting clasts of various sizes will be included to the glacier's bed. 
Finally, the sedimentary collection forming this bed will be abandoned some distance down-ice from its different sources, forming this way the process of glacial till deposition.

The presence of the frost line also needs to be considered during the design of foundations in GTA soils. The frost line is the depth at which the groundwater in soils is likely to freeze. In case of the GTA area, this line is assumed to be $1.5 \mathrm{~m}$ below the ground surface. As stated in the National Building Code, it is an essential requirement that all foundations need to be rested under the frost zone (NBC 2010). The drilled shaft is the most popular foundation type for noise barrier walls in the GTA because of its deep frost zone and difficulties in driving long piles in glacial tills with the presence of boulders.

\subsection{SUMMARY AND RESEARCH NEEDS}

Drilled shaft is the most popular foundation type for noise barrier walls. Soil properties vary largely in both regional and local scales. Analysing and designing of a shaft under lateral loading is a complex soil-shaft interaction problem. In addition, the lateral capacity of drilled shaft is a three-dimensional (3-D) problem.

Due to the uncertainties of ground conditions and high variations in soils, the current design methods tend to oversimplify the problems, and lead to overdesign. In order to optimize the design, the load and deformation behaviour of a drilled shaft require a thorough investigation. In this research, the 3-D FEM software, Plaxis 3D, will be used to predict the capacity of the shafts. Published case studies will be used to calibrate the modelling method, and verify the numerical results. 


\section{CHAPTER 3: ANALYSIS METHODS AND PROCEDURES}

\subsection{INTRODUCTION}

The modelling methods and procedures of 3-D FEM using Plaxis 3D will be discussed in this chapter along with the input parameters. In addition, ultimate lateral load capacity estimation methods using empirical theories are also discussed.

\subsection{ANALYSIS METHODS}

\subsubsection{BROMS'S (1964a) THEORY FOR COHESIVE SOILS}

Swedish professor Bengt Baltazar Broms developed this theory in 1964, which is applicable to purely cohesive soils (frictionless), as saturated cohesive soils loaded rapidly under drained conditions. Fig. 3.1 shows the soil reactions used in this theory.

According to Broms (1964a), some basic assumptions were made in his theory:

- The variation between the active and passive earth pressure is $9 c$, where $c$ is cohesion of the soil, or 2.25 times as large as would be calculated using the Rankine's earth pressure theory for frictionless soils. This is due to the 3-D earth pressure effects. This approximation seems to be rational with load test results for this type of soil.

- Due to the disturbance and/or frost action, the soil within $1.5 D$, where $D$ is a shaft diameter, below the ground surface provides no resistance to movement of the shaft. 


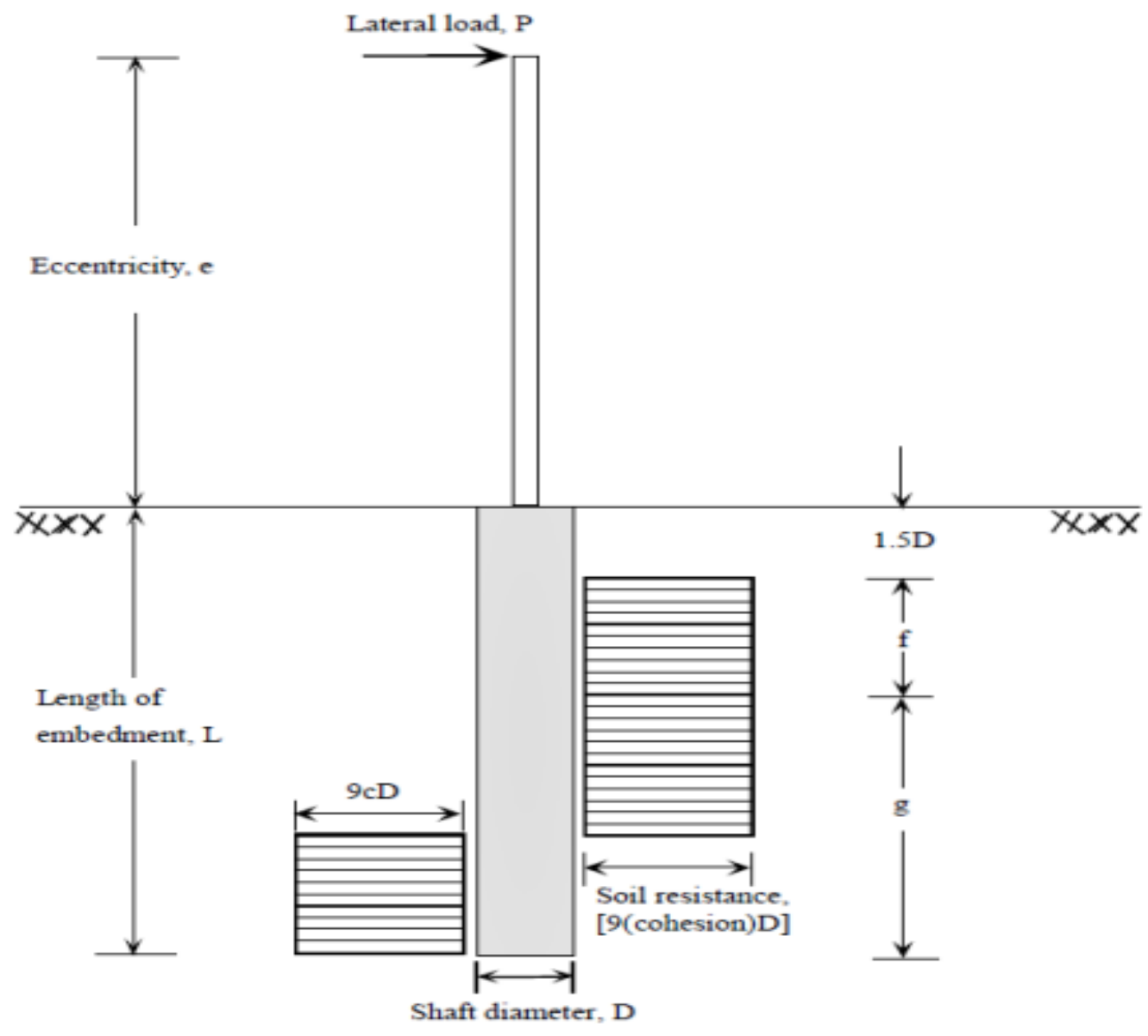

Figure 3.1 Soil reactions for Broms's method for cohesive soils (Helmers, 1997)

The following equations were derived using the principles of horizontal and moment equilibrium, and the distribution of soil resistance.

For horizontal equilibrium,

$$
\begin{aligned}
& P=f * 9 c D \\
& P(e+1.5 D+0.5 f)=2.25 D(L-1.5 D-f)^{2} * c
\end{aligned}
$$

Where

$P$ - Ultimate lateral load / lateral load capacity of the foundation

$f$ - Depth of point of zero shear

$c$ - Cohesion 
$D$ - Diameter of shaft

$e$ - Eccentricity of applied load

$L$ - Shaft length

Equations 3.1 and 3.2 can be used to calculate the magnitude of the lateral load capacity $(P)$ by using an iterative process.

\subsubsection{BROMS'S (1964b) THEORY FOR COHESIONLESS SOIL}

In 1964, Professor Bengt B. Broms published this theory, which is applicable to soils such as sands or gravels (internal friction angle $>0$, cohesion $=0$ ). If the contribution of cohesion to shaft capacity is ignored, it can also be used for soils like partly saturated silts or clays that have some cohesion. Fig. 3.2 shows the distribution of the passive soil reaction used in the theory.

The following assumptions were made to Broms's (1964b) theory;

- The variation between active and passive earth pressure is $3 K_{p} . K_{p}$ is the Rankine passive earth pressure coefficient. In cohesionless soils, this approximation is found to be in rational agreement with the load test results.

- The point of rotation is located at the base of the shaft. Due to this approximation, the computations can be simplified.

The following expression can be derived using the requirements of moment equilibrium together with the distribution of soil resistance.

$$
P=\frac{\gamma D L^{3} K_{p}}{2(e+L)}
$$

Where

$$
\gamma \text { - Unit weight of soil }
$$


$K_{p}$ - Rankine passive earth pressure coefficient

$K_{P}=\tan ^{2}(45+\varphi / 2)$

$\varphi$ - Particle friction angle

Therefore, ultimate lateral load can be calculated directly by using Eq. 3.3 and Eq. 3.4.

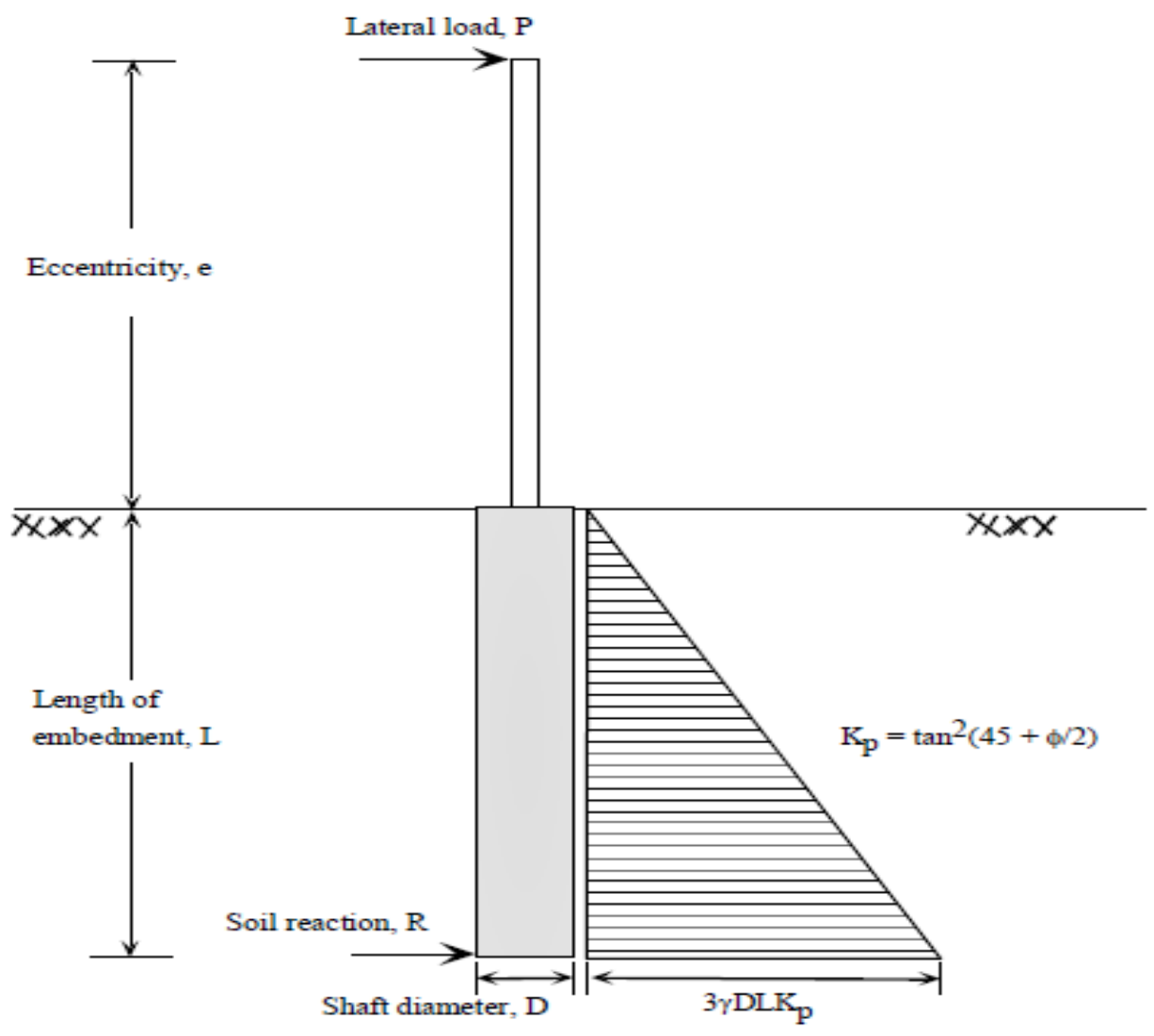

Figure 3.2 Soil reaction for Broms's method for cohesionless soils (Helmers, 1997) 


\subsubsection{BRINCH-HANSEN'S (1961) THEORY FOR SOILS HAVING COHESION AND FRICTION}

This theory can be applied to soils that have both cohesion and friction angle (i.e. $c>0$ and $\varphi>0$ ) such as partly saturated silts or clays. This theory may be used as a substitute to the Broms's theories if cohesion or friction is set to zero.

This theory is much more complex than the Broms's theory. However, the advantage is that it can be used for soils with both cohesion and friction. Fig. 3.3 shows the distribution of the net soil reaction used in the theory.

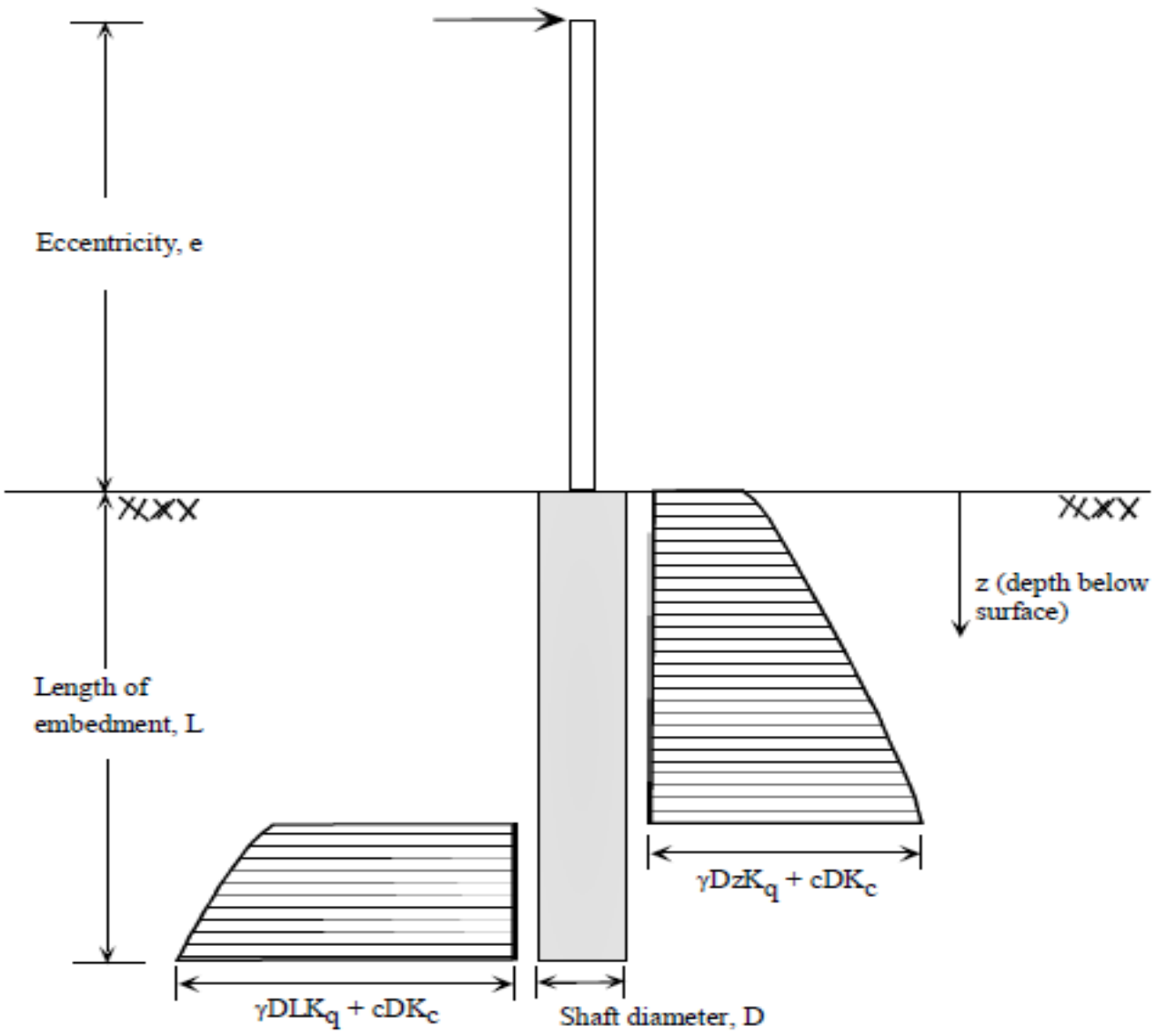

Figure 3.3 Soil reaction for Brinch-Hansen's theory (Helmers, 1997) 
The difference between passive and active earth pressure, $\sigma_{h}$ is given by Eq. 3.5 .

$$
\sigma_{h}=\gamma D z K_{q}+c D K_{c}
$$

Where

$D$ - Shaft diameter

$z$ - Depth below ground surface

$K_{q}$ - Coefficient for the frictional component of net soil resistance under 3-D conditions

$K_{c}$ - Coefficient for the cohesive component of net soil resistance under 3-D conditions

In this theory, the net soil resistance increases non-linearly with depth. The following equations are used to compute the frictional and cohesive coefficients (Eqs. 3.6 - 3.16)

$$
K_{q}=\frac{K_{q}^{0}+\left(K_{q}^{I}\right)\left(\alpha_{q}\right)(z / D)}{1+\left(\alpha_{q}\right)(z / D)}
$$

Where

$K_{q}$ - Passive earth pressure coefficient due to weight of soil at intermediate depth

$K_{q}^{0}$ - Passive earth pressure coefficient due to weight of soil at ground surface

$K_{q}^{0}=\left(e^{(0.5 \pi+\varphi) \tan \varphi} \cos \varphi \tan \left(45^{\circ}+0.5 \varphi\right)\right)-\left(e^{-(0.5 \pi-\varphi) \tan \varphi} \cos \varphi \tan \left(45^{\circ}-0.5 \varphi\right)\right)$

$K_{q}^{I}$-Passive earth pressure coefficient due to weight of soil at great depth

$K_{q}^{I}=N_{c}\left(d^{I}{ }_{c}\right) K_{0} \tan \varphi$

$\alpha_{q}=\frac{K_{q}^{0} K_{0} \sin \varphi}{\left(K_{q}^{I}-K_{q}^{0}\right) \sin \left(45^{\circ}+0.5 \varphi\right)}$

$K_{0}=1-\sin \varphi$

$\varphi$ - Particle friction angle

$K_{0}$ - At-rest earth pressure

$K_{C}=\frac{K_{C}^{0}+\left(K_{C}^{I}\right)\left(\alpha_{C}\right)(z / D)}{1+\left(\alpha_{C}\right)(z / D)}$ 
$K_{C}$ - Passive earth pressure coefficient due to cohesion at intermediate depth

$K_{C}^{0}$ - Passive earth pressure coefficient due to cohesion at ground surface

$K_{c}^{0}=\left(e^{(0.5 \pi+\varphi) \tan \varphi} \cos \varphi \tan \left(45^{\circ}+0.5 \varphi\right)-1\right) \cot \varphi$

$K_{C}^{I}$ - Passive earth pressure coefficient due to cohesion at great depth

$K_{C}^{I}=N_{C}\left(d^{I}{ }_{c}\right)$

$\alpha_{c}=\frac{K_{c}^{0}}{K_{c}^{I}-K_{c}^{0}} 2 \sin \left(45^{\circ}+0.5 \varphi\right)$

$N_{C}$-Bearing capacity factor

$N_{C}=\left(e^{\pi \tan \varphi} \tan ^{2}\left(45^{\circ}+0.5 \varphi\right)-1\right) \cot \varphi$

$\mathrm{d}_{\mathrm{c}}^{\mathrm{I}}$-depth coefficient at great depth

$d^{I}{ }_{C}=1.58+4.09 \tan ^{4} \varphi$

In addition, Fig. 3.4 shows the values of $K_{q}$ that vary with the friction angle and depth/diameter ratio (z/D), and Fig. 3.5 shows the values of $K_{c}$ that vary with the friction angle and depth/diameter ratio (z/D). 


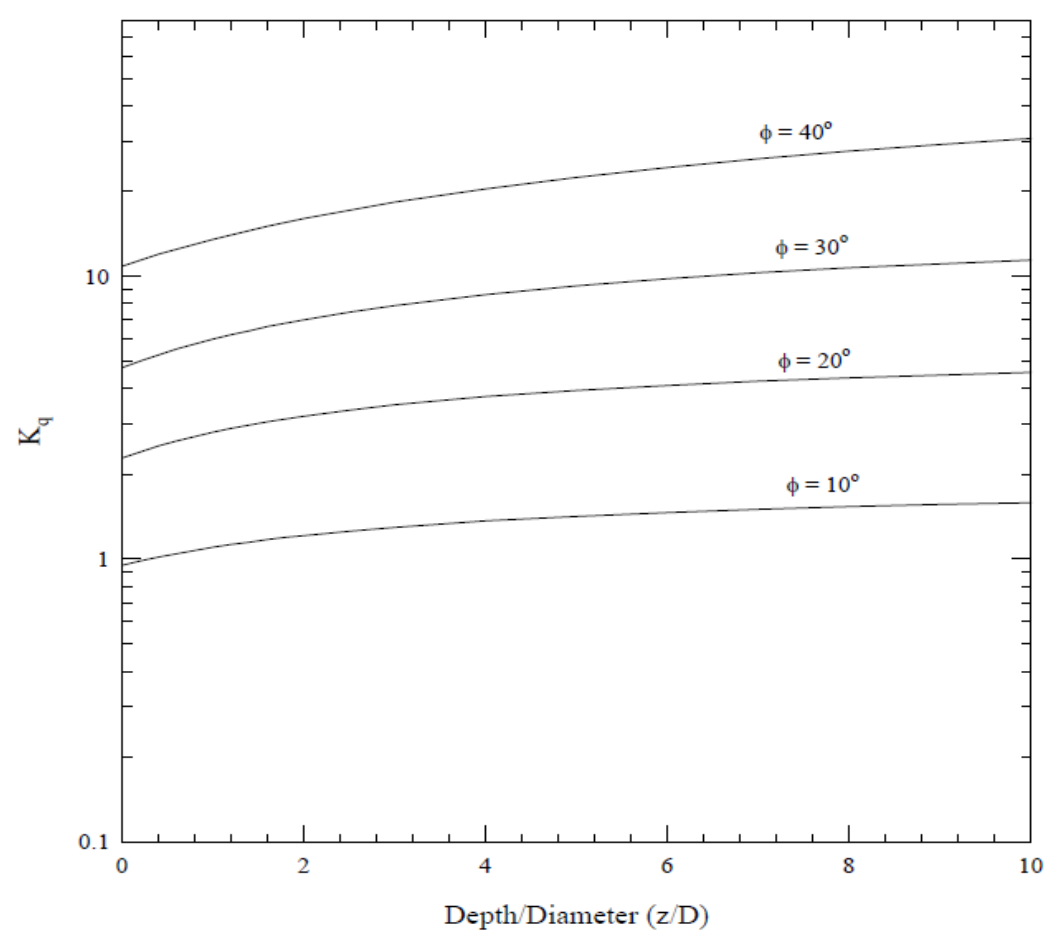

Figure 3.4 Variation of $\mathrm{K}_{\mathrm{q}}$ with depth (Helmers, 1997)

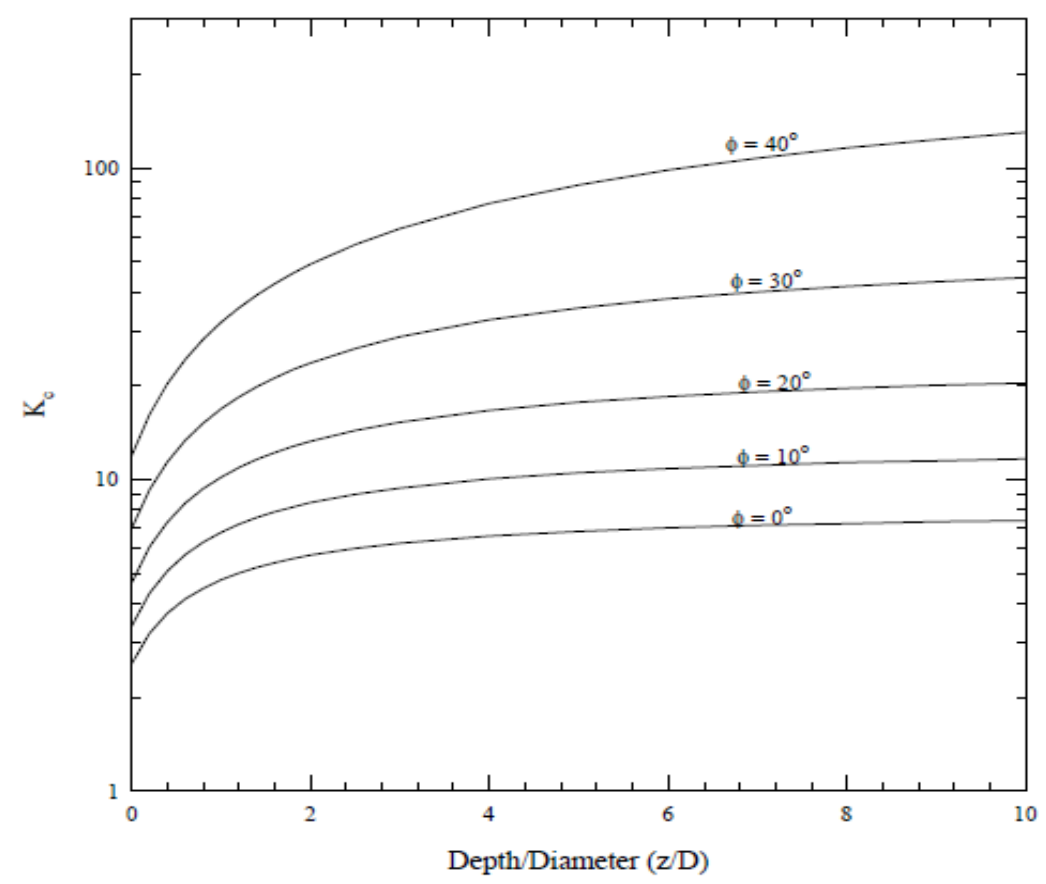

Figure 3.5 Variation of $K_{C}$ with depth (Helmers, 1997) 


\subsubsection{FINITE ELEMENT METHOD}

The finite element method (FEM) is described as a powerful numerical technique to find approximate solutions for partial differential equations using finite elements, and variational methods to minimize an error function, and produce a stable solution (Strang and Fix, 1973). Nowadays the FEM has become very popular in the geotechnical engineering practice in order to handle complex problems where analytical solutions are nearly impossible. In the FEM, the study object is divided into a number of finite elements, and the interaction between each one of these elements is analyzed given the model circumstances and conditions.

\subsubsection{CONSTITUTIVE BEHAVIOR}

According to Timoshenko and Goodier (1951), a stress in a soil mass must satisfy the following equations where inertia effects and all body forces are neglected except the self-weight $y$ in $\mathrm{x}$ (vertical) direction. Fig. 3.6 shows the stresses on a typical element. Compressive stresses are considered as positive. Equilibrium equations (Eqs. 3.17 - 3.19) are in terms of total stresses that must satisfy the boundary conditions.

$$
\begin{aligned}
& \frac{\partial \sigma_{X}}{\partial X}+\frac{\partial \tau_{Y X}}{\partial Y}+\frac{\partial \tau_{Z X}}{\partial Z}+\gamma=0 \\
& \frac{\partial \tau_{X Y}}{\partial X}+\frac{\partial \sigma_{Y}}{\partial Y}+\frac{\partial \tau_{Z Y}}{\partial Z}=0 \\
& \frac{\partial \tau_{X Z}}{\partial X}+\frac{\partial \tau_{Y Z}}{\partial Y}+\frac{\partial \sigma_{Z}}{\partial Z}=0
\end{aligned}
$$




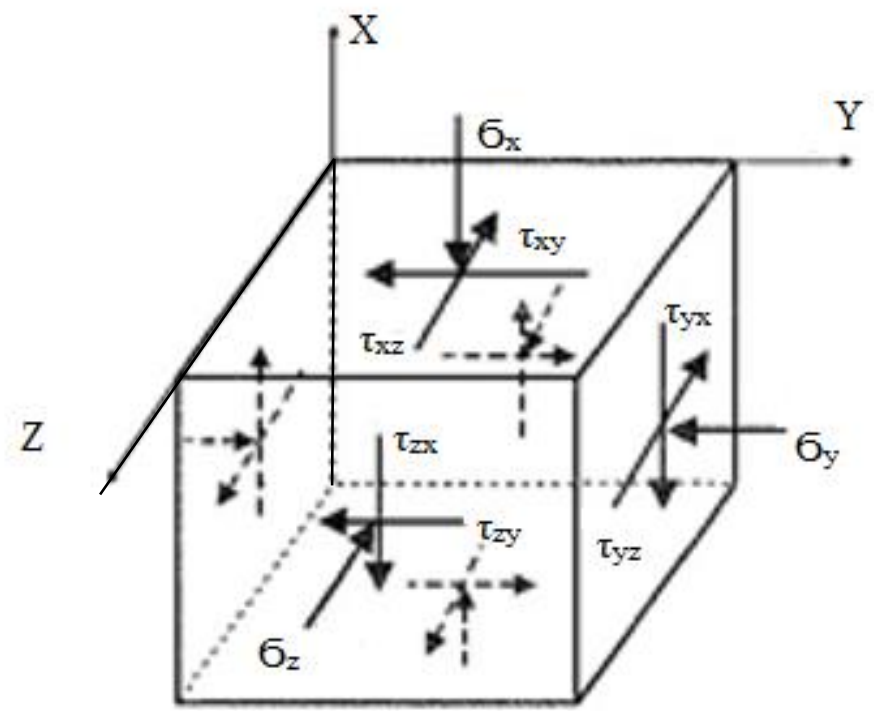

Figure 3.6 Stresses on a typical element

The constitutive behaviour is the stress strain behaviour of the soil which provides a link between equilibrium and compatibility. It can be expressed mathematically as (Eqs. 3.20 - 3.22)

$$
\left\{\begin{array}{l}
\Delta \sigma_{X} \\
\Delta \sigma_{Y} \\
\Delta \sigma_{Z} \\
\Delta \tau_{X Y} \\
\Delta \tau_{X Z} \\
\Delta \tau_{Z Y}
\end{array}\right\}=\left[\begin{array}{llllll}
D_{11} & D_{12} & D_{13} & D_{14} & D_{15} & D_{16} \\
D_{21} & D_{22} & D_{23} & D_{24} & D_{25} & D_{26} \\
D_{31} & D_{32} & D_{33} & D_{34} & D_{35} & D_{36} \\
D_{41} & D_{42} & D_{43} & D_{44} & D_{45} & D_{46} \\
D_{51} & D_{52} & D_{53} & D_{54} & D_{55} & D_{56} \\
D_{61} & D_{62} & D_{63} & D_{64} & D_{65} & D_{66}
\end{array}\right]\left\{\begin{array}{l}
\Delta \varepsilon_{X} \\
\Delta \varepsilon_{Y} \\
\Delta \varepsilon_{Z} \\
\Delta \gamma_{X Y} \\
\Delta \gamma_{X Z} \\
\Delta \gamma_{Z Y}
\end{array}\right\}
$$

Or

$$
\Delta \sigma=[D] \Delta \varepsilon
$$


For a linear elastic material, the $[D]$ matrix is written as

$$
\frac{E}{(1+\mu)}\left[\begin{array}{cccccc}
(1-\mu) & \mu & \mu & 0 & 0 & 0 \\
\mu & (1-\mu) & \mu & 0 & 0 & 0 \\
\mu & \mu & (1-\mu) & 0 & 0 & 0 \\
0 & 0 & 0 & (0.5-\mu) & 0 & 0 \\
0 & 0 & 0 & 0 & (0.5-\mu) & 0 \\
0 & 0 & 0 & 0 & 0 & (0.5-\mu)
\end{array}\right]
$$

Where

$$
\begin{aligned}
& E \text { - Modulus of elasticity } \\
& \mu \text { - Poisson's ratio }
\end{aligned}
$$

However, the soil behaviour is usually non-linear. Therefore, increments of stress and strain can be more realistically related using the constitutive equation as indicated in Eq. 3.20 (Potts \& Zdravkovic, 2001). It is also realistic for the $[D]$ matrix to depend on the current and past history. The constitutive behaviour can be stated by means of total or effective stresses. If it is needed to specify the constitutive behaviour in terms of effective stress, the principle of effective stress can be used to obtain total stresses required for use with equilibrium equations (Eqs.3.23 - 3.26)

$$
\begin{aligned}
& \sigma=\sigma^{\prime}+\sigma_{f} \\
& \Delta \sigma^{\prime}=\left[D^{\prime}\right] \Delta \varepsilon \\
& \Delta \sigma_{f}=\left\lfloor D_{f}\right\rfloor \varepsilon
\end{aligned}
$$

Therefore,

$$
\Delta \sigma=\left(\left[D^{\prime}\right]+\left\lfloor D_{f}\right\rfloor\right) \Delta \varepsilon
$$

Where

D'- Constitutive relationship relating the change in effective stress to the change in strain $D_{f}$ - Constitutive relationship relating the change in pore fluid pressure to the change in strain 


\subsubsection{STEPS INVOLVED IN THE FINITE ELEMENT METHOD}

The following steps are involved in the FEM.

\section{Step 1: Element discretization}

In this process, the geometry of the problem is modelled by an assembly of small regions termed as finite elements, which have nodes defined on the element boundaries, or within the element.

\section{Step 2: Primary variable approximation}

Primary variables such as displacements, stresses, etc., must be selected. The rules with regard to how these variables have to vary over a finite element are established. Nodal values are used to express the variations. Displacements are usually adopted as a primary variable in geotechnical engineering.

\section{Step 3: Element equations}

The elemental equations (Eq.3.27) are derived using an appropriate variational principle (e.g., the minimum potential energy).

$$
\left[K_{E}\right]\left\{\Delta d_{E}\right\}=\left\{\Delta R_{E}\right\}
$$

Where

$\left[K_{E}\right]$ - Element stiffness matrix

$\left\{\Delta d_{E}\right\}$ - Vector of incremental element nodal displacements

$\left\{\Delta R_{E}\right\}$-Vector of incremental element nodal forces 


\section{Step 4: Global equations}

The element equations are combined to form global equations (Eq. 3.28).

$$
\left[K_{G}\right]\left\{\Delta d_{G}\right\}=\left\{\Delta R_{G}\right\}
$$

Where

$\left[K_{G}\right]$ - Global stiffness matrix

$\left\{\Delta d_{G}\right\}$-Vector of all incremental global nodal displacements

$\left\{\Delta R_{G}\right\}$ - Vector of all incremental global nodal forces

\section{Step 5: Boundary conditions}

The global equations are modified by formulating boundary conditions. Loadings such as line and point loads, pressures, body forces, etc. affect $\left\{\Delta R_{G}\right\}$, and the displacements affect $\left\{\Delta d_{G}\right\}$.

\section{Step 6: Solve the global equations}

The displacements $\left\{\Delta d_{G}\right\}$ at all the nodes can be obtained by solving the global equations. These nodal displacements are used to evaluate stresses and strains.

\subsubsection{INVARIANTS}

The direction of the coordinate axes governs the magnitude of the components of the stress vector $\left(\sigma_{X}, \sigma_{Y}, \sigma_{Z}, \tau_{X Y}, \tau_{Y Z}, \tau_{X Z}\right)$. However, the principal stresses $\sigma_{1}, \sigma_{2}$, and $\sigma_{3}$, which don't depend on the direction of the coordinate axes, always act on the same planes and have the same magnitude; i.e. the principal stresses are invariant no matter which directions are chosen (Ports \& Zdravkovic, 2001).

Different invariant quantities are conveniently used in geotechnical engineering, which are combinations of the principal effective stresses (Eqs. 3.29 - 3.31). 
Mean effective stress is defined as:

$$
P^{\prime}=\frac{1}{3}\left(\sigma_{1}{ }^{\prime}+\sigma_{2}{ }^{\prime}+\sigma_{3}{ }^{\prime}\right)
$$

Deviatoric stress is defined as:

$$
J=\left(\frac{1}{\sqrt{6}}\right) \sqrt{\left(\sigma_{1}^{\prime}-\sigma_{2}{ }^{\prime}\right)^{2}+\left(\sigma_{2}{ }^{\prime}-\sigma_{3}{ }^{\prime}\right)^{2}+\left(\sigma_{3}{ }^{\prime}-\sigma_{1}{ }^{\prime}\right)^{2}}
$$

Lode's angle is defined as:

$$
\theta=\tan ^{-1}\left[\frac{1}{\sqrt{3}}\left(2 \frac{\left(\sigma_{2}^{\prime}-\sigma_{3}^{\prime}\right)}{\left(\sigma_{1}^{\prime}-\sigma_{3}^{\prime}\right)}-1\right)\right]
$$

\subsubsection{MOHR-COULOMB MODEL}

In this research, the Mohr-Coulomb (M-C) elasto-plastic constitutive model is used as a material model for soils. As shown in Fig. 3.7, the Mohr circles of stress at failure are obtained by plotting the results of the laboratory tests in term of effective stresses. The tangent line to the

failure circles from several tests, performed with different initial effective stresses, is called the Coulomb failure criterion (Eqs. 3.32 - 3.33).

$$
\tau_{f}=c^{\prime}+\sigma_{n f}^{\prime} \tan \varphi^{\prime}
$$

Where

$$
\begin{aligned}
& \tau_{f} \text {-Shear stress on the failure plane } \\
& \sigma_{n f}^{\prime} \text {-Normal effective stress on the failure plane } \\
& c^{\prime} \text {-Cohesion } \\
& \varphi^{\prime} \text {-Angle of Shearing Resistance }
\end{aligned}
$$




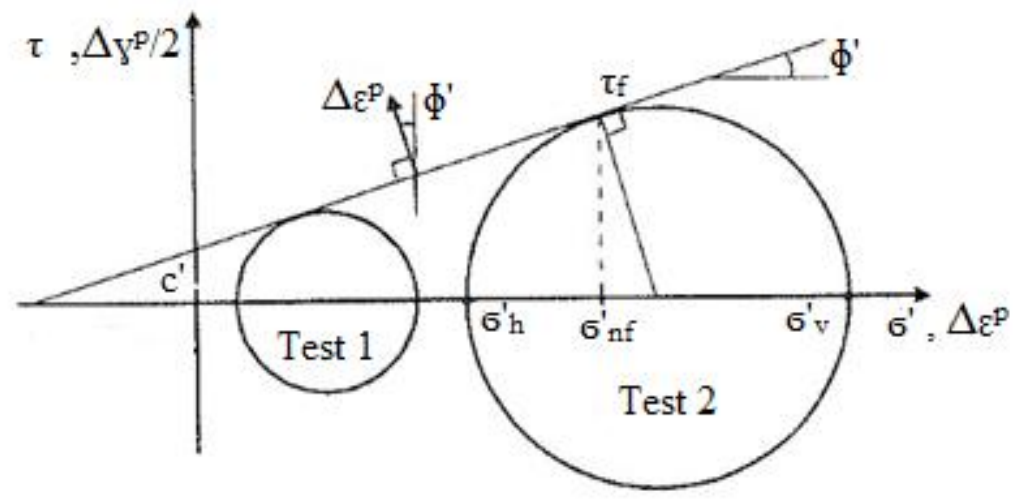

Figure 3.7 Mohr's circles of effective stress (Ports \& Zdravkovic, 2001)

The M-C failure criterion is defined as:

$$
\begin{aligned}
& \sigma_{1}{ }^{\prime}-\sigma_{3}{ }^{\prime}=2 c^{\prime} \cos \varphi^{\prime}+\left(\sigma_{1}{ }^{\prime}+\sigma_{3}{ }^{\prime}\right) \sin \varphi^{\prime} \\
& \sigma_{1}{ }^{\prime}=\sigma_{v}{ }^{\prime}, \text { and } \sigma_{3}{ }^{\prime}=\sigma_{h}{ }^{\prime}
\end{aligned}
$$

Therefore, the yield function (Eq. 3.34) is

$$
F\left(\left\{\sigma_{1}{ }^{\prime}\right\},\{k\}\right)=\sigma_{1}{ }^{\prime}-\sigma_{3}{ }^{\prime}-2 c^{\prime} \cos \varphi^{\prime}-\left(\sigma_{1}{ }^{\prime}+\sigma_{3}{ }^{\prime}\right) \sin \varphi^{\prime}
$$

This equation can be more conveniently written in terms of stress invariants $p^{\prime}, J$, and $\theta$ (Eqs. 3.35 - 3.36).

$$
F\left(\left\{\sigma_{1}^{\prime}\right\},\{k\}\right)=J-\left[\left(\frac{c^{\prime}}{\tan \varphi^{\prime}}\right)+p^{\prime}\right] g(\theta)=0
$$




$$
g(\theta)=\frac{\sin \phi^{\prime}}{\cos \theta+\left(\frac{\sin \theta \sin \phi^{\prime}}{\sqrt{3}}\right)}
$$

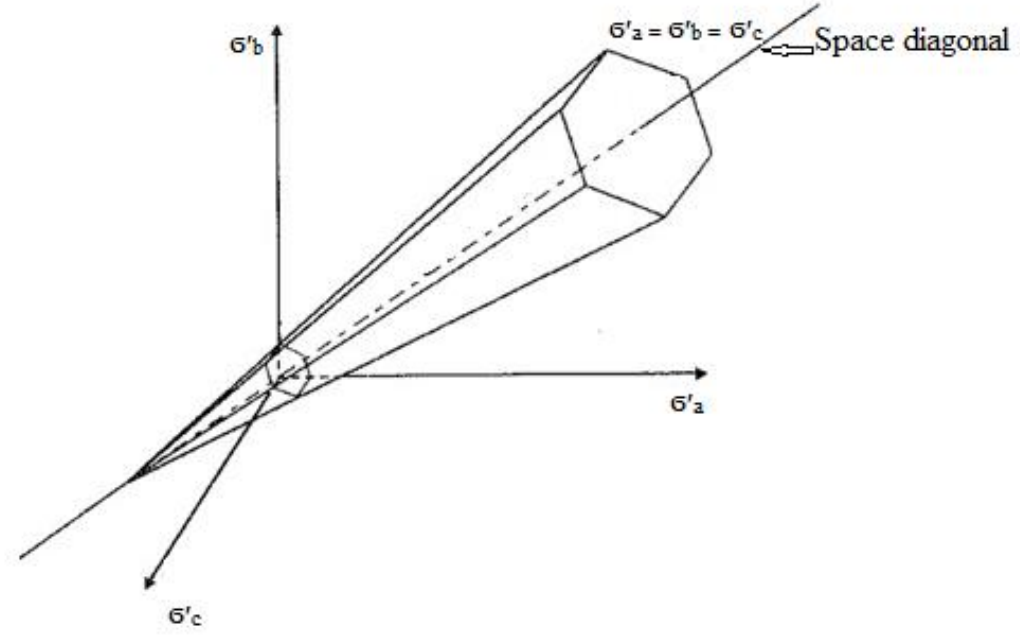

Figure 3.8 Mohr - Coulomb yield surface in principal stress space (Ports \& Zdravkovic, 2001)

As shown in the Fig 3.8, an irregular hexagonal cone is plotted by the yield function in principal effective stress space. 


\subsubsection{PLAXIS EMBEDDED PILE MODEL}

In Plaxis 3D software, the embedded pile model can be used to model a structural element, like a shaft in soil. The embedded pile is connected to the adjacent soils by special interfaces named skin interfaces and foot interfaces. According to the design of the embedded pile, volume is not taken into consideration. However, a particular elastic volume around the pile, whose dimension is same to the pile diameter is assumed. In this case, the plastic behavior can be ignored (Fig. 3.9). This model shows a good performance in modelling a pile subjected to axial loading as well as a pile subjected lateral loading (Dao, 2011).

Due to this reason, the embedded pile is considered to act like a volume pile. But, the soil-pile interaction is modelled at the centre rather than at the circumference. Since the embedded pile model does not take into account the installation effects of the pile, it can be used effectively in modelling the piles in which installation process results in low disturbance, like drilled shafts in this research.

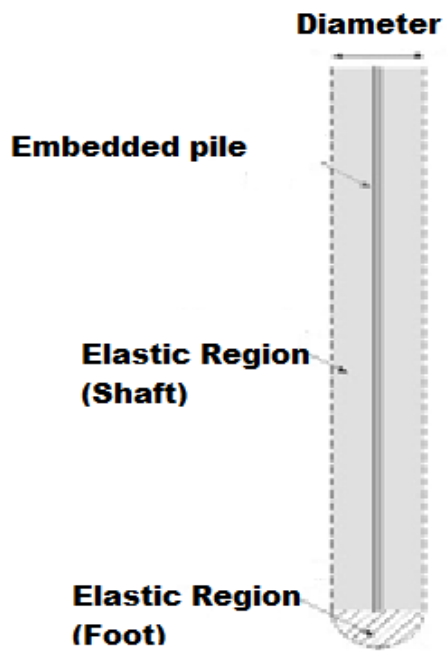

Figure 3.9 Elastic regions around embedded pile (Dao, 2011) 
The embedded pile has some benefits than the volume pile which is assigned with soil material. When it is compared to the volume pile, the embedded pile doesn't give influence on the mesh as generated from the geometry model. It also needs a lower mesh refinement and a reduced time for numerical calculations. Since it is considered as a beam structure, the embedded pile directly gives the results of force in Plaxis 3D output, which can't be obtained from the volume pile model.

\section{a) Soil-pile interaction}

After the generation of the mesh, the connection between the pile nodes and the existing soil nodes make the special interfaces, which model the soil-pile interaction. The behaviour of the interfaces is described by an elastic-plastic model. The interaction involves a skin resistance and a tip resistance. The sum of the skin resistance and the tip resistance is considered as the bearing capacity of the embedded pile. A failure criterion is applied to both the skin resistance and the tip resistance for differentiating between the interface elastic behavior and the interface plastic behavior (Dao, 2011).

The following constitutive equation represents the skin resistance of the interface.

$t^{\text {skin }}=K^{\text {skin }} . \Delta u_{r e l}$

Where

$t^{\text {skin }}$ - Force at the integration points

$K^{\text {skin }}$ - Material stiffness matrix of the interface

$\Delta u_{r e l}=u^{p}-u^{s}$ - Relative displacement vector between the soil and the pile

The above equation is represented in the 3D local coordinate system $(n, s, t)$ as given below (Eq. 3.38). 


$$
\left[\begin{array}{l}
t_{n} \\
t_{s} \\
t_{t}
\end{array}\right]=\left[\begin{array}{ccc}
K_{n} & 0 & 0 \\
0 & K_{s} & 0 \\
0 & 0 & K_{t}
\end{array}\right]\left[\begin{array}{lll}
u_{n}{ }^{p} & - & u_{n}{ }^{s} \\
u_{s}{ }^{p} & - & u_{s}{ }^{s} \\
u_{t}{ }^{p} & - & u_{t}{ }^{s}
\end{array}\right]
$$

Where

$t_{n}$ - Shear stress in axial direction

$t_{s}$ and $t_{t}$ - Normal stress in horizontal directions

$K_{n}$ - Elastic shear stiffness

$K_{s}$ and $K_{t}$ - Elastic normal stiffness in horizontal directions

$u^{p}$ - Displacement of the pile

$u^{s}$ - Displacement of the soil
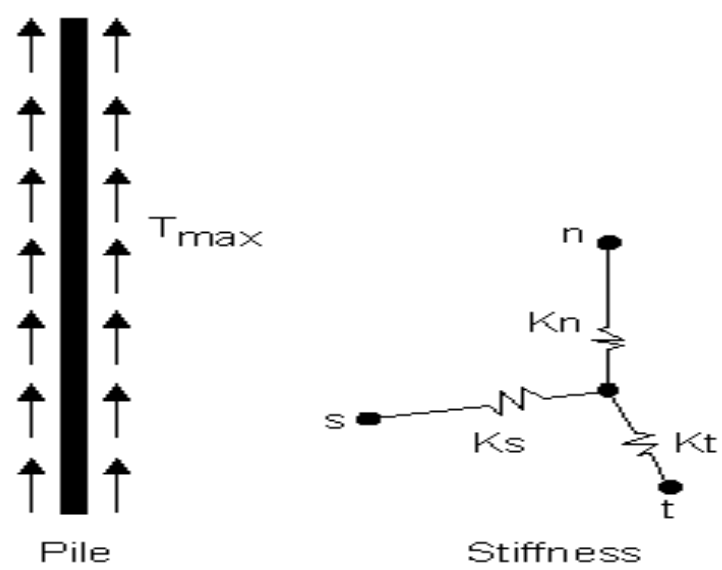

Figure 3.10 Shear resistance $T_{\max }$ along the pile (Dao, 2011)

The visualization of constitutive equation is shown in Fig. 3.10. The skin resistance, $T_{\max }$, can be defined as the capacity of the interface to withstand the shear force, $t_{n}$, along the pile.

In the case of elastic behavior of the shaft, the shear force, $t_{n}$, at a particular point has to be smaller than the local skin resistance at that point, $T_{\max }\left(t_{n}<T_{\max }\right)$. If $t_{n} \geq T_{\max }$, the plastic behavior can occur. 


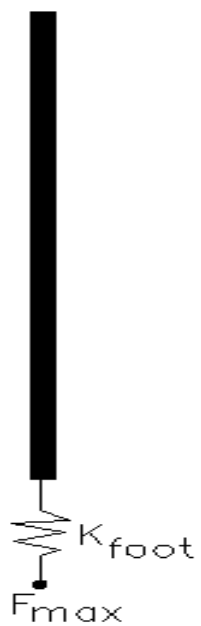

Figure 3.11 Maximum force at the pile tip (Dao, 2011)

The tip resistance is governed by a non-linear spring at the pile tip as shown in the Fig. 3.11. The capacity against the maximum force acting at the interaction between the pile tip and the soil is presented by the tip resistance as given in the equation below.

$$
0 \leq F_{\text {tip }}=K_{\text {tip. }}\left(u_{\text {tip }}^{p}-u_{\text {tip }}^{s}\right) \leq F_{\max }
$$

Where

$F_{t i p}$ - Force at the pile tip

$K_{t i p}$ - Material stiffness matrix of the spring element at the pile tip

$u^{p}{ }_{t i p}-u_{\text {tip }}^{s}$ - Relative displacement vector between the soil and the pile at the foot

The force at the pile tip, $F_{t i p}$, is zero in case of tension behavior. In the case of compression, the failure will happen when the force at the pile tip, $F_{t i p}$, is equal to the maximum resistance at the pile tip, $F_{\max }$. 


\section{b) Influence of $\mathbf{R}$ inter on the behaviour of the soil-pile interaction}

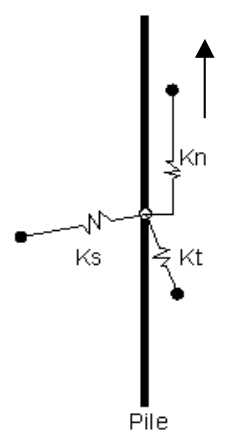

Figure 3.12 Node model for the soil-pile interaction (Dao, 2011)

The skin resistance of the pile, also called shear resistance of the interface, in the axial direction is determined based on a "slide" between the pile node and the soil node. The Plaxis describes the skin resistance by means of linear, multi-linear or layer dependent traction models.

The weakening behaviour of an interface between a structure element and surrounding soil can be modelled by the interface strength reduction factor, $R_{\text {inter }}$. Therefore, the "slide" between the pile and the soil in the axial direction of the pile can be controlled by $R_{\text {inter }}$. Thus, the value of $R_{\text {inter }}$ influences the relative displacement between the pile and the soil when the pile is subjected to axial loading (in n-direction), as shown in Fig. 3.12. Hence, the Plaxis setting uses the "slide" to model the pile-soil interaction in axial direction. There is no relative displacement between the pile and the soil resulted in horizontal directions (t-direction \& s-direction), since the normal stresses totally remain elastic. As a consequence, $R_{\text {inter }}$ has not influenced the displacements in terms of a laterally loaded pile. So, the embedded pile is perfect in modelling a pile with a "rough" surface, like drilled shafts (Dao, 2011). 


\section{CHAPTER 4 : 3-D FEM ANALYSES AND RESULTS}

\subsection{INTRODUCTION}

In this Chapter, Plaxis 3D FEM models are validated using the field load test results from five different sites in the state of Virginia in the United States. In addition, the numerical results of Plaxis 3D models are compared to the solutions from the empirical theories such as Broms's (1964b) theory for cohesionless soils, and Brinch-Hansen's (1961) theory for soils having both cohesion and friction. These theories have been discussed in Chapter 3.

\subsection{FIELD LOAD TESTS IN VIRGINIA, U.S.}

The field load tests on 20 drilled shafts have been conducted at five sites in the State of Virginia, U.S. to evaluate the lateral load behaviour of drilled shafts in soils (Helmers, 1997). These five sites are Prices Fork, Salem, Suffolk, Fairfax County, and Parkway Roberts Road, where the soil conditions are Elastic Silt (MH), Sandy Lean Clay (CL), Sandy Lean Clay (CL), Variable Clay (MH to $\mathrm{CH}$ ), and Non-Plastic Sandy Silt (ML), respectively. The tests have been performed on $0.2 \mathrm{~m}$ (Prices Fork, Salem, and Suffolk), and 0.225 m (Fairfax, and Roberts Road) diameter drilled shafts, and their lengths are $1.22 \mathrm{~m}$.

There were different types of soil conditions at the five sites in Virginia. Table 4.1 provides the list of ultimate loads and the values of $\left(N_{1}\right)_{60}$ for the five sites, which have been obtained from the field load tests and the standard penetration tests (SPT). 
Table 4.1 List of average ultimate loads and the values of $\left(N_{l}\right)_{60}$

\begin{tabular}{|l|c|c|}
\hline Site & SPT $\left(N_{1}\right)_{60}$ & Field test ultimate load $(\mathbf{k N})$ \\
\hline Prices Fork & 15 & 17.79 \\
\hline Salem & 22 & 20.46 \\
\hline Suffolk & 8 & 20.02 \\
\hline Fairfax County Parkway & 13 & 16.46 \\
\hline Roberts Road & 38 & 20.68 \\
\hline
\end{tabular}

The differences in testing practices can be at least partly compensated by changing the measured $N$ to $\left(N_{1}\right)_{60}$ by using the following equation (Skempton, 1986).

$$
\begin{aligned}
& \left(N_{1}\right)_{60}=N C_{E} C_{N} C_{R} C_{B} C_{S} \\
& C_{N}=\left[\frac{1}{\left(\sigma^{\prime} / P\right)}\right]^{0.5} \\
& \left(N_{1}\right)_{60}=C_{N} N_{60}
\end{aligned}
$$

Where

$C_{E}$-Hammer energy correction factor

$C_{B}$-Borehole diameter correction

$C_{S}$-Sampler correction

$C_{R}$-Rod length correction

$P$ - Atmospheric pressure

$\sigma$-Effective overburden pressure

$C_{N-}$ Overburden pressure correction factor

$N$ - Measured SPT ' $N$ ' value

$N_{60}$ - SPT-N value corrected to $60 \%$ of theoretical free fall hammer energy

$\left(N_{1}\right)_{60}$ - SPT-N value corrected for both vertical effective stress and input energy 
The soils have been classified using the results of Atterberg Limit and grain size analysis tests. Unconsolidated undrained triaxial tests have been performed to assess the shear strength parameters of soils at each site. The classifications and properties of soil at the test sites are given below in Table 4.2 as obtained from the Helmer's report.

The SPT based soil and rock classification systems are given below in Table 4.3. Typical values of Young's modulus for granular materials according to USCS are given in Table 4.4. The typical values of Young's modulus for cohesive materials according to USCS are given in Table 4.5.

Table 4.2 Properties of the soil at the test sites

\begin{tabular}{|c|c|c|c|c|c|c|c|}
\hline Site & $\begin{array}{l}\text { Unit } \\
\text { Wt. } \\
\left(\mathbf{k N} / \mathbf{m}^{3}\right)\end{array}$ & $\begin{array}{l}\text { Dry } \\
\text { Density } \\
\left(\mathbf{k N} / \mathbf{m}^{3}\right)\end{array}$ & $\begin{array}{l}\text { Friction } \\
\text { Angle } \\
\text { (Degrees) }\end{array}$ & $\begin{array}{l}\text { Cohesion } \\
\text { (kPa) }\end{array}$ & $\begin{array}{l}\text { Modulus } \\
\left(\mathrm{kN} / \mathbf{m}^{2}\right)\end{array}$ & $\begin{array}{l}\text { Dilatancy } \\
\text { Angle } \\
\text { (Degrees) }\end{array}$ & $\begin{array}{l}\text { Soil } \\
\text { Classification }\end{array}$ \\
\hline $\begin{array}{l}\text { Prices } \\
\text { Fork }\end{array}$ & 17.28 & 12.09 & 31 & 19.15 & 8500 & 1 & $\begin{array}{c}\text { Elastic Silt } \\
(\mathrm{MH})\end{array}$ \\
\hline Salem & 19.96 & 16.49 & 34 & 16.76 & 13800 & 4 & $\begin{array}{c}\text { Sandy Lean } \\
\text { Clay (CL) }\end{array}$ \\
\hline Suffolk & 19.17 & 15.71 & 31 & 16.76 & 8000 & 1 & $\begin{array}{c}\text { Sandy Lean } \\
\text { Clay (CL) }\end{array}$ \\
\hline $\begin{array}{l}\text { Fairfax } \\
\text { County }\end{array}$ & 17.91 & 13.04 & 30 & 9.57 & 8000 & 0 & $\begin{array}{c}\text { Variable Clay } \\
(\mathrm{MH} \text { to } \mathrm{CH})\end{array}$ \\
\hline $\begin{array}{c}\text { Roberts } \\
\text { Road }\end{array}$ & 17.28 & 14.93 & 40 & 7.18 & 28000 & 10 & $\begin{array}{c}\text { Non-Plastic } \\
\text { Sandy Silt } \\
\text { (ML) }\end{array}$ \\
\hline
\end{tabular}


Table 4.3 SPT - Based soil and rock classification systems (Skempton, 1986)

\begin{tabular}{|l|l|l|}
\hline Sands & $\left(\mathrm{N}_{1}\right)_{60}$ & \\
& $0-3$ & Very loose \\
& $3-8$ & Loose \\
& $8-25$ & Medium \\
& $25-42$ & Dense \\
& $42-58$ & Very dense \\
\hline Clays & $\mathrm{N}_{60}$ & \\
& $0-4$ & Very soft \\
& $4-8$ & Soft \\
& $8-15$ & Firm \\
& $15-30$ & Stiff \\
& $30-60$ & Very stiff \\
& $>60$ & Hard \\
\hline Weak rock & $\mathrm{N}_{60}$ & Very weak \\
& $0-80$ & Weak \\
& $80-200$ & Moderately weak to very strong \\
\hline Chalk & $>200$ & \\
& $\mathrm{~N}_{60}$ & Very weak \\
& $0-25$ & Weak \\
& $25-100$ & Moderately weak \\
& $100-250$ & Moderately strong to very strong \\
\hline
\end{tabular}

Table 4.4 Typical values of Young's modulus for granular materials (Kézdi \& Rétháti, 1974 \& Prat et al., 1995)

\begin{tabular}{|l|l|l|l|l|}
\hline USCS & Description & $\begin{array}{l}\text { Loose } \\
\text { (MPa) }\end{array}$ & $\begin{array}{l}\text { Medium } \\
(\mathbf{M P a})\end{array}$ & $\begin{array}{l}\text { Dense } \\
(\mathbf{M P a})\end{array}$ \\
\hline GW, SW & Gravels/Sand well-graded & $30-80$ & $80-160$ & $160-320$ \\
\hline SP & Sand, uniform & $10-30$ & $30-50$ & $50-80$ \\
\hline GM , SM & Sand/Gravel Silt & $7-12$ & $12-20$ & $20-30$ \\
\hline
\end{tabular}


Table 4.5 Typical values of Young's modulus for cohesive materials (Kézdi \& Rétháti, 1974 and Prat et al., 1995)

\begin{tabular}{|c|c|c|c|c|c|}
\hline USCS & Description & $\begin{array}{l}\text { Very soft to } \\
\text { soft(MPa) }\end{array}$ & $\begin{array}{l}\text { Medium } \\
\text { (MPa) }\end{array}$ & $\begin{array}{l}\text { Stiff to very } \\
\text { stiff(MPa) }\end{array}$ & $\begin{array}{l}\text { Hard(MP } \\
\text { a) }\end{array}$ \\
\hline ML & $\begin{array}{l}\text { Silts with slight } \\
\text { plasticity }\end{array}$ & $2.5-8$ & $10-15$ & $15-40$ & $40-80$ \\
\hline $\mathrm{ML}, \mathrm{CL}$ & $\begin{array}{l}\text { Silts with low } \\
\text { plasticity }\end{array}$ & $1.5-6$ & $6-10$ & $10-30$ & $30-60$ \\
\hline CL & $\begin{array}{l}\text { Clays with low- } \\
\text { medium plasticity }\end{array}$ & $0.5-5$ & $5-8$ & $8-30$ & $30-70$ \\
\hline $\mathrm{CH}$ & $\begin{array}{l}\text { Clays with high } \\
\text { plasticity }\end{array}$ & $0.35-4$ & $4-7$ & $7-20$ & $20-32$ \\
\hline OL & Organic silts & - & $0.5-5$ & - & - \\
\hline $\mathrm{OH}$ & Organic clays & - & $0.5-4$ & - & - \\
\hline
\end{tabular}


Many locations in Virginia have partly saturated soils with both cohesion and friction contributing to their shear strengths. It is assumed that the strength of the soil is characterized entirely by cohesion or entirely by friction by most of the theories used for drilled shaft capacity calculations (Helmers, 1997). Therefore, drilled shaft capacities have been examined through experimental studies in Virginia soils for the effective design of drilled shaft sound wall foundations.

In this Chapter, 3-D FEM is first verified through the field tests for drilled shafts in Virginia, U.S. The field load test setup at sites in Virginia is schematically shown in Fig. 4.1

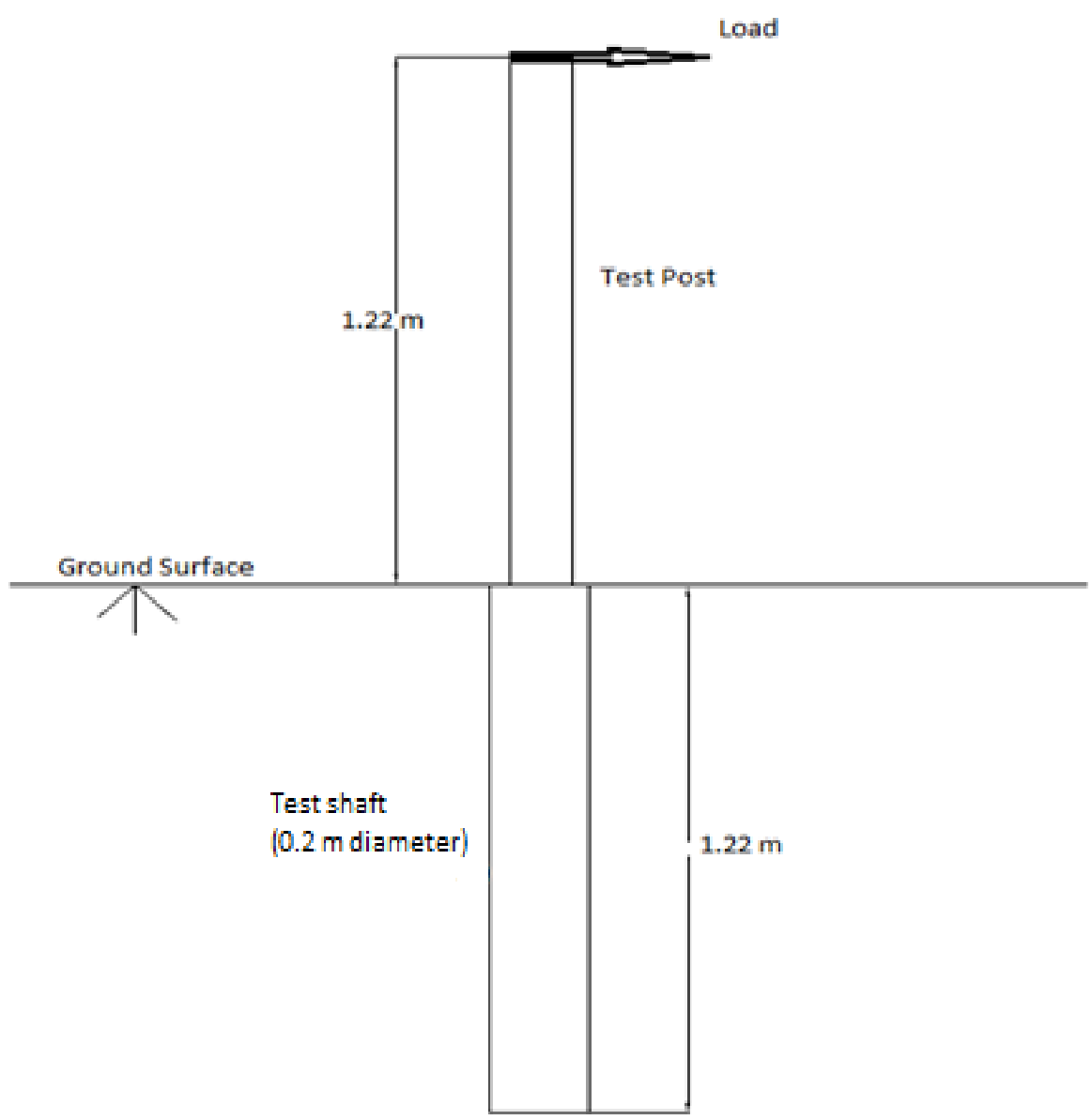

Figure 4.1 Schematic field test setup at sites in Virginia, US 
According to the criterion suggested by Bierschwale et al. (1981) and also noted in Mayne et al. (1992), a shaft can be considered rigid if the length to diameter ratio, $L / D$, is six or less. Poulos and Davis (1980) suggested another criterion for rigidity which is defined as follows:

$$
K_{r}=\frac{E_{p} I_{p}}{E_{s} L^{4}}
$$

Where

$$
\begin{aligned}
& K_{r} \text {-Dimensionless stiffness ratio } \\
& E_{p} \text {-Modulus of elasticity of shaft concrete }(20 \mathrm{GPa}) \\
& I_{p} \text {-Gross (uncracked) moment of inertia of the shaft }\left(1.35 * 10^{-4} \mathrm{~m}^{4} \text { for D }=0.2 \mathrm{~m}\right) \\
& E_{s^{-}} \text {Young's modulus of soil } \\
& L-\text { Shaft length }(1.22 \mathrm{~m})
\end{aligned}
$$

If $K_{r}>0.01$, a shaft can be considered as rigid. Otherwise it will be considered as flexible. For a rigid shaft, the bending deformations of the shaft will not be taken into consideration in the design.

For the field tests in Virginia, US, the shaft can be considered as a rigid shaft based on both criteria. For example, in the Salem site, the Young's modulus of the stiffest soil is given as 13.8 MPa. The dimensionless stiffness ratio $K_{r}$ can be calculated as 0.088 , which is significantly greater than the minimum value for a rigid shaft. The length to diameter ratio also was 6.1 , close to the ratio of 6.0 .

Figure 4.2 shows the load-deformation curves, which are the curves from the field tests performed at each site. The deflection values have been taken from the top of the shafts (at ground level). The top of shaft deflection values for each site from the field tests are given in Table 4.6. Due to the variations in soil conditions at the five sites, the maximum loads and the magnitudes of deflection are different from one site to another. 


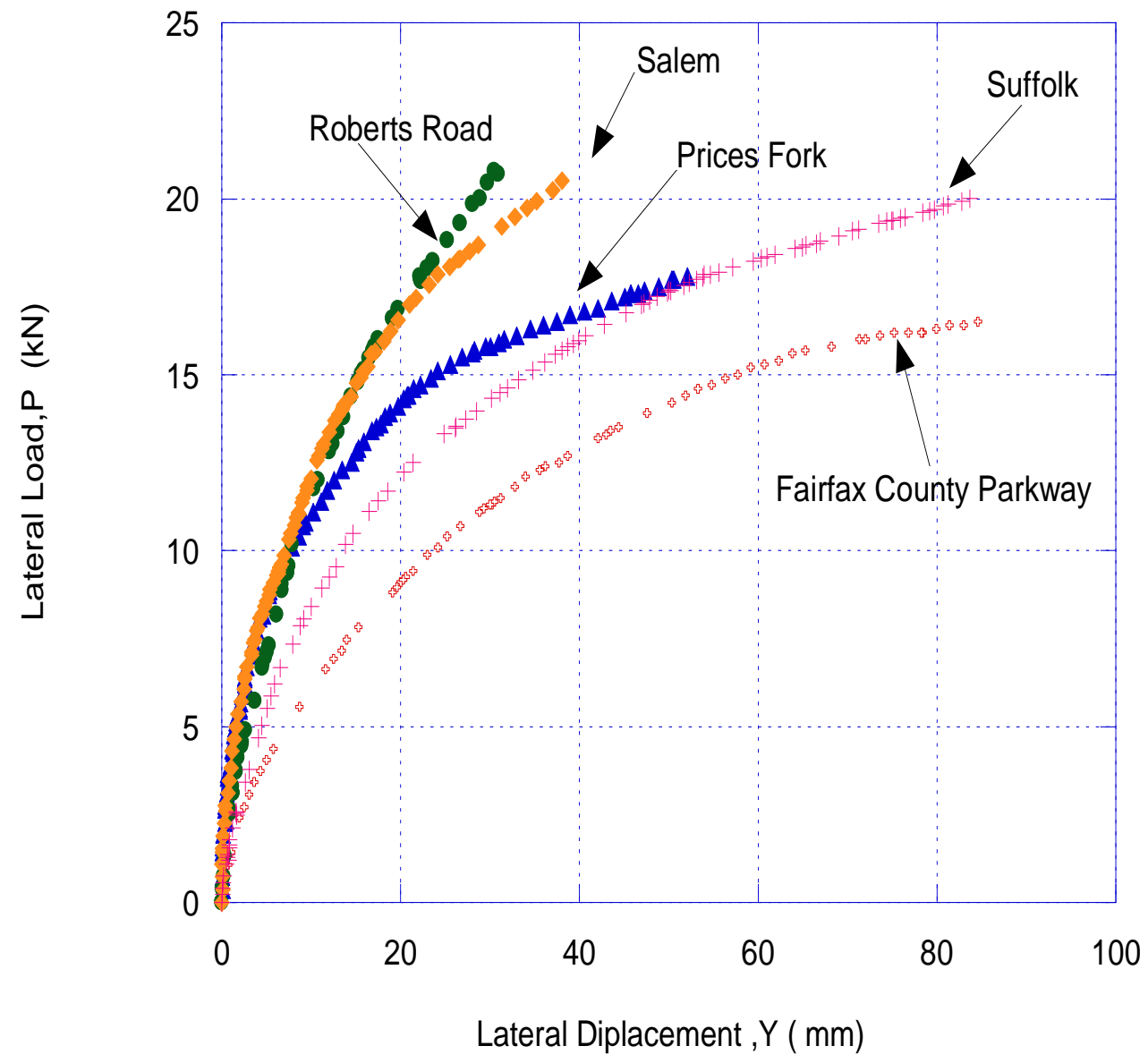

Figure 4.2 Load - deflection curves from field tests in VA, U.S. 
Table 4.6 Top of shaft deflections from the field tests

\begin{tabular}{|l|l|l|}
\hline Site in Virginia & Average ultimate load $(\mathbf{k N})$ & Top of shaft deflection ( mm) \\
\hline Prices Fork & 17.79 & 52.07 \\
\hline Salem & 20.46 & 38.70 \\
\hline Suffolk & 20.02 & 83.80 \\
\hline Fairfax County Parkway & 16.46 & 83.82 \\
\hline Roberts Road & 20.68 & 30.48 \\
\hline
\end{tabular}




\subsection{FINITE ELEMENT ANALYSES}

\subsubsection{3-D FEM MODEL OF A LATERALLY LOADED PILE}

In this part of the research, numerical modelling is conducted on a single pile in soil by using the FEM package, Plaxis 3D. The pile is modelled using an embedded pile model available in Plaxis 3D. The model geometry can be created with dimensions of $6 \mathrm{~m}$ in both $\mathrm{x}$ and $\mathrm{y}$ directions, and $3.5 \mathrm{~m}$ in $\mathrm{z}$ direction (Table 4.7). The soil is assumed to have one layer, and the width ( $\mathrm{x}$ axis) and the length (y axis) of the soil block are pre-defined in the model tab on the project properties window. The limits of the soil contour is defined as the $\mathrm{x} \min =0, \mathrm{x} \max =6 \mathrm{~m}$, and $\mathrm{y} \min =0$, and $\mathrm{y} \max =6 \mathrm{~m}$. The depth ( $\mathrm{z}$ axis) is applied using the "create borehole" button, in this function groundwater table level can also be selected. The top boundary of the soil layer is at $\mathrm{z}=0$, and the bottom boundary of the soil layer is at $\mathrm{z}=-3.5 \mathrm{~m}$. Once the soil block is drawn, the soil properties can be assigned to it. The soil is modelled with the M-C model since this test is not intended to pay attention on time-dependent behavior and also there is only limited soil testing available.

Table 4.7 3-D FEM model dimensions

\begin{tabular}{|l|l|l|}
\hline Dimensions & Height & Embedment ratio (L/D) of the shaft \\
\hline $6 \mathrm{~m} \times 6 \mathrm{~m}$ & $3.5 \mathrm{~m}$ & 6 \\
\hline
\end{tabular}

The next step is to create the structure phase where the pile is inserted into the soil mass through the "create embedded pile" function. The embedded pile is located at the $\{3,3,0\}$ of the coordinate system with the pile head at the ground surface. The embedded pile has dimensions of $0.2 \mathrm{~m}$ in diameter and $1.22 \mathrm{~m}$ in length. The material properties of the pile can also be assigned in this mode. Next, a loading post is attached to the embedded pile to apply an eccentric load. The beam element is used to simulate the loading post. 
It can be done through the "create beam" option. The material properties of the loading post can be assigned in this mode. On the top of the loading post, a point load is applied in $\mathrm{x}$ direction for lateral loading. The lateral load is applied at a height of $1.22 \mathrm{~m}$ as a pulling force. In order to eliminate the effect of the end boundaries of the soil layer on the results, optimum distances are selected between pile and soil boundaries as given in Table 4.7 .

\subsubsection{MESH GENERATION}

Once the geometry modelling process is complete, calculations are proceeded which consist of the generation of meshes and definition of the construction stages. The defined geometry has to be divided into finite elements in order to perform a FEM calculation. A mesh is a composition of finite elements that can be created in mesh mode in Plaxis 3D. A sufficiently fine mesh should be selected to obtain accurate numerical results. In Plaxis 3D, a fully automatic generation of finite elements meshes is allowed. The coarseness of the mesh element distribution can be selected from the sizes that include very coarse, coarse, medium, fine and very fine. Since coarser mesh contains fewer elements, it is less capable of steep changes in gradient of deformation. If a finer mesh is used, calculation time and cost of running the model shall be increased.

It is preferred to have a more accurate finer finite element mesh in areas where large stress concentrations are expected while other parts of the geometry might not require a fine mesh. Local refinement is connected to the local coarseness factor that can be specified for each geometric entity. The coarseness factor value is set to 1 for most geometry entities. A 10-node tetrahedral element, as shown in Fig. 4.3, is used to model the soil. 


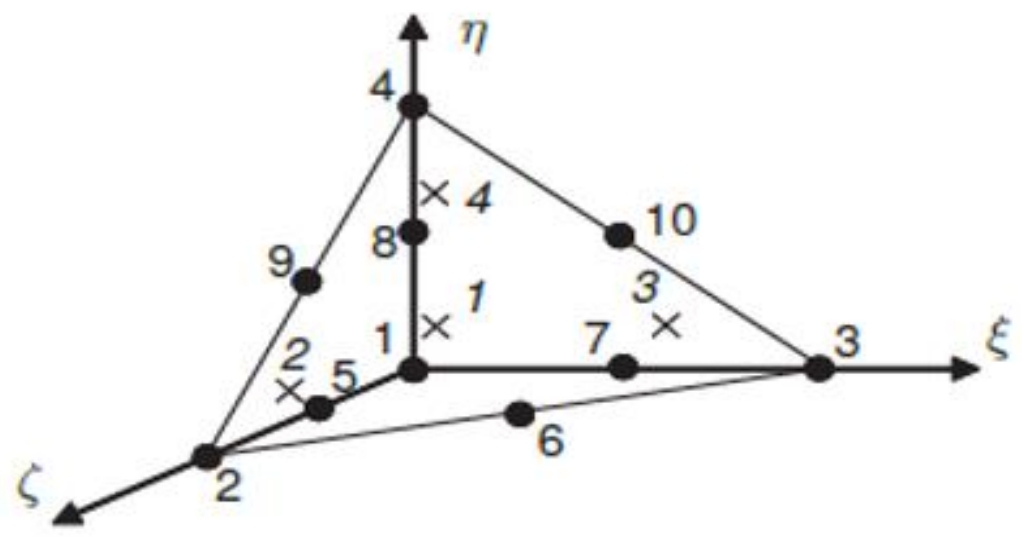

Figure 4.3 3-D finite element mesh used for model the soil

\subsubsection{CALCULATION PROCESS}

A calculation process in Plaxis is divided into calculation phases. In each calculation phase, a number of calculation steps are needed since the non-linear behaviour of the soil requires loadings in small proportions (load steps).

In the first calculation phase, the initial stress field for the initial geometry configuration is calculated using $k_{0}$ procedure calculation type. After this initial phase, subsequent calculation phases are defined. In the "staged construction" mode, the calculation process can be divided into different phases to simulate the field case. In this research, the calculation process was divided into 4 phases to simulate the field test as shown in Fig.4.4; i.e. initial phase, pile casting, loading post construction, and load application. The effective stresses and pore water pressures are calculated in the soil block during the initial phase. In the next stages, the pile is inserted into the soil followed by the loading post stage. After that, the load is applied until ultimate state is reached. The plastic calculation type is used for deformation calculations. 


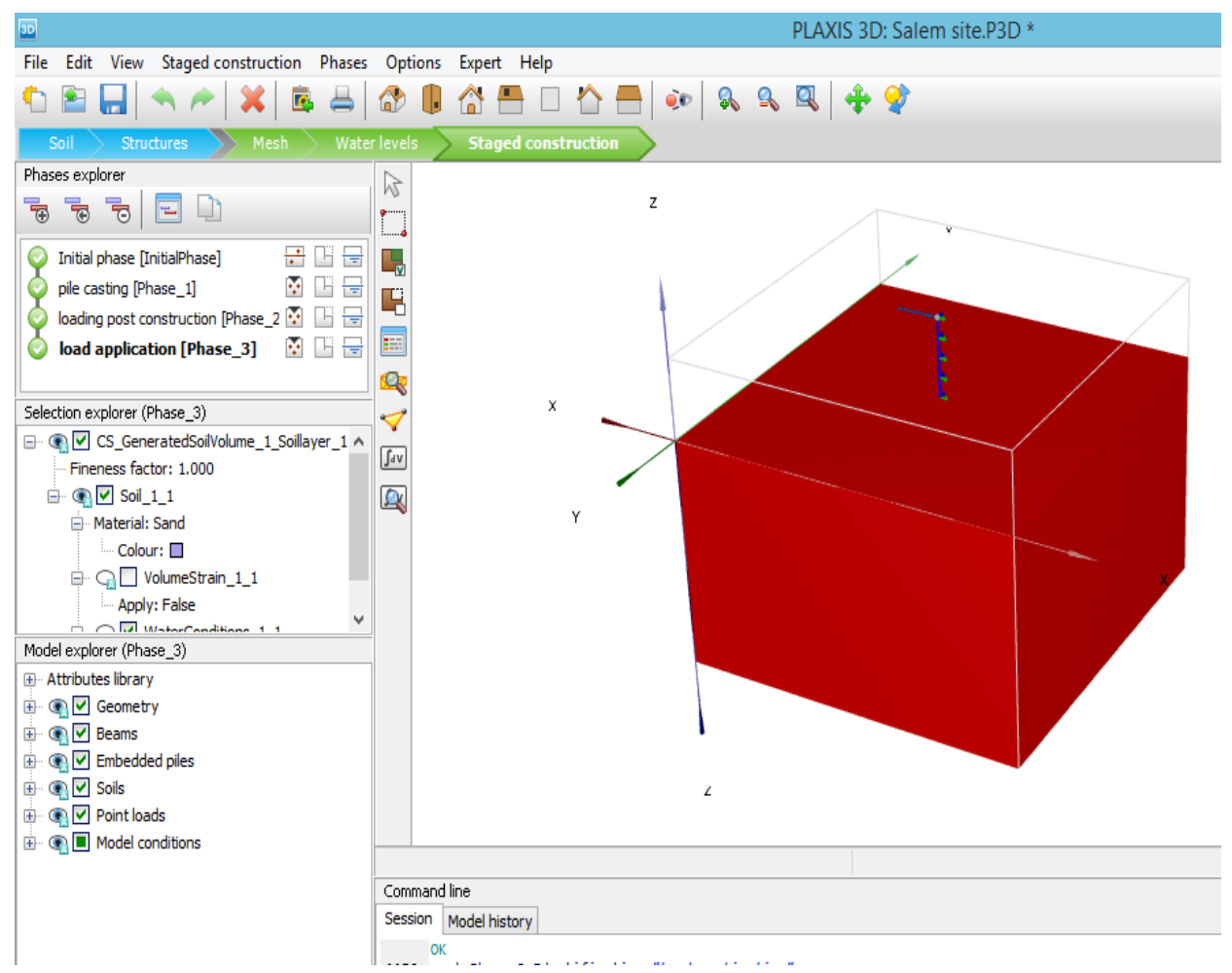

Figure 4.4 Construction phases in Plaxis 3D

There are many different definitions regarding the ultimate pile capacity either from deflection or from load point view. It can be determined based on the excessive lateral displacement of the shaft head or the rotation of the shaft $(\mathrm{Hu}$, et al. 2006). According to Sawwaf (2006), the ultimate lateral capacities can be defined as the loads corresponding to the lateral displacements at the shaft head equal to around $10 \%$ of the diameter of the shaft. As stated by Dickin and Nazir (1999), it can also be obtained from the $P-Y$ curve as the point where the curve turns into linear or considerably linear. It can also be defined as the maximum load from the $P-Y$ curve when the load cannot be increased with deflection. In the Helmer's field test in Virginia, in order to avoid additional deflection, loading has been terminated once the tests reached desired deflections. The ultimate capacity referred in this thesis is taken as the maximum load applied during the field test. In real design, the pile capacity may be even limited to deflection requirements, in another word, service limit conditions. 
The model pile and the loading post are considered to be linearly elastic. The non-linear behaviour of soil is simulated using the MC model because of its easiness, reasonable number of model parameters and reasonable accuracy. This model has a fixed yield surface, and the plastic straining does not affect this yield surface.

The dilatancy is overestimated by the theory of associated plasticity for MC-type yield functions. So a plastic potential function is introduced as well as the yield function. The plastic potential function includes the parameter of the dilatancy angle, which is required to model positive plastic volumetric strain increments. A total of five input parameters are required for the elastoplastic MC model: elasticity modulus (E), Poisson's ratio (v), internal friction angle $(\phi)$, cohesion (c), and dilatancy angle $(\psi)$. These properties for the soil in the Salem site are shown in Table 4.8 along with the properties for the pile and the loading post in Table 4.9. The Jaky's formula (Jaky, 1944) offers the at rest earth pressure coefficient $K_{0}=1-\sin \phi$, which is used to generate the initial stresses in the numerical model. The total lateral load is applied in stages in order to get load-displacement relationships at the pile head.

If the structure has a local system of axes $(1,2,3)$, the first direction is always the axial direction. The other directions (second and third) will always be perpendicular to the structure axis. The bending moment $\mathrm{M}_{3}$ is the bending moment formed because of the bending around the third axis. The shear force over the $2^{\text {nd }}$ beam axis is denoted as $\mathrm{Q}_{12}$. 
Table 4.8 Properties of the soil -Salem site

\begin{tabular}{|l|l|}
\hline Parameter & Value \\
\hline Soil classification & Sandy Lean Clay $(\mathrm{CL})$ \\
\hline Material model & Mohr Coulomb \\
\hline Friction angle (degree) & 34 \\
\hline Dilation angle (degree) & 4 \\
\hline Cohesion $\left(\mathrm{kN} / \mathrm{m}^{2}\right)$ & 16.76 \\
\hline Modulus of elasticity $\left(\mathrm{kN} / \mathrm{m}^{2}\right)$ & 13800 \\
\hline Poisson's ratio & 0.3 \\
\hline Dry unit weight of soil $\left(\mathrm{kN} / \mathrm{m}^{3)}\right.$ & 16.49 \\
\hline Bulk unit weight of soil $\left(\mathrm{kN} / \mathrm{m}^{3}\right)$ & 19.96 \\
\hline Strength-reduction factor at the interface, $R_{\text {inter }}$ & 1.0 \\
\hline
\end{tabular}

Table 4.9 Properties of the pile and the loading post

\begin{tabular}{|l|l|l|}
\hline Parameter & Pile & Loading post \\
\hline Material & Concrete & Steel \\
\hline Modulus of elasticity $\left(\mathrm{kN} / \mathrm{m}^{2}\right)$ & $20.68 \mathrm{E} 6$ & $210.0 \mathrm{E} 6$ \\
\hline Length $(\mathrm{m})$ & 1.22 & 1.22 \\
\hline Dimensions $(\mathrm{m})$ & $\begin{array}{l}\text { Diameter }-0.2 \text { or } 0.225 \\
(\text { circular })\end{array}$ & $\begin{array}{l}\text { Size }-0.075 * 0.125 \\
\text { Thickness }-0.0125 \\
\text { (rectangular, tubular })\end{array}$ \\
\hline Unit weight $\left(\mathrm{kN} / \mathrm{m}^{3}\right)$ & 24 & 77 \\
\hline Area $\left(\mathrm{m}^{2}\right)$ & 0.03142 & $4.500 \mathrm{E}-3$ \\
\hline Moment of Inertia $\left(\mathrm{I}_{2}\right)(\mathrm{m} 4)$ & $0.07854 \mathrm{E}-3$ & $8.567 \mathrm{E}-6$ \\
\hline Moment of Inertia $\left(\mathrm{I}_{3}\right)(\mathrm{m} 4)$ & $0.07854 \mathrm{E}-3$ & $3.573 \mathrm{E}-6$ \\
\hline
\end{tabular}




\subsubsection{3-D FEM RESULTS AND ANALYSES}

In Plaxis, the mesh coarseness provides a significant influence on the calculation results. The model is implemented with five types of mesh coarseness: very coarse, coarse, medium, fine mesh, and very fine mesh. In order to evaluate the mesh dependence. The number of element and node obtained from using these different types of mesh coarseness are given below in Table 4.10. The results on the lateral deformation at the pile head are shown in Table 4.11, along with the measured value.

Table 4.10 Numbers of elements and nodes generated for different mesh coarseness conditions

\begin{tabular}{|l|l|l|}
\hline Type of mesh & Number of elements generated & Number of nodes generated \\
\hline Very Coarse & 940 & 1638 \\
\hline Coarse & 2227 & 3661 \\
\hline Medium & 6392 & 9925 \\
\hline Fine & 19225 & 28487 \\
\hline Very fine & 50197 & 71371 \\
\hline
\end{tabular}

Table 4.11 The influence of mesh coarseness on the maximum pile head displacements at the end of analysis

\begin{tabular}{|l|c|}
\hline Types of mesh & Lateral displacement at the pile top, $\boldsymbol{U} \boldsymbol{( m m})$ \\
\hline Very coarse & 21.21 \\
\hline Coarse & 25.63 \\
\hline Medium & 31.38 \\
\hline Fine & 37.39 \\
\hline Very fine & 38.70 \\
\hline Field Measurement & $\mathbf{3 8 . 4 8}$ \\
\hline
\end{tabular}


As shown in the results, more displacement is obtained for the model which uses a finer mesh. The difference in deformations at the pile head is about $45 \%$ when the mesh changes from "very coarse" into "very fine". At the end of the analyses, the very fine mesh density was selected due to its accuracy, which consists of 50197 soil elements and 72371 nodes. The average element size was $0.058 \mathrm{~m}$.

The results can be viewed in the output mode and the most notable results are the deformed mesh, total displacement, lateral displacement at the pile head, bending moment, and shear force. In the case of the Salem site, the lateral displacement $(U x)$ at the pile head is $38.70 \mathrm{~mm}$, which is comparable to field measurement of $38.48 \mathrm{~mm}$.

The geometry of the model is shown in Fig. 4.5. The 3-D finite element mesh is also shown in Fig. 4.6. In addition, the typical deformed mesh and the total displacement in the $x$ direction (horizontal) at the pile head after FEM analysis are shown in Fig. 4.7 and Fig. 4.8, respectively. Fig. 4.9 shows the bending moment (M3) at the end of FEM analysis. The distribution of shear force along the pile depth is shown in Fig. 4.10. 


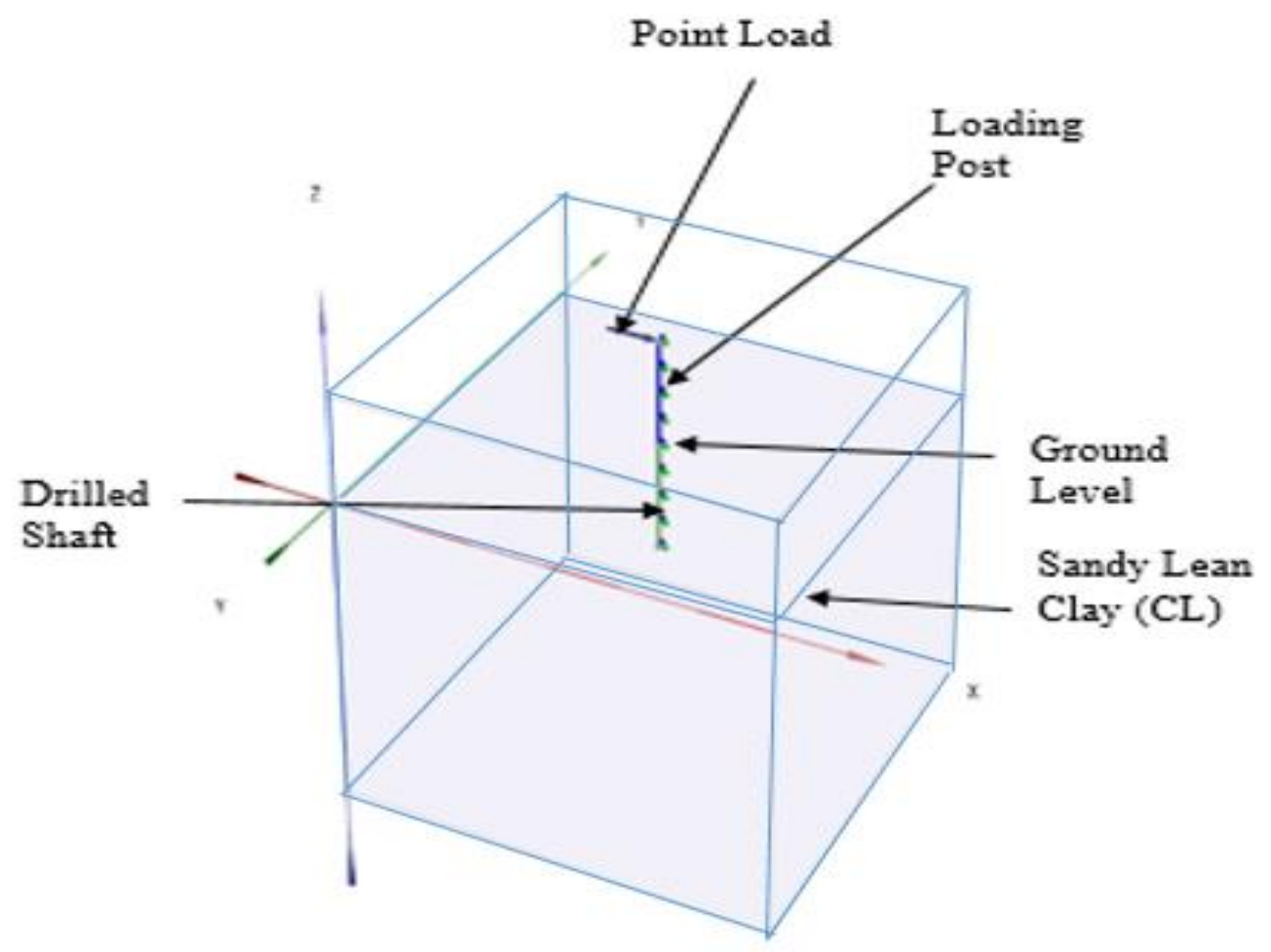

Figure 4.5 The geometry of a 3-D FEM model used in this study

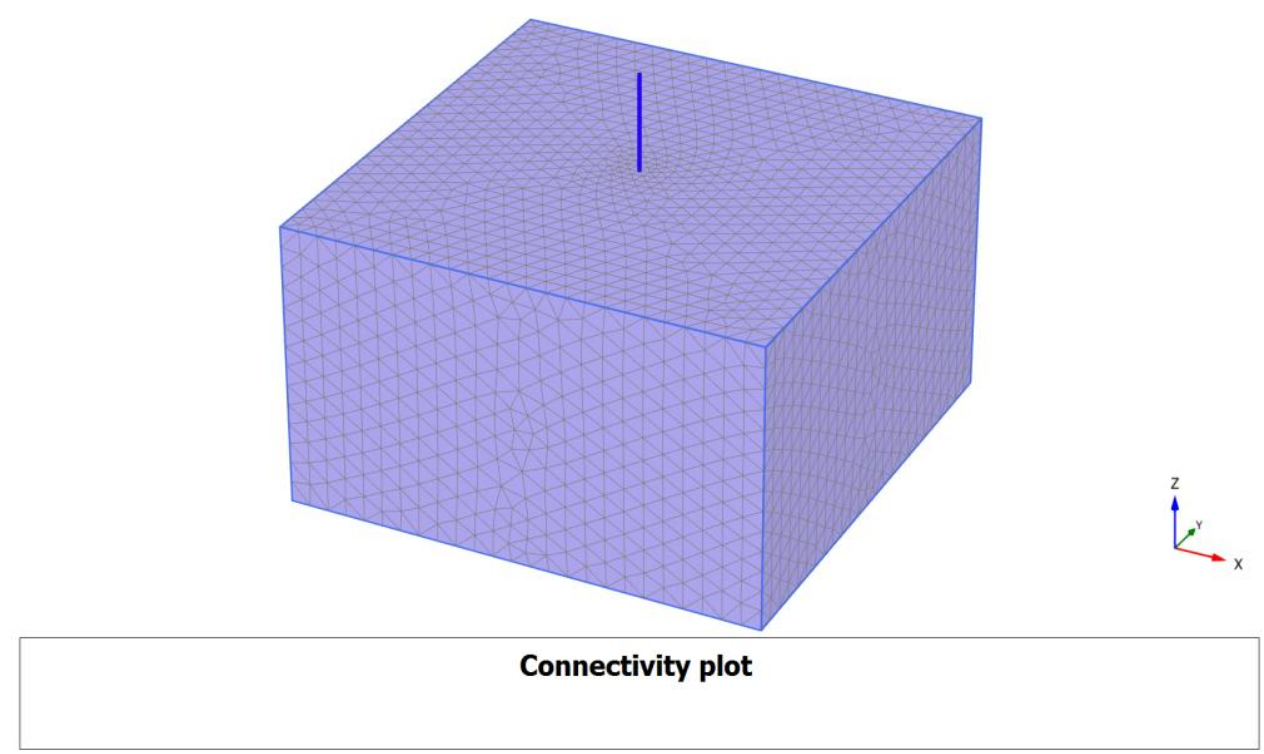

Figure 4.6 Typical mesh generation of the 3-D FEM model in Plaxis 3D 


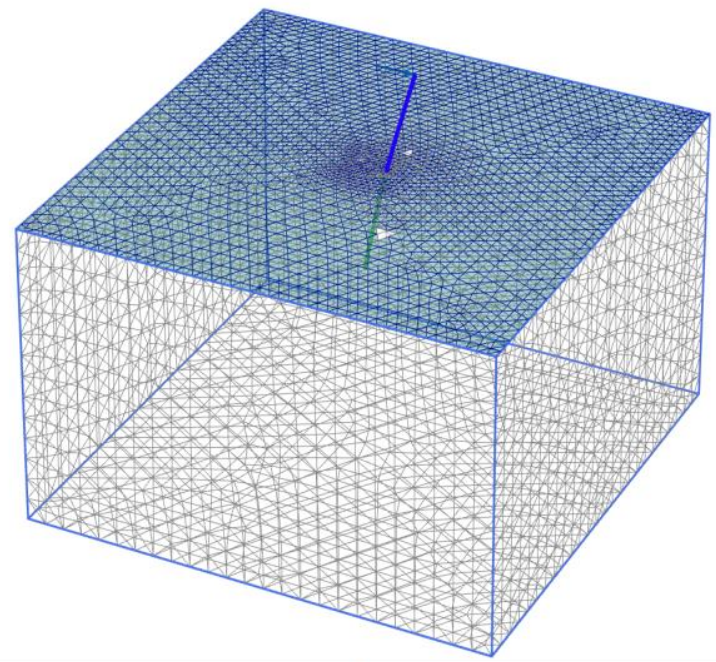

Deformed mesh $|\mathrm{u}|$ (scaled up 5.00 times)

Maximum value $=0.1118 \mathrm{~m}$ (at Node 1$)$

Figure 4.7 Typical deformed mesh after FEM analysis in Plaxis 3D
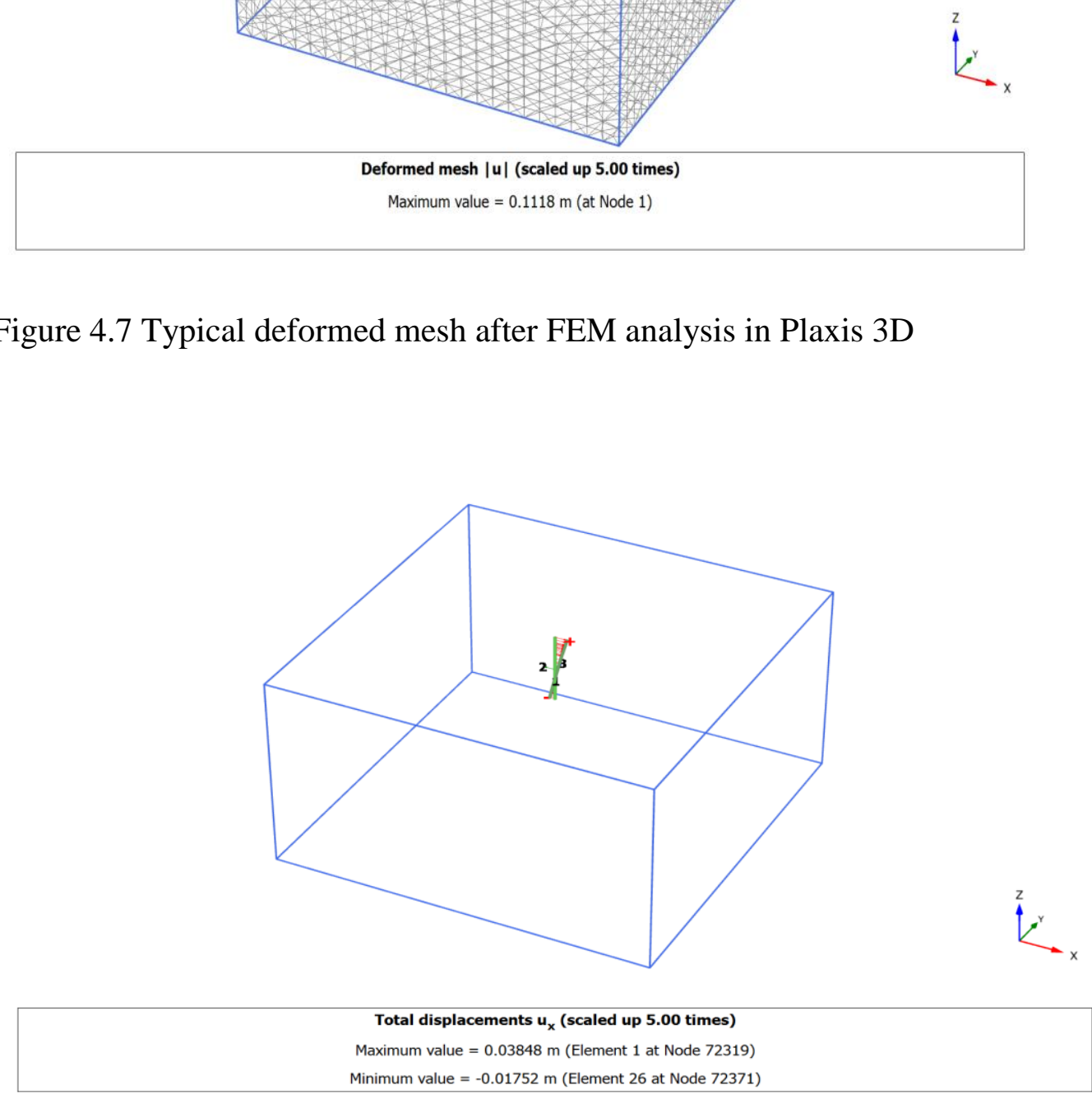

Figure 4.8 Total horizontal displacemet, $U x$, at the pile head after FEM analysis 

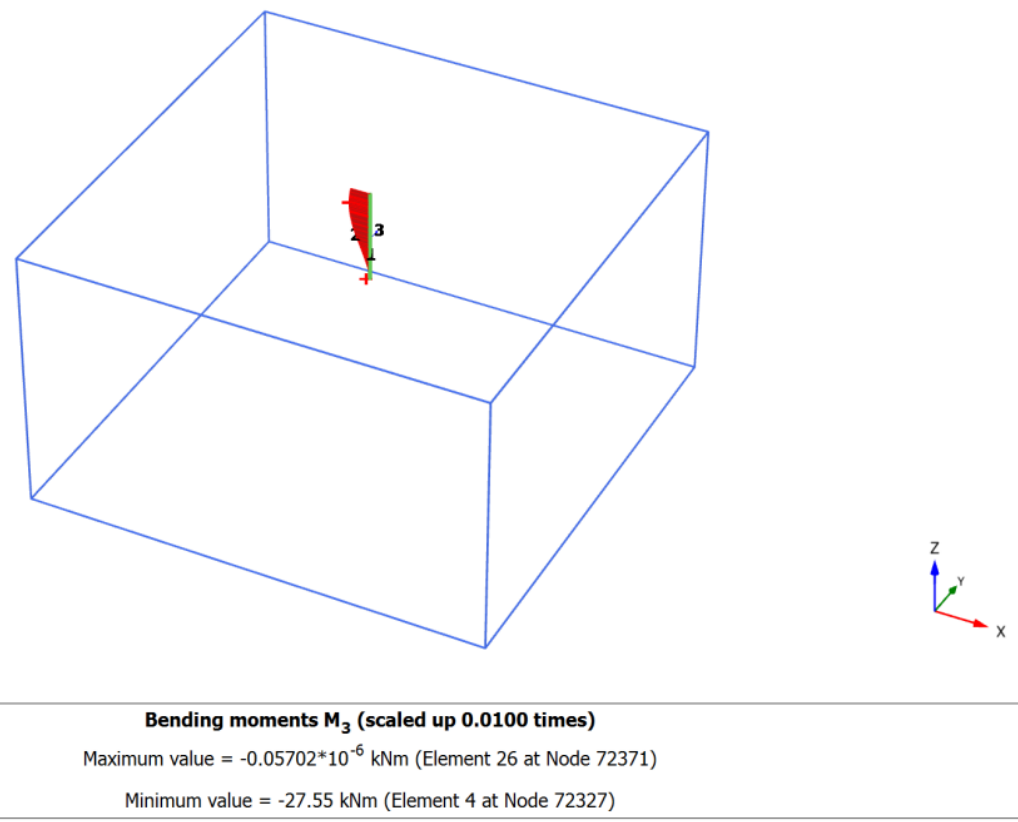

Figure 4.9 Distribution of bending moment along the pile depth at the end of FEM analysis
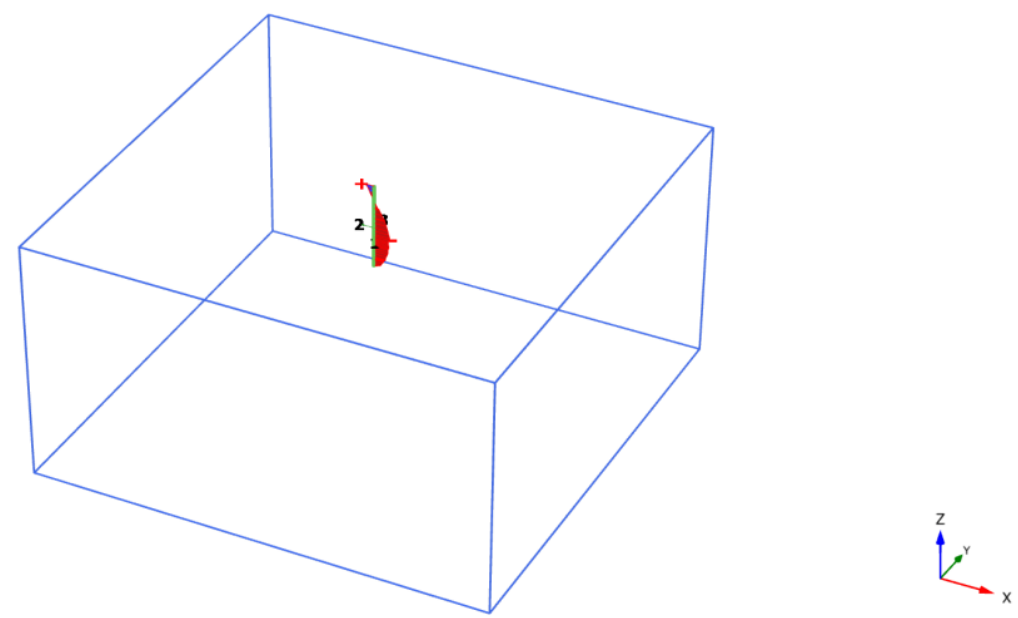

Shear forces $Q_{12}$ (scaled up $5.00 * 10^{-3}$ times)

Maximum value $=21.52 \mathrm{kN}$ (Element 1 at Node 72319)

Minimum value $=-41.38 \mathrm{kN}$ (Element 14 at Node 72347)

Figure 4.10 Distribution of shear force along the pile depth at the end of FEM analysis 


\subsection{3-D FEM RESULT ANALYSES AND DISCUSSSIONS}

Numerical analyses are conducted using Plaxis 3D to simulate the field tests carried out at five sites in Virginia, U.S. In this Chapter, the 3-D FEM results will be compiled and presented. The numerical results are also compared with the field measurements and the empirical theories to evaluate the accuracy and reliability of 3-D FEM in simulating laterally loaded shafts for noise barrier walls.

\subsubsection{ULTIMATE CAPACITY FROM NUMERICAL RESULTS}

The results of the ultimate lateral load capacity and the lateral displacement at the pile head in $x$ direction are provided in Table 4.12, which are obtained from 3-D FEM analyses for field tests at all five sites in Virginia, U.S.

Table 4.12 3-D FEM simulation of field tests in Virginia, U.S.

\begin{tabular}{|l|c|c|}
\hline Test Site & $\begin{array}{l}\text { FEM lateral capacity } \\
(\mathbf{k N})\end{array}$ & $\begin{array}{l}\text { FEM lateral displacement } \\
\text { at the pile head (mm) }\end{array}$ \\
\hline Prices Fork & 18.5 & 52.50 \\
\hline Salem & 20.75 & 38.70 \\
\hline Suffolk & 20.85 & 83.58 \\
\hline Fairfax County & 15.50 & 83.96 \\
\hline Roberts Road & 22.00 & 29.65 \\
\hline
\end{tabular}

The 3-D FEM analysis results for five field tests in Virginia, U.S. are shown below: the lateral displacement along the shaft depth, $U_{x}$ (Figs. 4.11, 4.15, 4.19, 4.23, \& 4.27), the bending moment, $M_{3}$, along the pile depth (Figs. 4.12, 4.16, 4.20, 4.24, \& 4.28), and the shear force, $\mathrm{Q}_{12}$, along the pile depth (Figs. 4.13, 4.17, 4.21, 4.25, \& 4.29). Another important output that can be obtained from the numerical simulation is the $P-Y$ graph. This graph shows the change of lateral load and corresponding lateral displacement at the pile head in $x$ direction. The $P-Y$ graphs from the simulations can be observed in Figs. 4.14, 4.18, 4.22, 4.26, \& 4.30. 


\section{Lateral displacement vs. depth graph (Salem site)}

Figure 4.15 shows the lateral displacement in $x$ direction along the shaft depth at the end of FEM analysis in the Salem test site. The maximum lateral displacement at the shaft head in the $\mathrm{x}$ direction is $38.7 \mathrm{~mm}$. The rotation depth of the shaft is $0.8 \mathrm{~m}$ from the ground surface, which is $66 \%$ of the shaft length. The rotation angle of the shaft is $2.77^{\circ}$. As it can be seen in the graph that the gradient is consistent throughout the shaft even after the end of FEM analysis. No prominent deformation in the shaft is observed. This means that in the case of a stiff and short shaft, the lateral capacity is mainly controlled by the failure of surrounding soil.

\section{Bending moment vs. depth graph (Salem site)}

Figure 4.16 shows the distribution of bending moment $\left(\mathrm{M}_{3}\right)$ along the shaft depth at the end of FEM analysis in the Salem test site. If the structure has a local system of axes $(1,2,3)$, the first direction is always the axial direction. The other directions (second and third) will always be perpendicular to the structure axis. The bending moment $\mathrm{M}_{3}$ is the bending moment formed because of the bending around the third axis. As it can be seen in the curve that the maximum bending moment of $27.55 \mathrm{kNm}$ occurs at the depth of $0.25 \mathrm{~m}$ from the top of the shaft, which is around $20 \%$ of the shaft length. There are also smooth changes observed in the curve.

\section{Shear force vs. depth graph (Salem site)}

Figure 4.17 shows the distribution of shear force along the shaft depth at the end of FEM analysis in the Salem test site. The shear force over the $2^{\text {nd }}$ beam axis is denoted as $Q_{12}$. As it can be observed in the graph that the maximum shear force is $41.38 \mathrm{kN}$ at the depth of $0.78 \mathrm{~mm}$ from the top of the shaft. The shear force curve is not as smooth as the one for moment. This may have occurred due to the interface modelling issue between the soil and the shaft. 


\section{Load vs. deflection, $P$ - $Y$, curve (Salem site)}

Figure 4.18 shows the lateral load vs. lateral displacement curve $(P-Y$ curve) at the end of FEM analysis in the Salem site. The ultimate lateral load capacity is determined when the lateral displacement at the shaft head of the model equals the measured lateral displacement value from the field tests. In this analysis for the Salem site, the ultimate lateral load capacity is obtained as $20.75 \mathrm{kN}$ and the corresponding lateral displacement at the pile head is $38.7 \mathrm{~mm}$. The lateral displacement at the shaft head is around $19 \%$ of the shaft diameter. It is also observed in the $P-Y$ graph that the curve also has become linear at this point. Therefore, the above conditions stated by the researchers on ultimate lateral load capacity are satisfied. 


\section{a] 3-D FEM Results for Field Tests at Prices Fork Site}

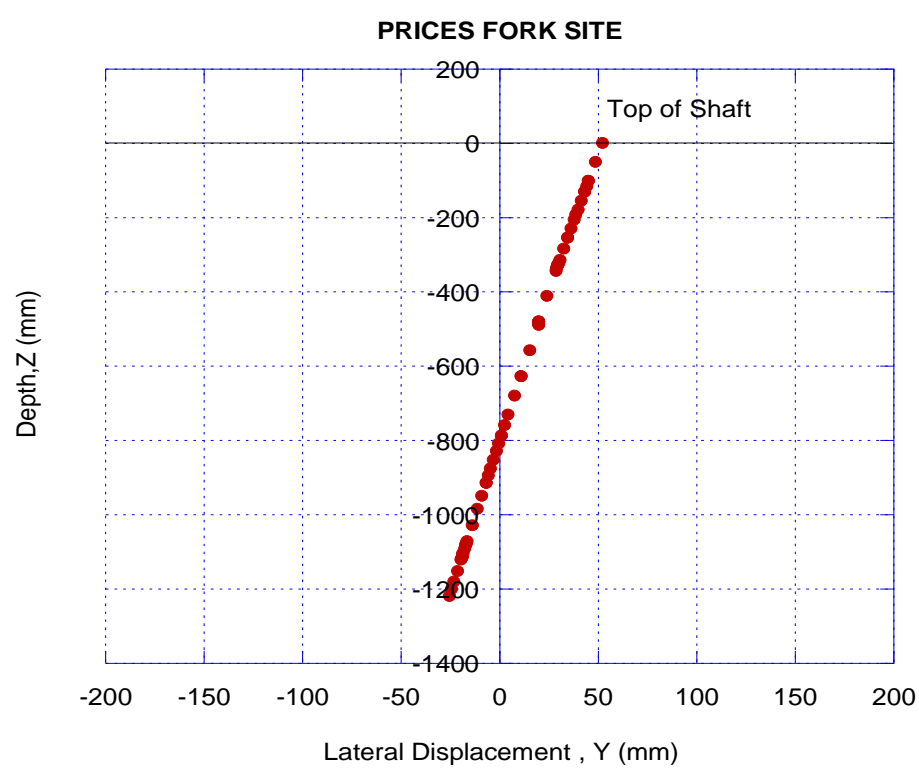

Figure 4.11 Total deflection of the shaft at the end of FEM analysis

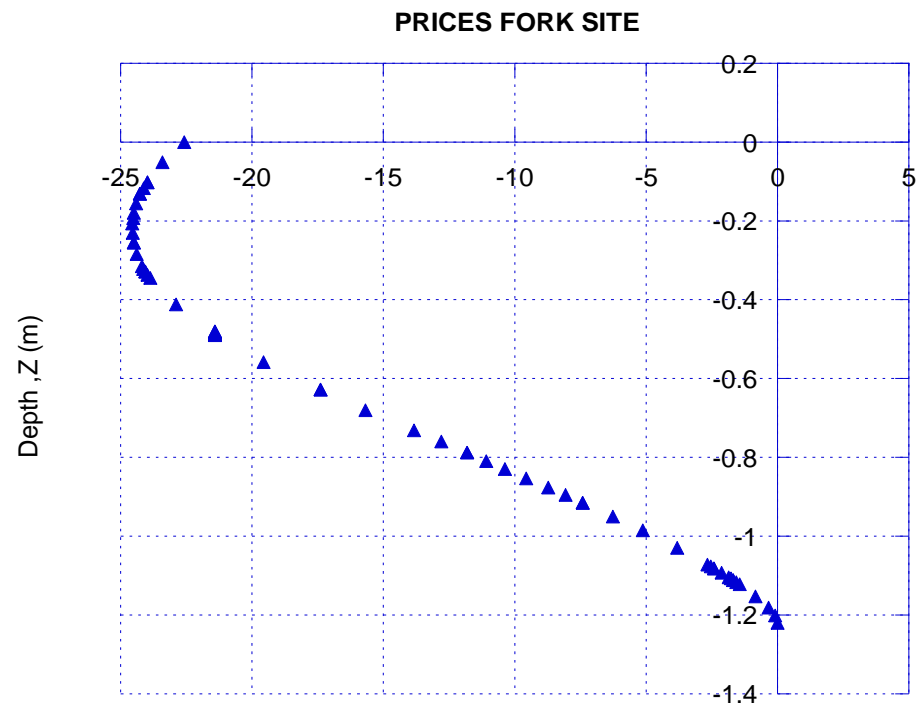

Bending moment , $\mathrm{M} 3(\mathrm{kNm})$

Figure 4.12 Distribution of bending moment along the depth at the end of FEM analysis 


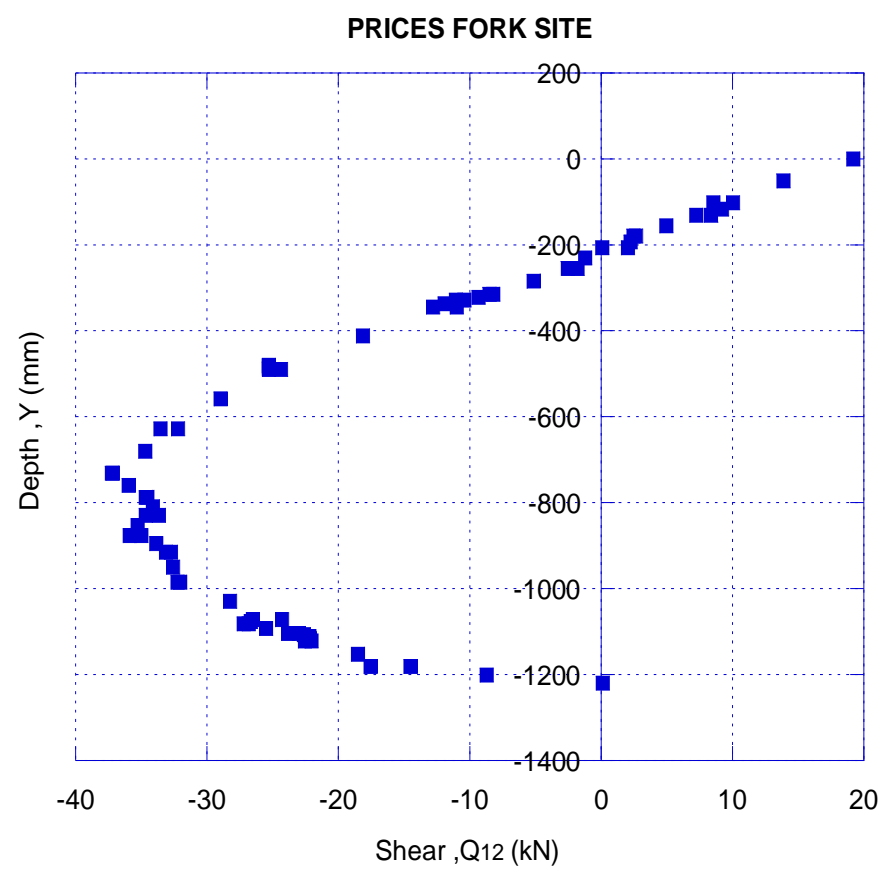

Figure 4.13 Distribution of shear force along the depth at the end of FEM analysis

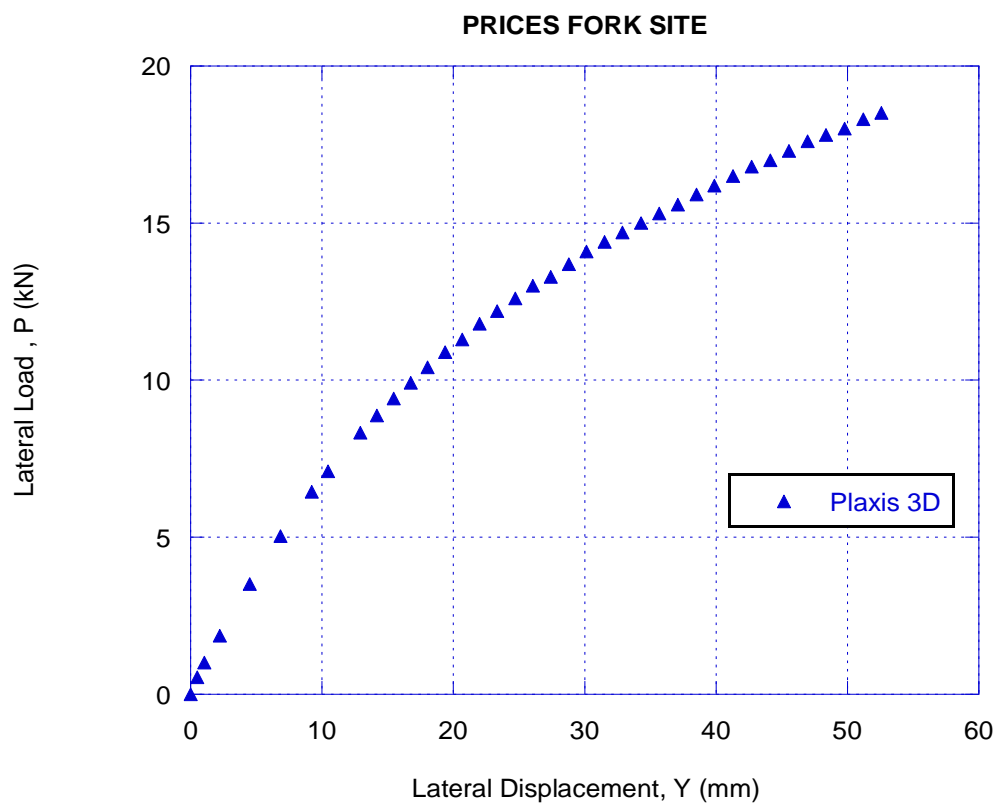

Figure 4.14 Load and deflection, $P-Y$, curve of drilled shaft 


\section{b] 3-D FEM Results for Field Tests at Salem Site}

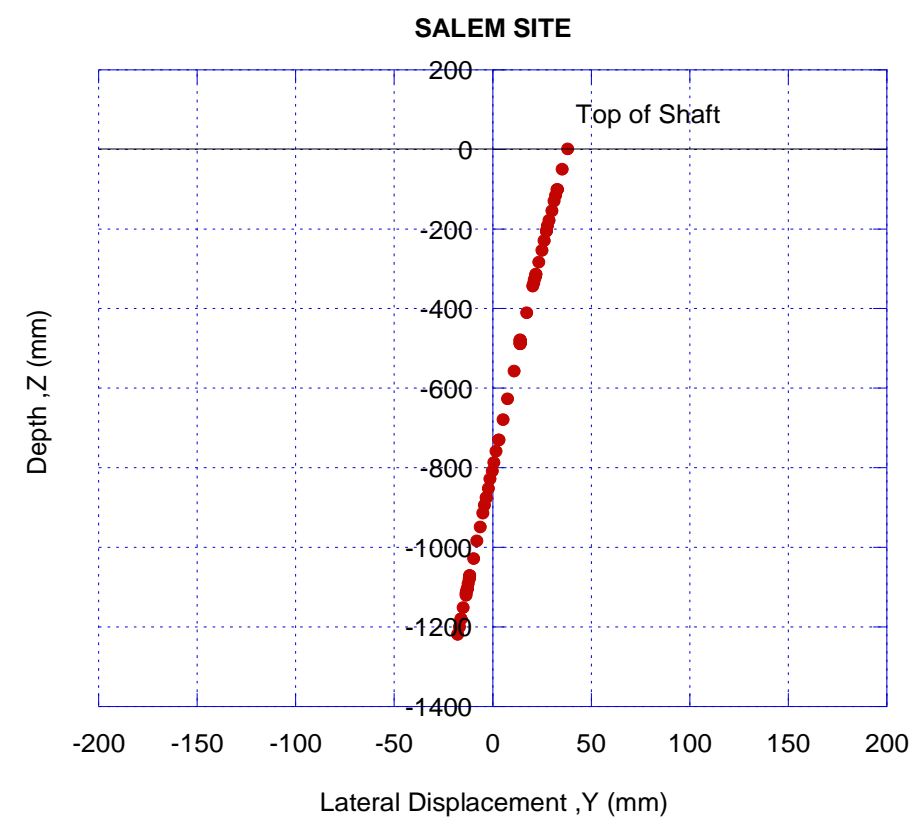

Figure 4.15 Total deflection of the shaft at the end of FEM analysis

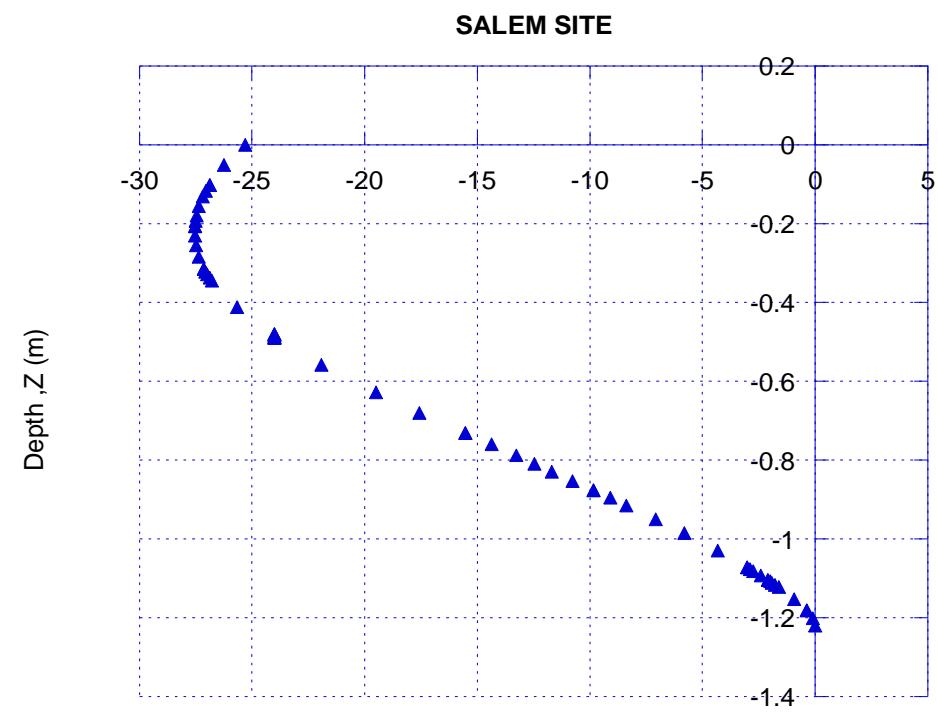

Bending Moment ,M3 (kNm)

Figure 4.16 Distribution of bending moment along the depth at the end of FEM analysis 


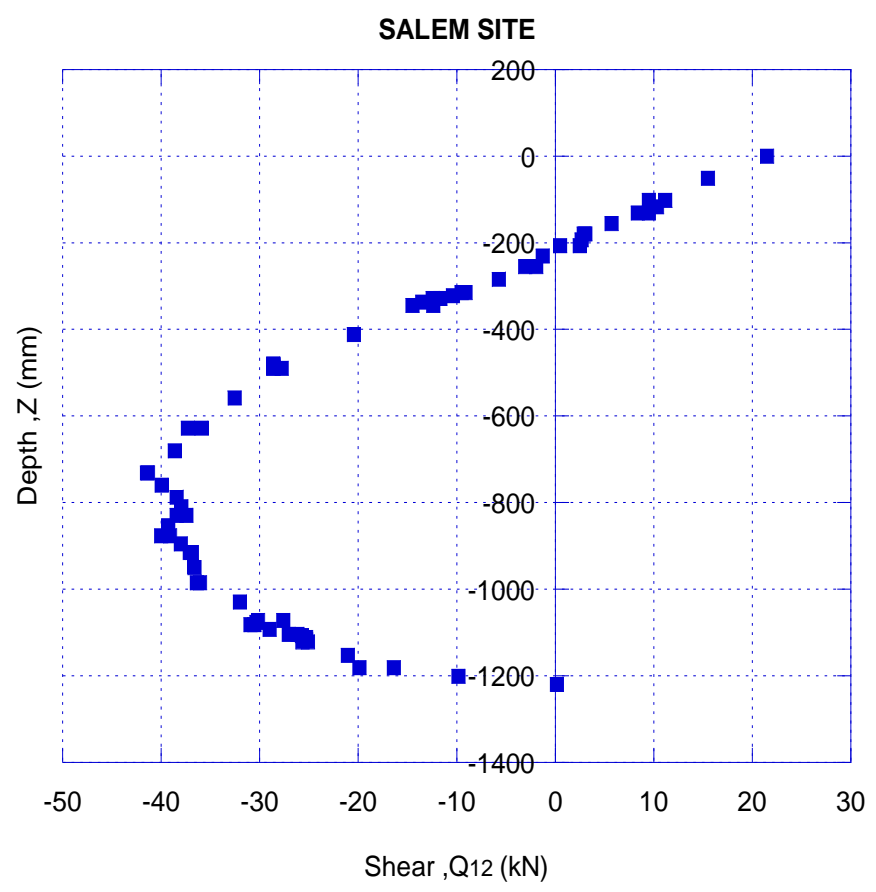

Figure 4.17 Distribution of shear force along the depth at the end of FEM analysis

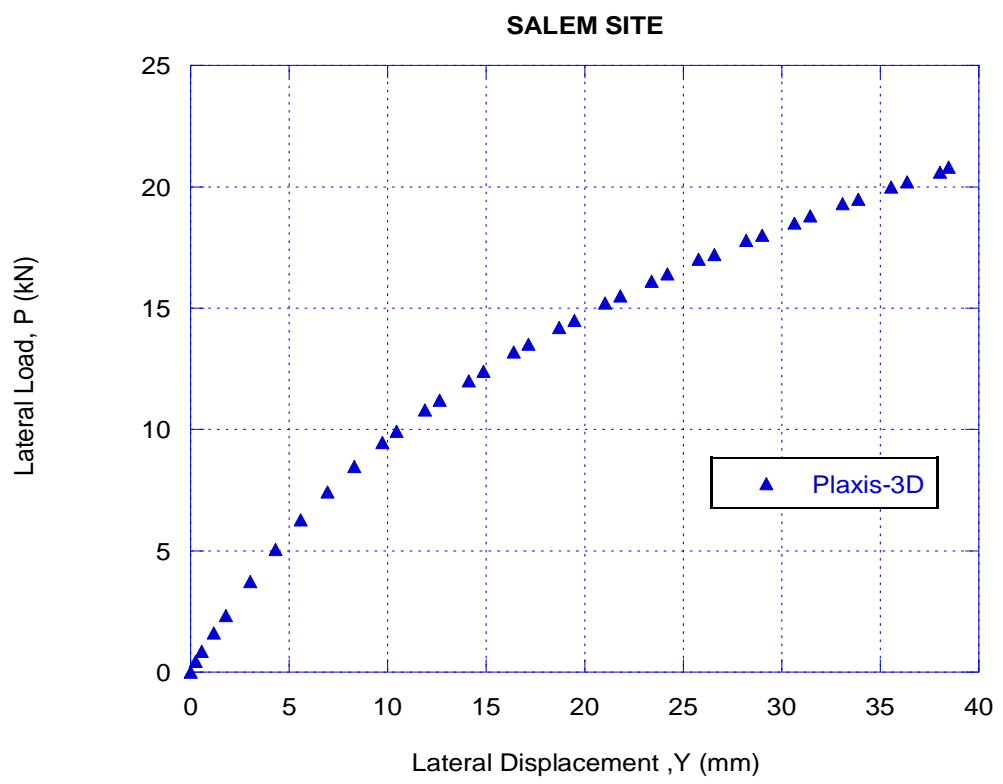

Figure 4.18 Load and deflection, $P-Y$, curve of drilled shaft 


\section{c] 3-D FEM Results for Field Tests at Suffolk Site}

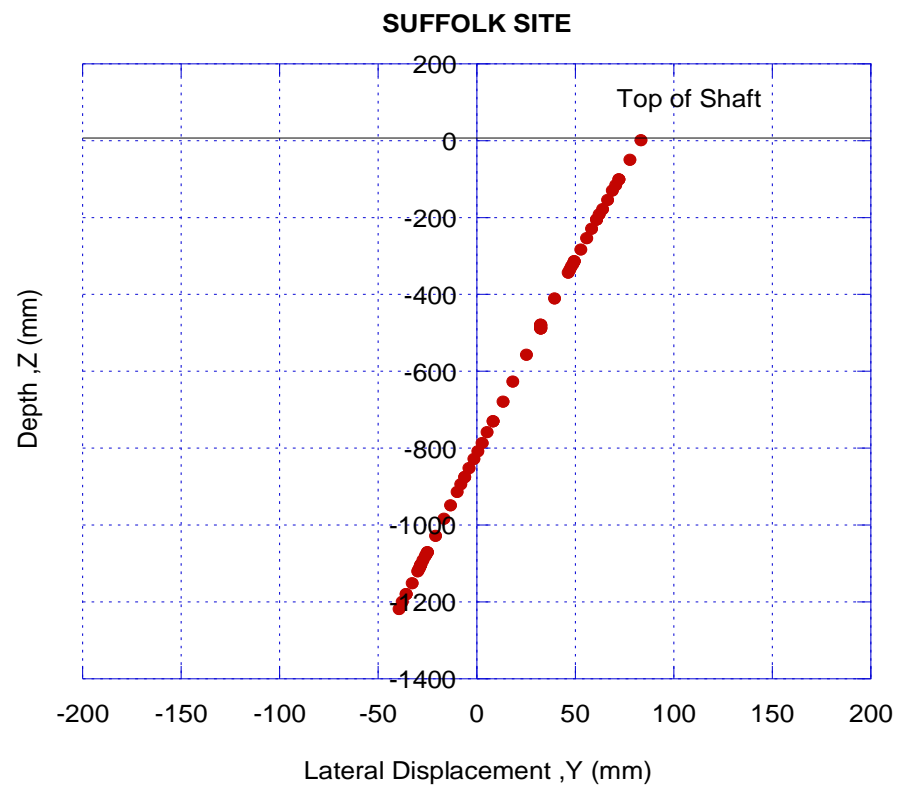

Figure 4.19 Total deflection of the shaft at the end of FEM analysis

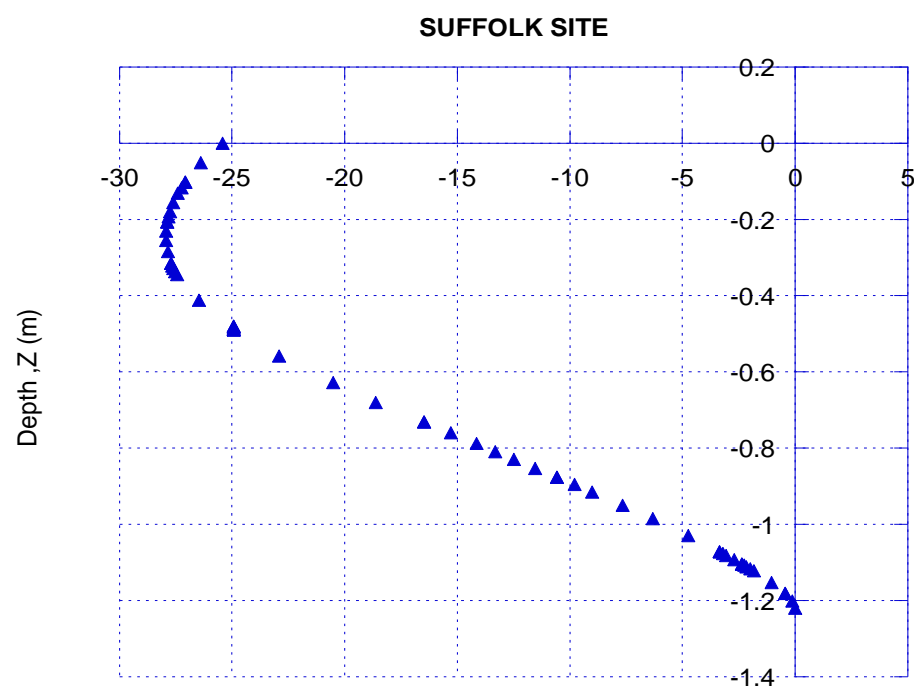

Bending Moment ,M3 (kNm)

Figure 4.20 Distribution of bending moment along the depth at the end of FEM analysis 


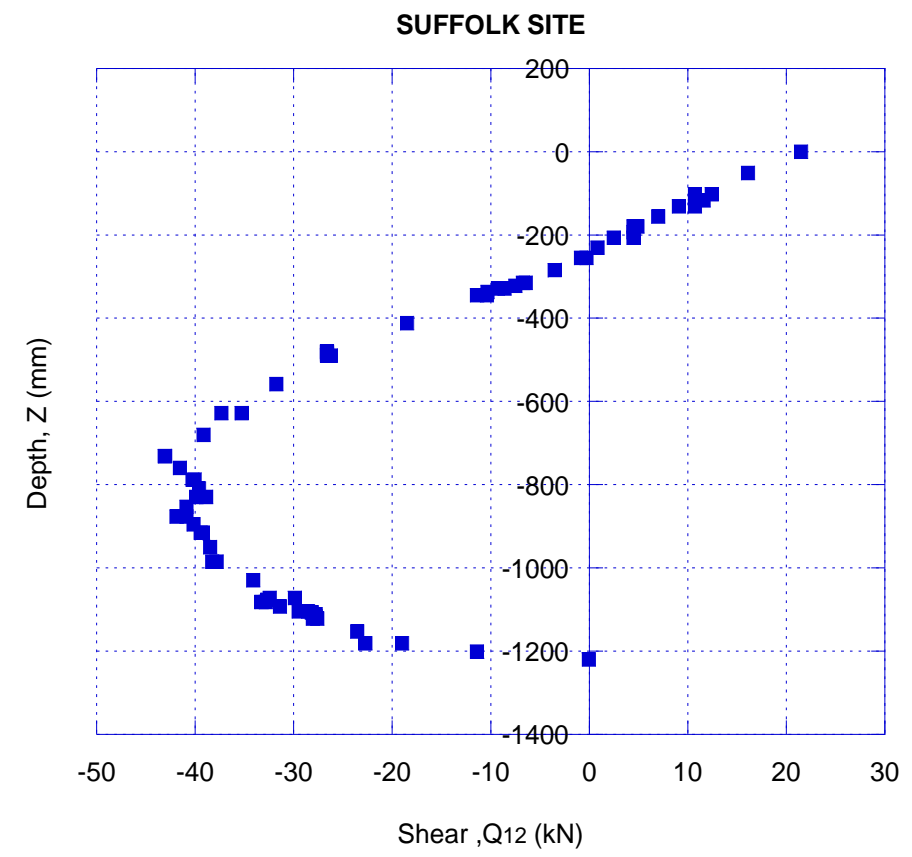

Figure 4.21 Distribution of shear force along the depth at the end of FEM analysis

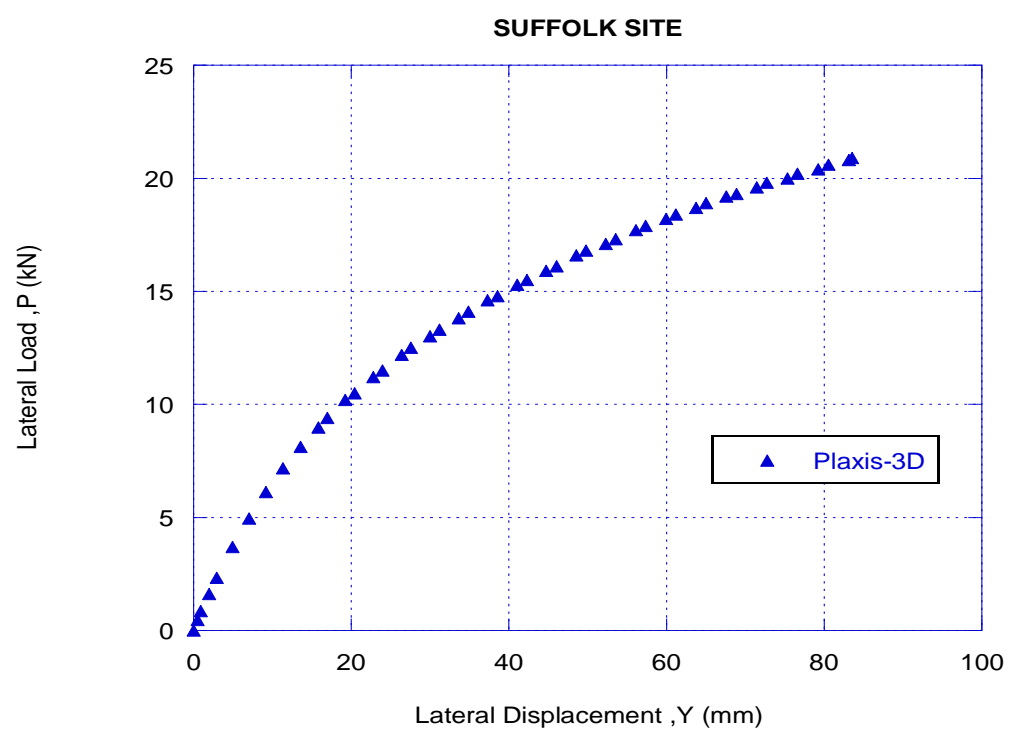

Figure 4.22 Load and deflection, $P-Y$, curve of drilled shaft 


\section{d] 3-D FEM Results for Field Tests at Fairfax County Site}

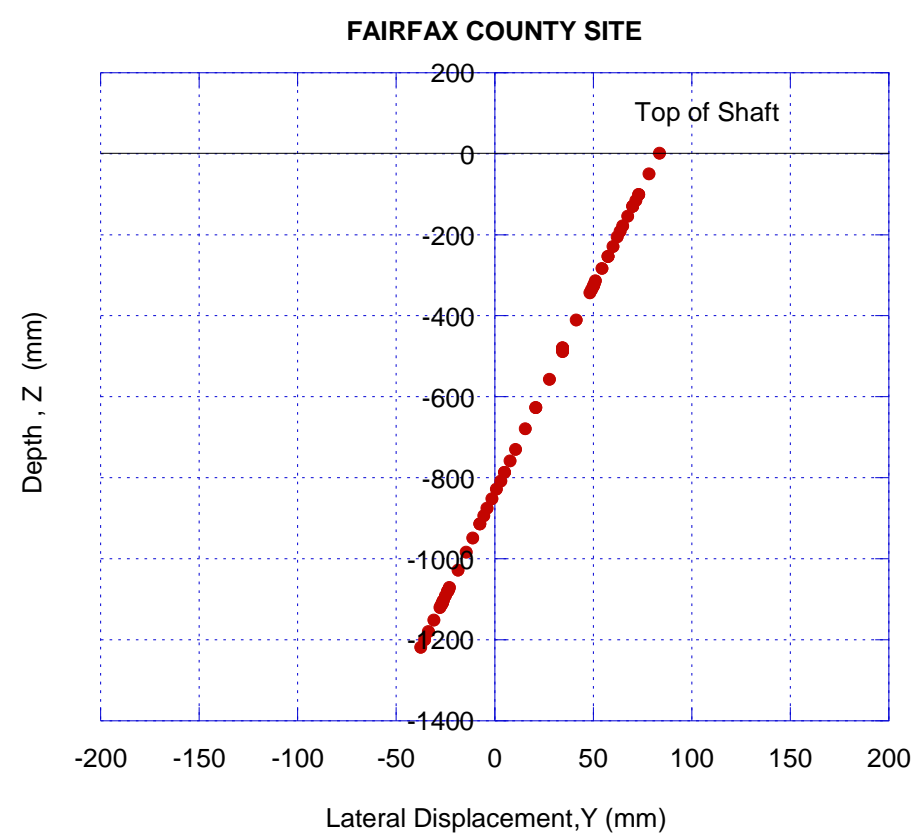

Figure 4.23 Total deflection of the shaft at the end of FEM analysis

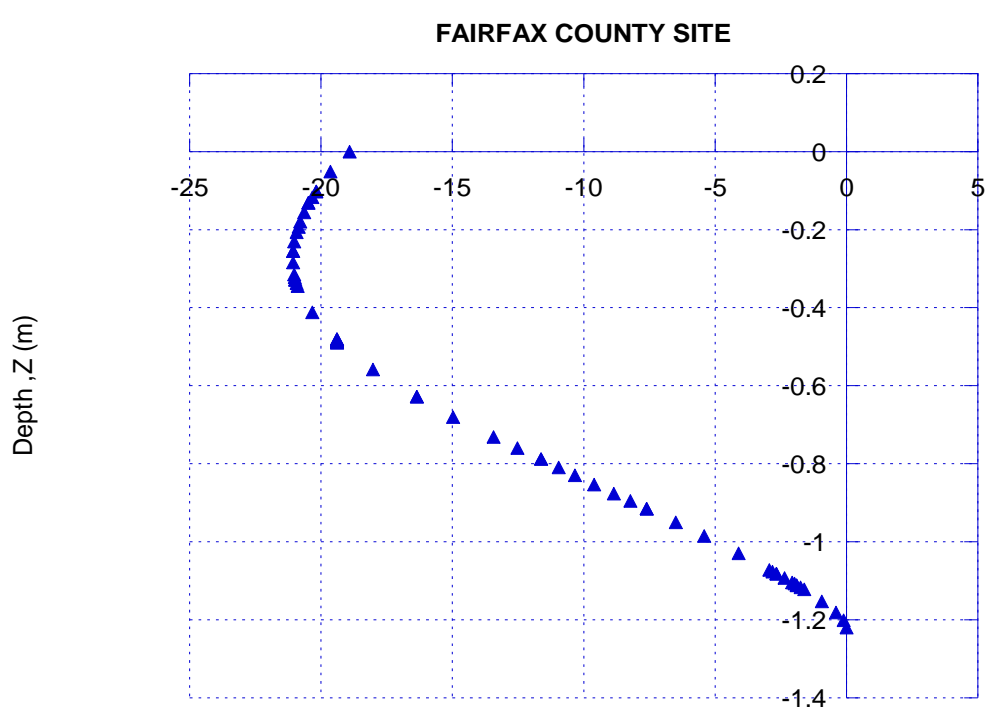

Bending Moment ,M3 (kNm)

Figure 4.24 Distribution of bending moment along the depth at the end of FEM analysis 


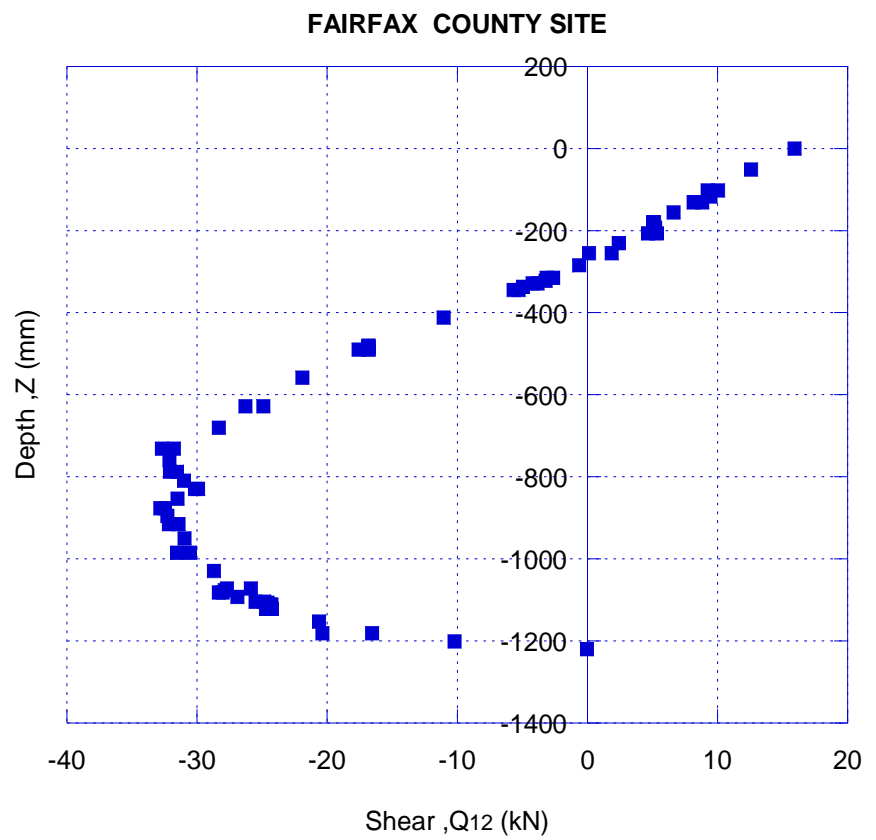

Figure 4.25 Distribution of shear stress along the depth at the end of FEM analysis

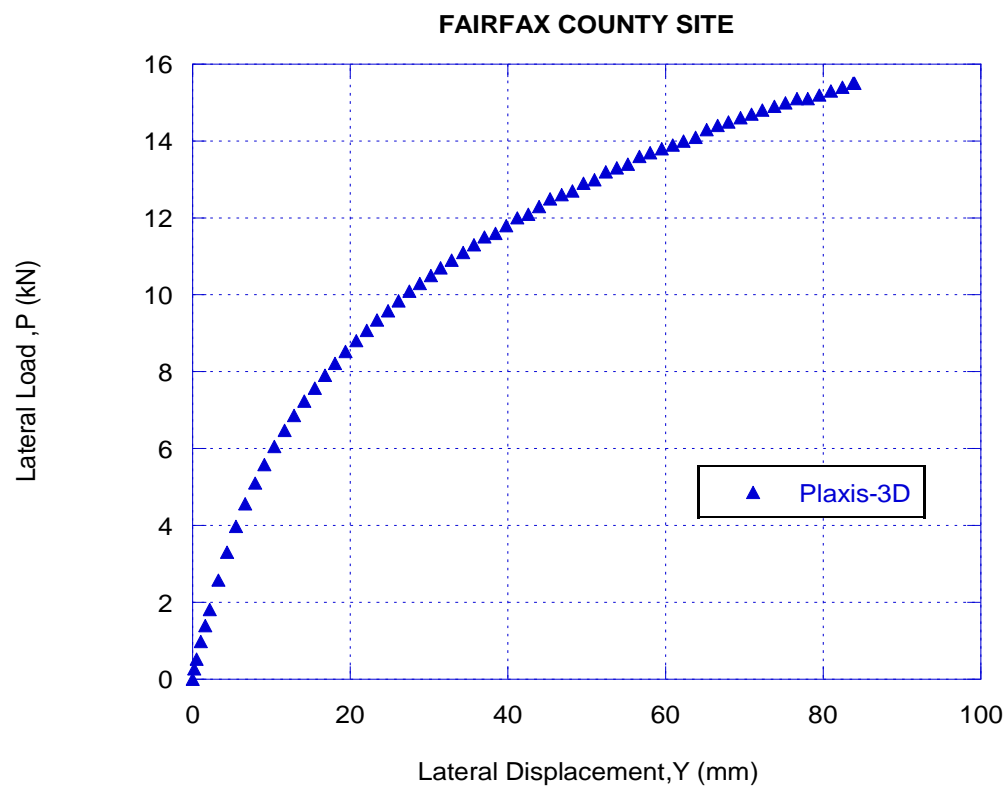

Figure 4.26 Load and deflection, $P-Y$, curve of drilled shaft 


\section{e] 3-D FEM Results for Field Tests at Roberts Road Site}

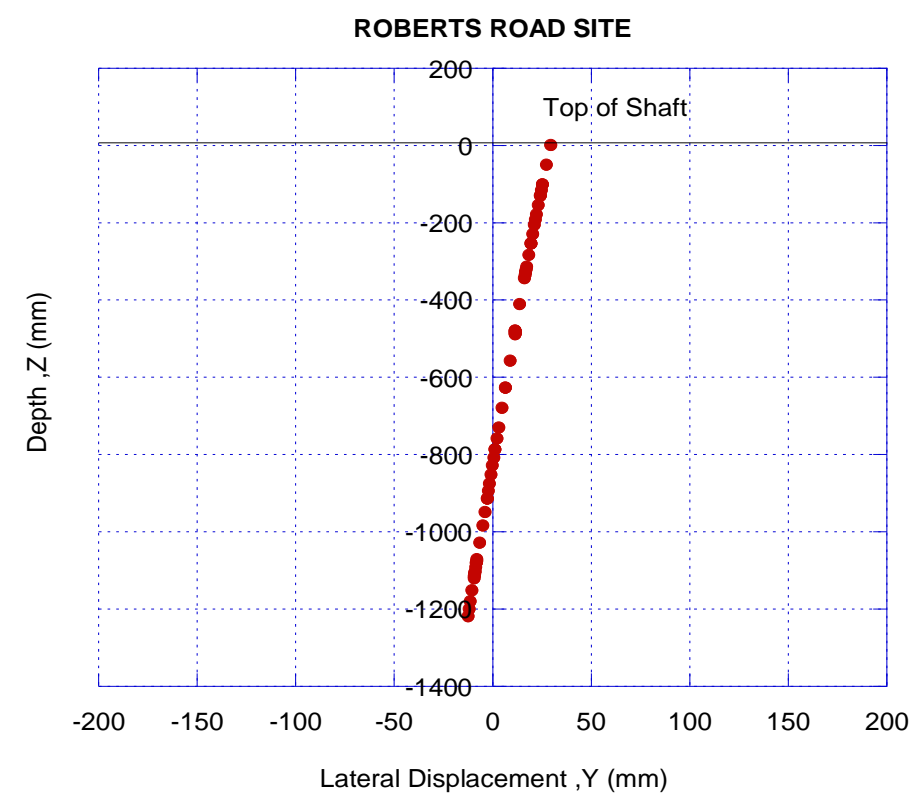

Figure 4.27 Total deflection of the shaft at the end of FEM analysis

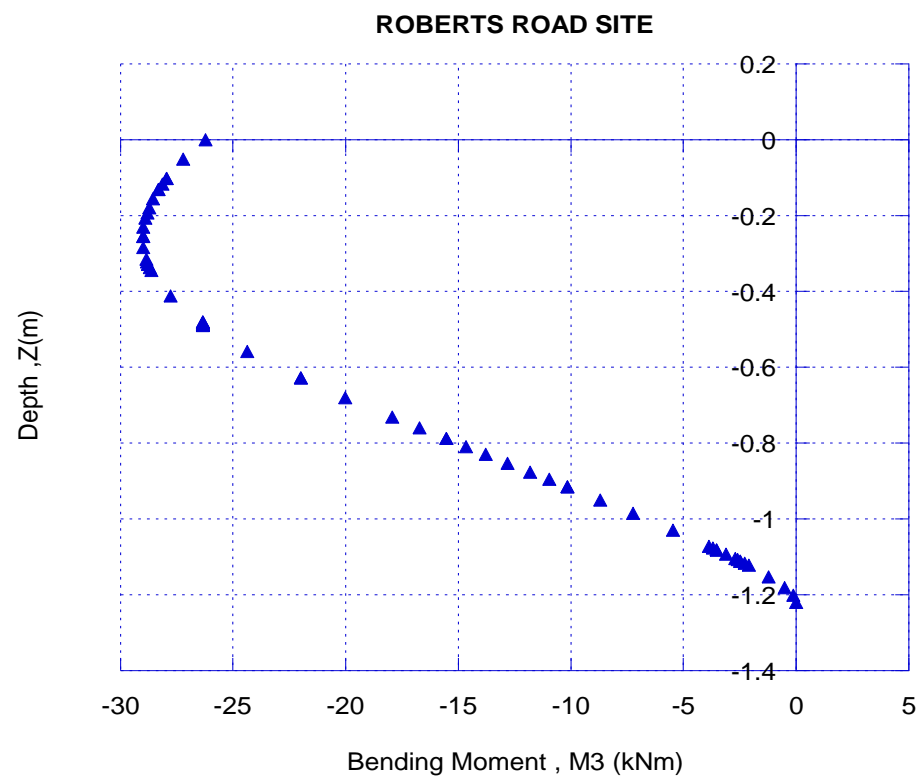

Figure 4.28 Distribution of bending moment along the depth at the end of FEM analysis 


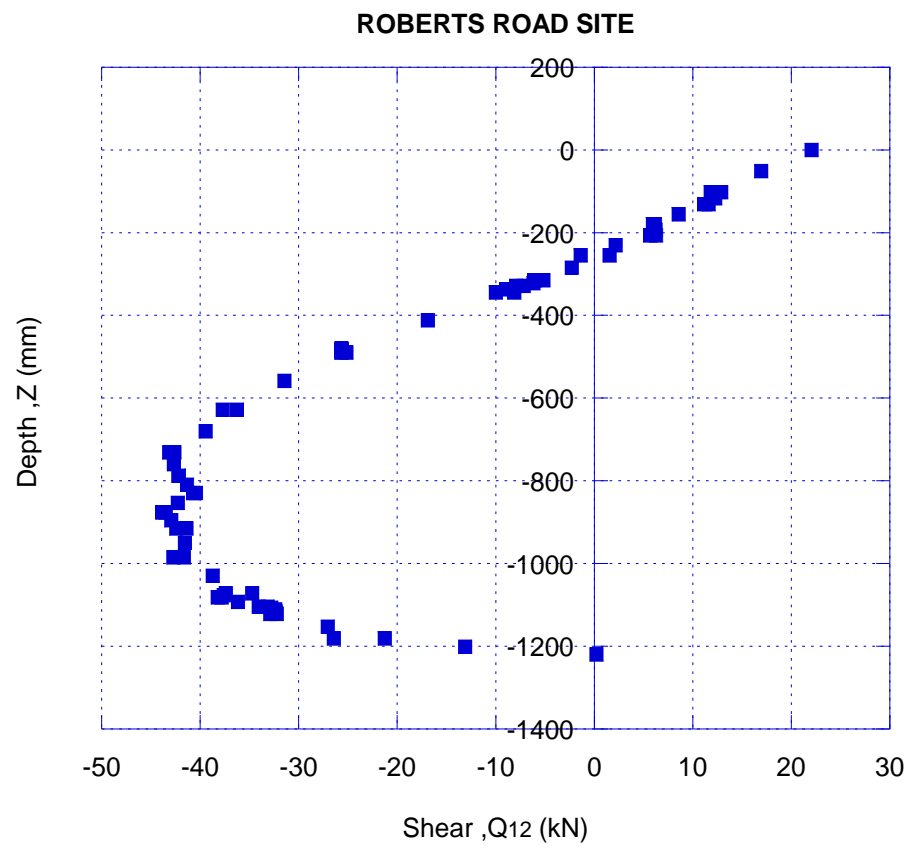

Figure 4.29 Distribution of shear stress along the depth at the end of FEM analysis

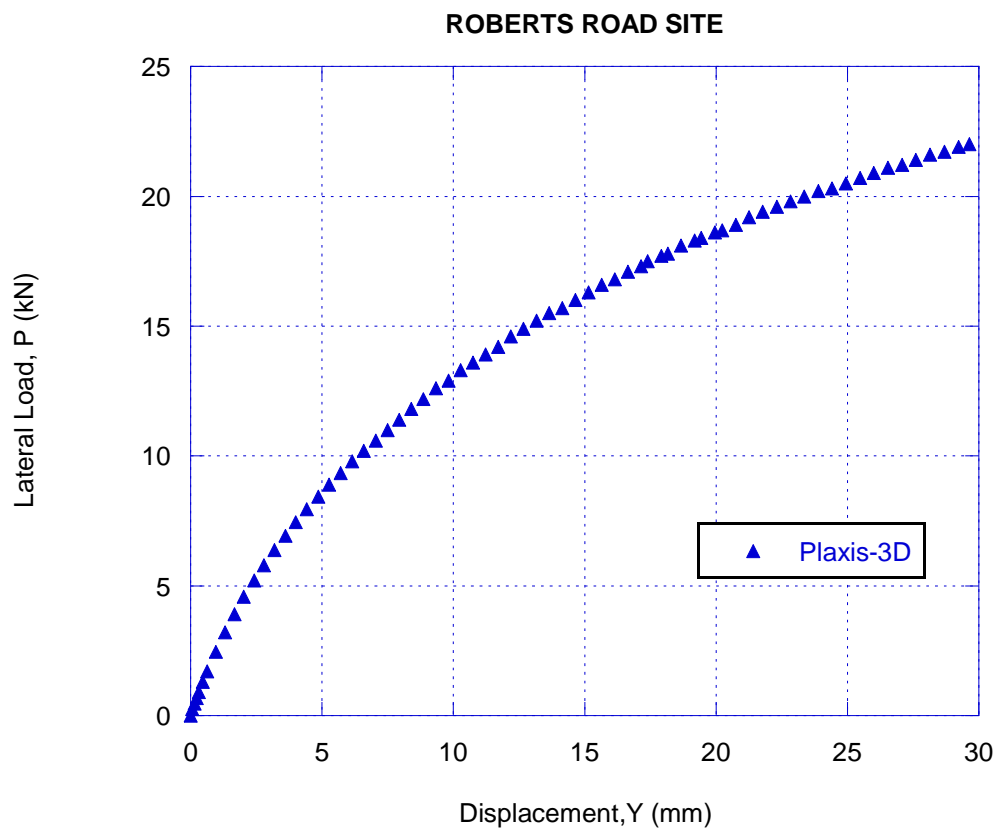

Figure 4.30 Load and deflection, $P-Y$, curve of drilled shaft 


\subsubsection{COMPARISON WITH FIELD MEASUREMENTS}

These field load tests were carried out by Helmers (1997). The average field measurements from these field load tests can be viewed in Table 4.13, which are compiled with the numerical analyses results for further comparison.

Table 4.13 Comparison with field measurements on ultimate lateral load

\begin{tabular}{|l|c|c|c|}
\hline Test Site & $\begin{array}{c}\text { Field measurements } \\
(\mathbf{k N})\end{array}$ & $\begin{array}{c}\text { 3-D FEM result } \\
(\mathbf{k N})\end{array}$ & $\begin{array}{c}\text { FEM/Measured ratio } \\
(\mathbf{\%})\end{array}$ \\
\hline Prices Fork & 17.34 & 18.50 & 107.5 \\
\hline Salem & 20.46 & 20.75 & 102.0 \\
\hline Suffolk & 20.01 & 20.85 & 105.3 \\
\hline Fairfax County & 16.45 & 15.50 & 94.3 \\
\hline Roberts Road & 20.68 & 22.00 & 106.4 \\
\hline & & Average & 103.1 \\
\hline
\end{tabular}

The 3-D FEM numerical results agree very well with field measurements on the ultimate lateral load for shafts in Virginia, U.S. The ratio of FEM result/field measurement varies from $94 \%$ to $107.5 \%$ with an average ratio of $103.1 \%$.These values are considered to be very consistent and reliable given the variations in ground conditions and field shaft construction.

\subsubsection{COMPARISON WITH ULTIMATE LATERAL LOAD CAPACITY THEORIES}

The lateral load capacities of drilled shafts have been calculated using the values of unit weight, cohesion, and friction angle discussed before for each site by the following methods.

1) Broms's (1964b) theory for cohesionless soils

2) Brinch-Hansen's (1961) theory for soils with both cohesion and friction 
The capacities calculated using these methods are compared with 3-D FEM analyses as presented in Tables 4.14 and 4.15 .

Table 4.14 Comparison of 3-D FEM analyses \& Broms's (1964b) theory on ultimate lateral load

\begin{tabular}{|l|c|c|c|}
\hline Test Site & Broms (1964b) (kN) & 3-D FEM (kN) & 3-D FEM / Broms (1964b) \\
\hline Prices Fork & 4.09 & 18.5 & 4.52 \\
\hline Salem & 5.24 & 20.75 & 3.96 \\
\hline Suffolk & 4.53 & 20.85 & 4.60 \\
\hline Fairfax County & 4.57 & 15.5 & 3.39 \\
\hline Roberts Road & 6.75 & 22.00 & 3.26 \\
\hline \multicolumn{2}{|c|}{ Average } & 3.95 \\
\hline
\end{tabular}

It can be seen that Broms's (1964) theory significantly underestimates the lateral capacity of short shafts used in Virginia, U.S. The ratio of 3-D FEM analyses over the prediction by Broms's (1964b) theory ranges from 3.26 (for Roberts Road site) to 4.60 (for Suffolk site), with an average ratio of about 3.95. The large differences between 3-D FEM analyses and Broms's (1964b) theory are due to the fact that Broms's (1964b) theory is formulated for soils without cohesion while 3-D FEM is calculated with both cohesion and friction angles given in Table 4.2. 
Table 4.15 Comparison with Brinch-Hansen's (1961) theory on ultimate lateral load

\begin{tabular}{|l|c|c|c|}
\hline Test Site & $\begin{array}{l}\text { Brinch-Hansen } \\
\mathbf{( 1 9 6 1 )}(\mathbf{k N})\end{array}$ & 3-D FEM (kN) & $\begin{array}{l}\text { 3-D FEM /Brinch-Hansen } \\
\mathbf{( 1 9 6 1 )}\end{array}$ \\
\hline Price's Fork & 21.22 & 18.5 & 0.87 \\
\hline Salem & 24.11 & 20.75 & 0.86 \\
\hline Suffolk & 19.18 & 20.85 & 1.09 \\
\hline Fairfax County & 12.19 & 15.5 & 1.27 \\
\hline Roberts Road & 20.69 & 22.00 & 1.06 \\
\hline \multicolumn{2}{|c|}{ Average } & & 1.03 \\
\hline
\end{tabular}

As shown in Table 4.15, Brinch- Hansen's (1961) theory provides a much more reasonable estimation of ultimate lateral load of drilled shafts in Virginia, US. The ratio of 3-D FEM over prediction using Brinch-Hansen's (1961) theory ranges from 0.86 (Salem) to 1.27 (Fairfax) with an average value of about 1.03 . The main improvement is due to the fact that both cohesion and friction is considered in Brinch-Hansen's (1961) theory compared to only cohesion or friction can be considered in Broms's theories. 
Table 4.16 Summary of ultimate lateral capacities of drilled shafts in Virginia along with predictions from FEM \& theoretical formulas

\begin{tabular}{|l|c|c|c|c|}
\hline Test Site & $\begin{array}{c}\text { Field } \\
\text { Measurements } \\
(\mathbf{k N})\end{array}$ & $\begin{array}{c}\text { Broms (1964b) } \\
\text { Prediction } \\
\mathbf{( k N )}\end{array}$ & $\begin{array}{c}\text { Brinch-Hansen } \\
\mathbf{( 1 9 6 1 )} \text { Prediction } \\
\mathbf{( k N )}\end{array}$ & $\begin{array}{c}\text { 3-D FEM } \\
\text { Analysis } \\
(\mathbf{k N})\end{array}$ \\
\hline Prices Fork & 17.34 & 4.09 & 21.22 & 18.50 \\
\hline Salem & 20.46 & 5.24 & 24.11 & 20.75 \\
\hline Suffolk & 20.01 & 4.53 & 19.18 & 20.85 \\
\hline Fairfax County & 16.45 & 4.57 & 12.19 & 15.50 \\
\hline Roberts Road & 20.68 & 6.75 & 20.69 & 22.00 \\
\hline
\end{tabular}

Table 4.16 provides the summary of the results. The $P-Y$ curve comparison between field measurements and 3-D FEM analyses, and theoretical estimations are shown for each of all five sites separately in Figs. 4.31 - 4.35. The differences in the slope of the curves between Plaxis 3D and field test are observed in all five sites. They may be due to the simplifications of ground condition, the installation effects, roughness of the pile surface, and pile material. Theoretical estimations using Broms's (1964b) theory and Brinch-Hansen's (1961) theory also have been marked in the P-Y curve by horizontal lines. 


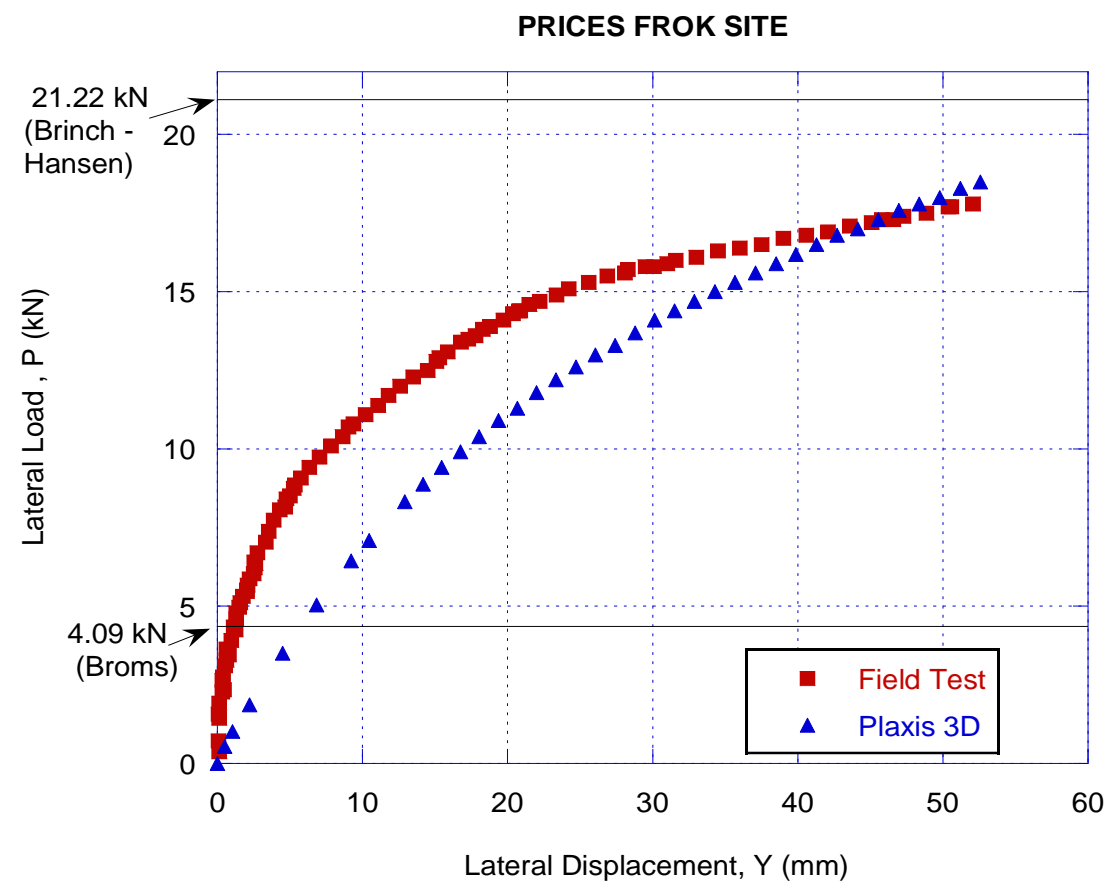

Figure 4.31 Comparison of the load-deformation curves for the Prices Fork site test

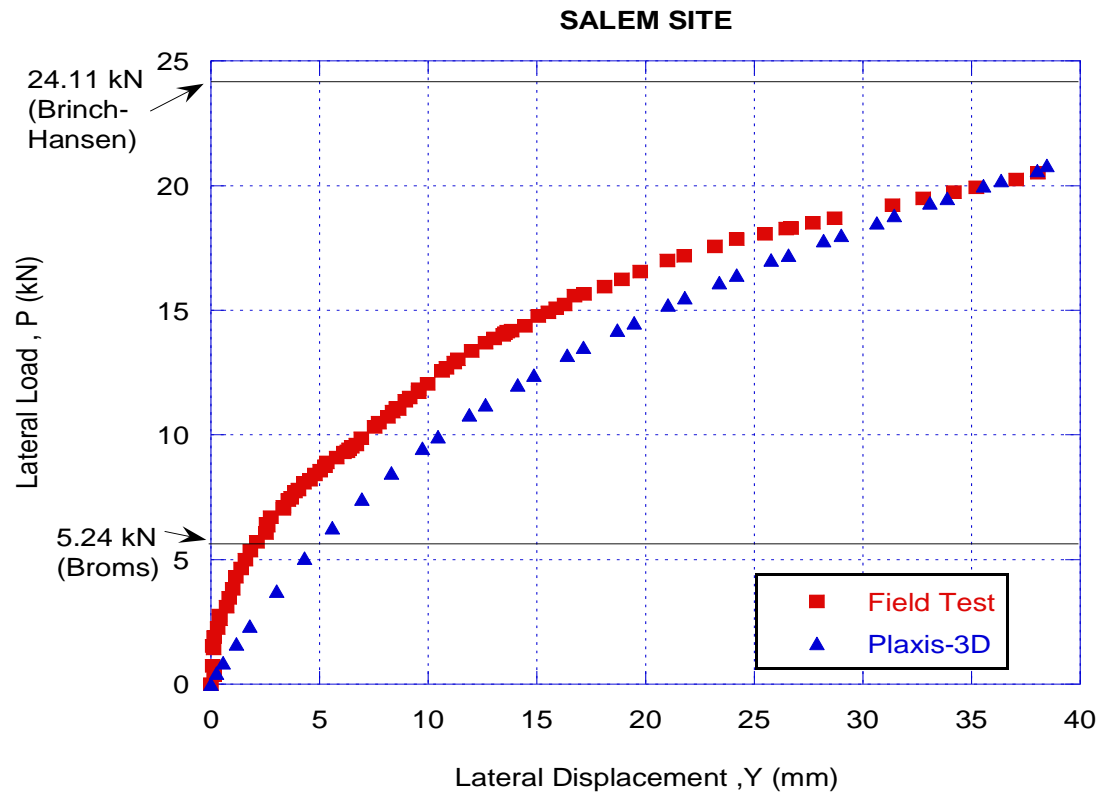

Figure 4.32 Comparison of the load-deformation curves for the Salem Site test 


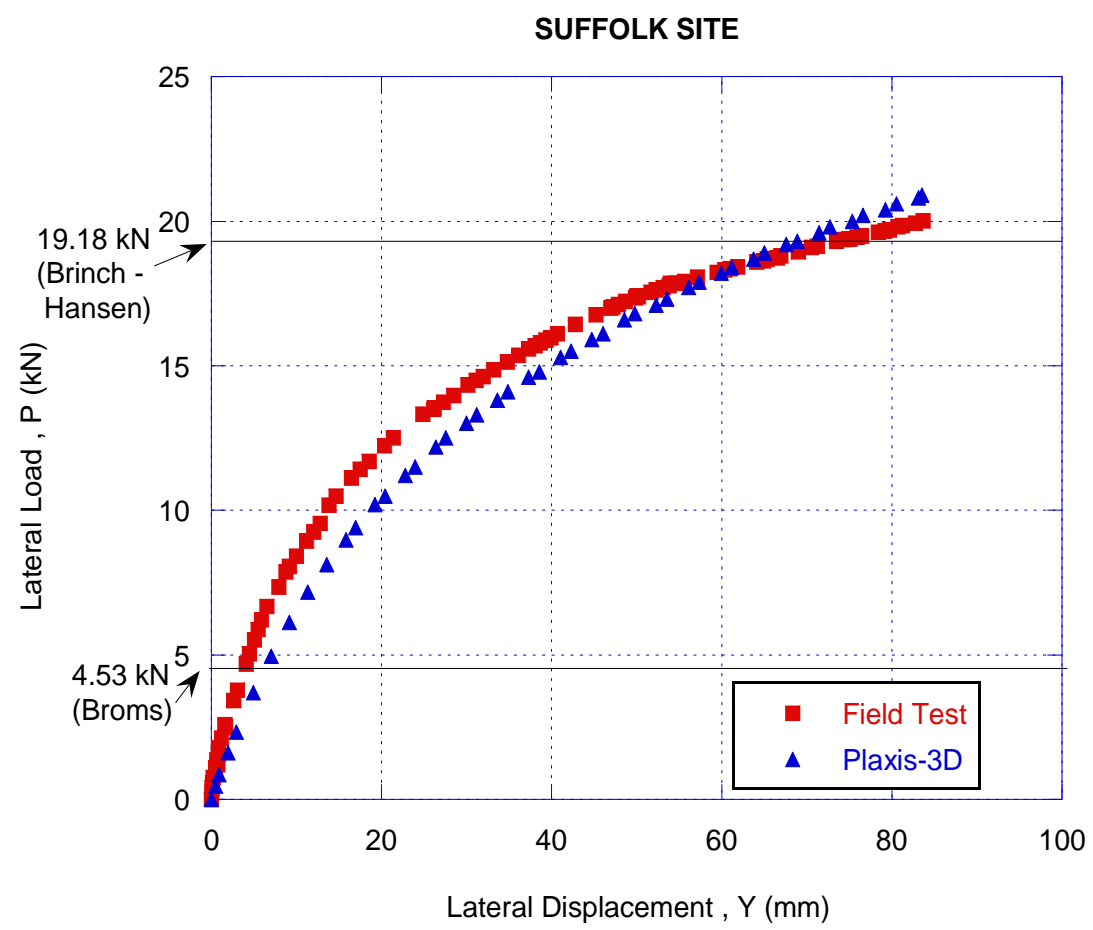

Figure 4.33 Comparison of the load-deformation curve for the Suffolk Site test

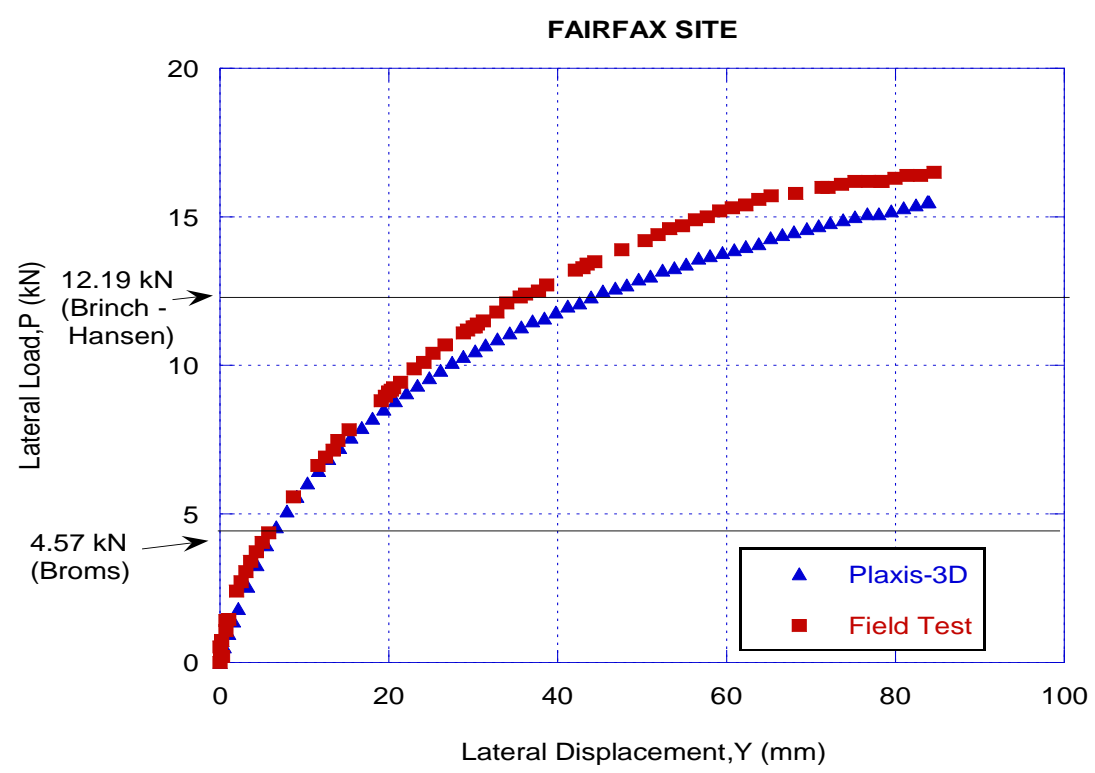

Figure 4.34 Comparison of the load-deformation curve for the Fairfax Site test 


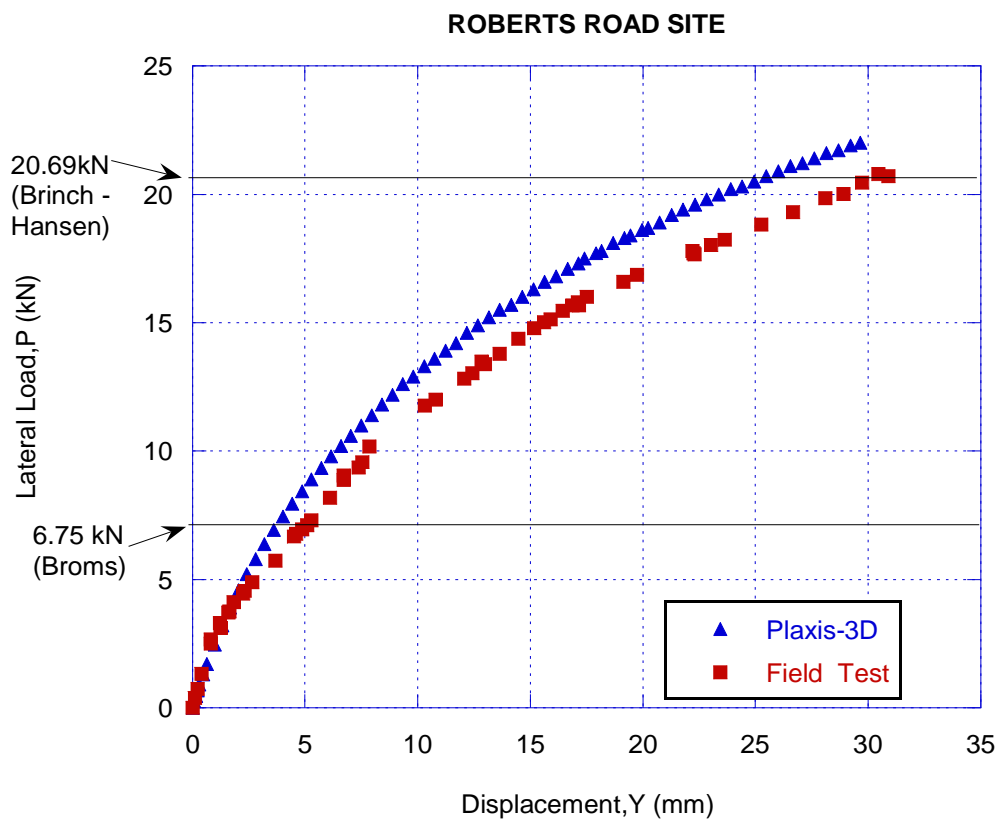

Figure 4.35 Comparison of the load-deformation curve for the Roberts Road Site test 


\subsection{SUMMARY}

In this Chapter, Plaxis 3D FEM models are calibrated and validated using the field load test results from five different sites in the state of Virginia, U.S. The following conclusions can be drawn:

- Based on comparison with field measurements of five shafts in Virginia, US, the 3-D FEM modelling method is feasible in simulation a drilled shaft under a lateral loading. 3-D FEM analysis results agree very well with the field measurements in terms of both ultimate lateral capacity and $P-Y$ curve.

- According to the comparison studies with 3-D FEM analysis, the Broms's (1964b) theory for cohesionless soils significantly underestimates the lateral load capacities of short shafts at all five test sites. The ratio on ultimate lateral capacity between Broms's (1964b) 3-D FEM analysis and theoretical prediction varies from 3.3 to 4.6 with an average value of 3.9 .

- Brinch-Hansen's (1961) theory, which considers both the cohesion and friction angle in the calculations, provides more accurate estimation of lateral capacity of shaft. The ratio of 3-D FEM over prediction using Brinch-Hansen's (1961) theory ranges from 0.86 (Salem) to 1.27 (Fairfax) with an average value of about 1.03.

- The embedded pile shows a good performance in modelling the laterally loaded rigid shafts. It is perfect in modelling the shaft having a "rough" surface $\left(R_{i n t}=1\right)$. The embedded pile is modelled without any local mesh refinement around the pile. However, in this research, very fine mesh is used, therefore the local mesh refinement around the pile is not required for a reasonable result. 
- The discrepancies between the 3-D FEM results and field measurements are caused by several factors. During the simulations, the soil is assumed to be a uniform soil block, which is different from the reality. In addition, the pile is also assumed uniform and perfectly elastic in the modelling, which may not be the same in reality Even though 3-D FEM can provide a very satisfactory simulation of shaft foundations for sound walls. 


\section{CHAPTER 5: PARAMETRIC STUDIES AND ANALYSES}

\subsection{INTRODUCTION}

In this Chapter, a parametric study is conducted on a single pile in the sandy soil conditions using Plaxis 3D. An experimental model test conducted by Uncuoglu \& Laman (2011) is used in evaluation of the modelling method first. After that, a parametric analysis is conducted to investigate the influence of soil parameters, including Young's modulus and friction angle.

\subsection{MODEL TEST - UNCUOGLU \& LAMAN CASE STUDY}

Fig. 5.1 shows a schematic view of the experimental model set-up used to examine the behaviour of laterally loaded pile problem by Uncuoglu \& Laman (2011). The model dimensions have been selected by Uncuoglu \& Laman (2011) with considering the influence of the soil boundaries to the pile (Table 5.1).

These tests have been conducted on 1/20-scale circular model shaft (steel, $0.05 \mathrm{~m}$ diameter, 0.2 $\mathrm{m}$ length). The lateral load is applied at a height of $0.3 \mathrm{~m}$ to a circular loading post (steel, 0.025 $\mathrm{m}$ diameter, and $0.330 \mathrm{~m}$ height) which is attached to the model shaft. Therefore, in the original dimensions, it can be assumed that the lateral load is applied at a height of $6 \mathrm{~m}$ above the sand surface. The tests have been conducted on different layers of dense sand, and loose sand combinations. The ultimate lateral load capacity is determined when the lateral load corresponds to the lateral displacement equal to $5 \mathrm{~mm}$ at the pile head.

Uncuoglu \& Laman (2011) also used the same geometry and same soil conditions to carry out an FEM analysis, including parametric studies using an early version of Plaxis 3D, Plaxis 3D Foundation. In this research, the newer version of Plaxis 3D, where the embedded pile method is implemented to model shaft, is used to conduct the FE studies, including parametric studies by using the same geometry model in the dense sand condition. For this research, a shaft in the 
dense sand condition only is considered. In the case of dense sand, ultimate lateral load capacity has been measured as $56 \mathrm{~N}$ to get $5 \mathrm{~mm}$ lateral displacement at the pile head.

\subsubsection{MODEL DIMENSIONS}

Table 5.1 Model dimensions by Uncuoglu \& Laman (2011)

\begin{tabular}{|c|c|c|}
\hline Internal dimensions (m) & Height $(\mathbf{m})$ & Embedment ratio (L/D) of the pile \\
\hline $0.96 \times 0.48$ & 0.5 & 4 \\
\hline
\end{tabular}

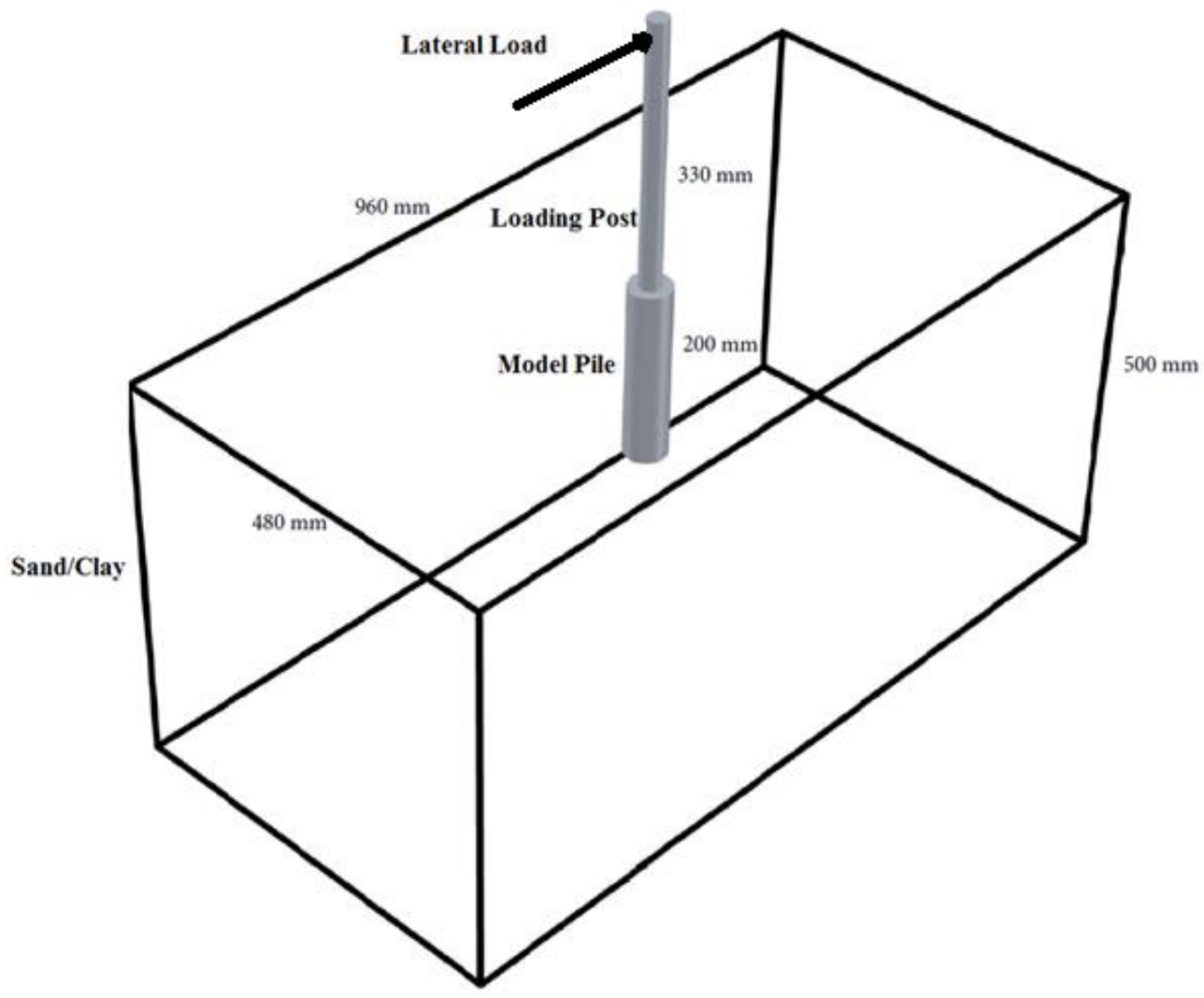

Figure 5.1 The schematic view of the model test setup used by Uncuoglu \& Laman (2011) 


\subsection{3-D FEM MODEL OF A LATERALLY LOADED PILE}

The model pile and the loading post are considered to be linearly elastic. The non-linear behaviour of the sandy soil is modelled using the M-C material model because of its easiness, reasonable number of model parameters, and reasonable accuracy. This model has a fixed yield surface, and the plastic straining does not affect this yield surface. The dilatancy is overestimated by the theory of associated plasticity for MC-type yield functions. So a plastic potential function is introduced as well as the yield function. The plastic potential function includes a parameter of dilatancy angle, which is required to model positive plastic volumetric strain increments.

A total of five input parameters are required in in the elastic plastic M-C model: the elasticity modulus (E), Poisson's ratio (v), internal friction angle $(\phi)$, cohesion (c), and dilatancy angle $(\psi)$. In the case of dry sand, cohesion (c) is considered as zero. However, in order to avoid convergence problems in the finite element analyses, Plaxis suggests a small value that is larger than $0.20 \mathrm{kPa}$. A value of $0.30 \mathrm{kPa}$ is used in this study for cohesion in the dry sand, a similar value was also used by Laman et al. (1999). The Jaky's formula (Jaky, 1944) offers at rest earth pressure coefficient $K_{0}=1-\sin \phi$, which is used to generate the initial stresses in the model. The total lateral load is applied in stages in order to get load-displacement relationships at the pile head. The input parameters of the pile and the loading post are given below in Table 5.2 . 
Table 5.2 Input parameters of the pile and the loading post

\begin{tabular}{|l|c|c|}
\hline Parameter & Model pile & Loading post \\
\hline Material & Steel & Steel \\
\hline Modulus of elasticity $\left(\mathrm{kN} / \mathrm{m}^{2}\right)$ & $210.0 \mathrm{E} 6$ & $210.0 \mathrm{E} 6$ \\
\hline Length $(\mathrm{m})$ & 0.2 & 0.33 \\
\hline Diameter $(\mathrm{m})$ & 0.050 & 0.025 \\
\hline Unit weight $\left(\mathrm{kN} / \mathrm{m}^{3}\right)$ & 77 & 77 \\
\hline Area $\left(\mathrm{m}^{2}\right)$ & $1.963 \mathrm{E}-3$ & $0.4910 \mathrm{E}-3$ \\
\hline Moment of Inertia $\left(\mathrm{I}_{3}\right)\left(\mathrm{m}^{4}\right)$ & $0.3068 \mathrm{E}-6$ & $0.03068 \mathrm{E}-3$ \\
\hline Moment of Inertia $\left(\mathrm{I}_{4}\right)\left(\mathrm{m}^{4}\right)$ & $0.3068 \mathrm{E}-6$ & $0.03068 \mathrm{E}-3$ \\
\hline
\end{tabular}

The embedded pile model is available in the latest version of PLAXIS 3D. In this embedded pile model, beam elements are connected to the adjacent soil by means of special interfaces identified as skin interface and foot interface (Plaxis 3D, 2013). Although the volume is not taken into account in the embedded pile, a specific elastic region around the pile whose dimension is same as the pile diameter is assumed where plastic behavior can be ignored. Due to this reason, the embedded pile is considered to behave similar to the volume pile. Hence, the embedded pile model is described as a 'simplified' model of the volume pile. The embedded pile is able to resemble the real pile behavior, including a lateral loaded pile (Dao, 2011).

In this Chapter, the embedded pile method is used to model a laterally loaded shaft in the sandy soil conditions. However, the installation effect of the pile is not taken into consideration. A parametric study is conducted to examine the influence on the lateral loaded shaft from the elasticity modulus, dilatancy angle, friction angle, and the soil-shaft interface. The ranges of these parameters are shown in Table 5.3. 
Table 5.3 Range of parameters investigated in this study

\begin{tabular}{|l|c|}
\hline Parameter & Sand \\
\hline Friction angle (degrees) & $47,44,41$ \\
\hline Dilation angle (degrees) & 0.3 \\
\hline Cohesion $\left(\mathrm{kN} / \mathrm{m}^{2}\right)$ & $10,1000,10000,30000$ \\
\hline Modulus of elasticity & $102000,98970,68250,0$ \\
\hline E reference $\left(\mathrm{kN} / \mathrm{m}^{2}\right)$ & 0.3 \\
\hline $\left.\mathrm{E}_{\text {increment }} \mathrm{kN} / \mathrm{m}^{2}\right)$ & 17.06 \\
\hline Poisson's ratio & 20.33 \\
\hline Dry unit weight of soil $\left(\mathrm{kN} / \mathrm{m}^{3)}\right.$ & $0.13,0.35,0.7$ \\
\hline Bulk unit weight of soil $\left(\mathrm{kN} / \mathrm{m}^{3}\right)$ & \\
\hline Strength-reduction factor at the interface, $R_{\text {inter }}$ & \\
\hline
\end{tabular}

In order to simplify the parametric study, the effect of any factor is investigated while the other factors are being fixed, e.g. the influence of elasticity modulus is investigated by changing its value while keeping the values of other parameters constant. The value of the applied lateral eccentric load in the parametric analyses carried out in sand condition is $80 \mathrm{~N}$.

\subsubsection{MESH GENERATION}

In order to eliminate the effect of the end boundaries of the soil layer on the results, optimum lateral distances are selected between pile and model boundaries. The coarseness of the finite element mesh may affect the results of numerical analyses. A series of trial analyses are performed with meshes of different coarseness. At the end of the analyses, a very fine mesh density is selected to be able to obtain consistent numerical results. A total of 32580 soil elements and 47641 nodes are used in the model with an average element size of $0.0033 \mathrm{~m}$. 


\subsubsection{TYPICAL TEST RESULTS}

A typical deformed mesh at the end of analysis is shown in Fig. 5.2

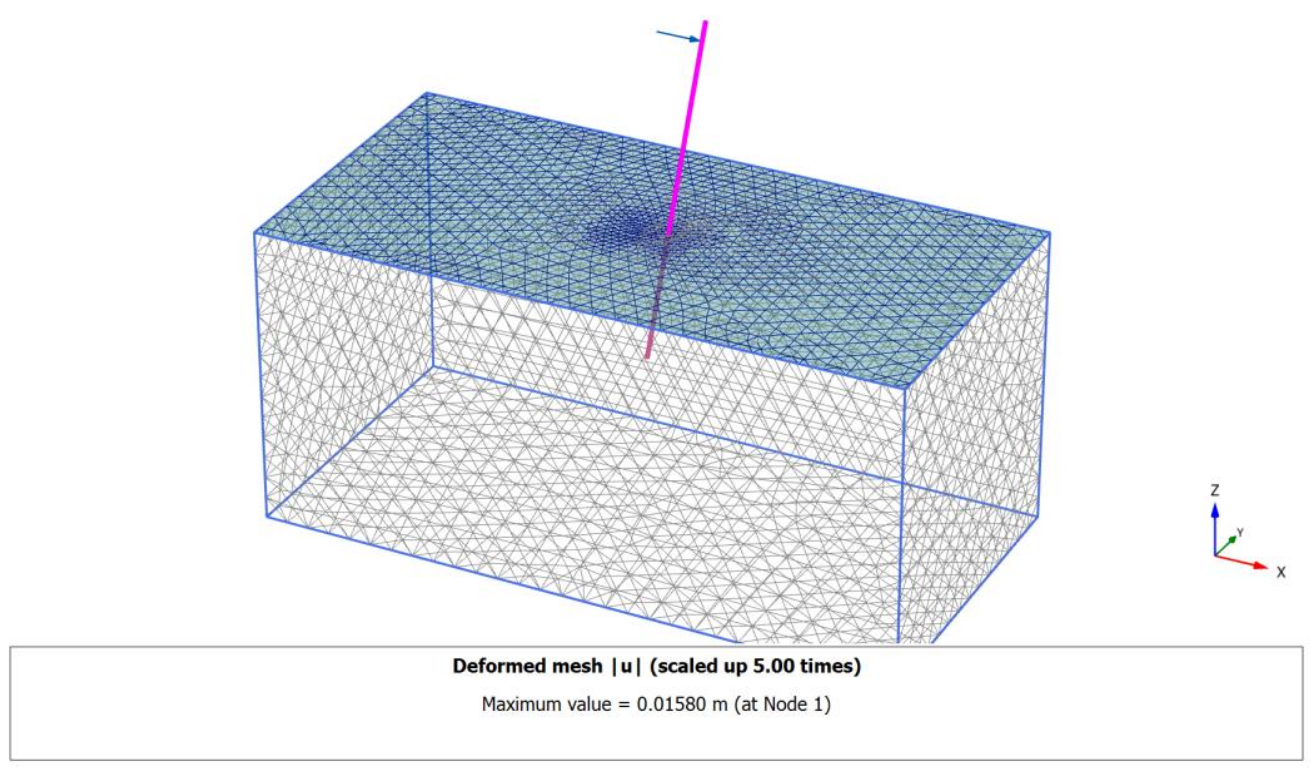

Figure 5.2 A typical deformed mesh after FEM analysis- Uncuoglu \& Laman case 


\subsection{3-D FEM PARAMETRIC ANALYSIS OF A LATERALLY LOADED PILE IN SAND}

\subsubsection{EFFECT OF INCREASING ELASTICITY MODULUS WITH DEPTH}

It is generally assumed that the strength and stiffness of the sand are increasing with depth. Nonlinear and permanent deformation behaviour in the sand is displayed under loading conditions. The deformability of the sand is varied depending on the void ratio extent. It can be assumed that the elasticity modulus increases linearly with depth for sands and it is possible to obtain acceptable solutions in this way (Yang and Liang, 2006). But in the horizontal direction, the modulus of elasticity of the sand can be considered as constant (Terzaghi, 1955). The variation of the elasticity modulus with depth is described by the following function.

$$
E=E_{\text {reference }}+E_{\text {increment }} y
$$

Where

$E_{\text {ref }}$ - The value of the elasticity modulus at the level of the reference depth ( $\left.y_{\text {reference }}\right)$

$E_{\text {increment }}$ : Increment of elasticity modulus with depth

$Y$ : Depth in the sand layer from the reference depth

The influence of the elasticity modulus of sand is analysed by investigating the lateral response of a short rigid pile that is subjected to lateral loading. A series of analyses are carried out with four different values of $E_{\text {reference }}$ selected to study the effect of the elasticity modulus in the sand. The results of the numerical analyses are summarized in Table 5.4. The lateral load-lateral displacement relations observed at the pile head is illustrated in Fig.5.3. 
The value of elasticity modulus for the dense sand is $30000 \mathrm{kPa}$. It has been obtained from drained triaxial test conducted under $100 \mathrm{kPa}$ confining pressure (Uncuoglu \& Laman, 2011). The dry unit weight of the dense sand is $17.06 \mathrm{kN} / \mathrm{m}^{3}$. Therefore, an effective stress value of 100 $\mathrm{kPa}$ can be obtained at a depth of $5.86 \mathrm{~m}$ below the sand surface in original conditions. This depth is equal to a depth of $0.29 \mathrm{~m}$ in the model dimensions. The $E_{\text {ref }}$ and $E_{\text {increment }}$ values of the elasticity modulus have been selected considering given data and using the equation 5.1.

Table 5.4 The influence of the elasticity modulus in the sand

\begin{tabular}{|c|c|c|c|c|}
\hline $\mathrm{E}_{\text {reference }}\left(\mathrm{kN} / \mathrm{m}^{2}\right)$ & 10 & 1000 & 10000 & 30000 \\
\hline $\mathrm{E}_{\text {increment }}\left(\mathrm{kN} / \mathrm{m}^{2} / \mathrm{m}\right)$ & 102000 & 98970 & 68250 & 0 \\
\hline \multicolumn{5}{|c|}{ Lateral displacement $u_{x=0}(\mathrm{~mm})$-Plaxis 3D Embedded pile } \\
\hline - Medium mesh density & 2.465 & 2.132 & 1.243 & 0.7275 \\
\hline - Fine mesh density & 2.702 & 2.286 & 1.315 & 0.785 \\
\hline - Very fine mesh density & 3.204 & 2.645 & 1.516 & 0.920 \\
\hline Depth of rotation point $\mathrm{R}_{\mathrm{D}}(\%)$ & 77 & 76.5 & 73.5 & 71 \\
\hline Rotation angle $\mathrm{R}\left(^{\circ}\right)$ & 1.19 & 0.99 & 0.591 & 0.371 \\
\hline $\begin{array}{l}\text { Lateral displacement } \mathrm{u}_{\mathrm{x}=0} \\
(\mathrm{~mm}) \text { - Plaxis } 3 \mathrm{D} \text { Foundation }\end{array}$ & 2.41 & 2.03 & 1.13 & 0.64 \\
\hline Dilatancy angle $\psi\left({ }^{\circ}\right)$ & \multicolumn{4}{|c|}{14} \\
\hline Friction angle $\left(^{\circ}\right)$ & \multicolumn{4}{|c|}{44} \\
\hline$R_{\text {inter }}$ & \multicolumn{4}{|c|}{0.7} \\
\hline Dry unit weight of soil $\left(\mathrm{kN} / \mathrm{m}^{3}\right)$ & \multicolumn{4}{|c|}{17.06} \\
\hline Unit weight of soil $\left(\mathrm{kN} / \mathrm{m}^{3}\right)$ & \multicolumn{4}{|c|}{20.33} \\
\hline Lateral load P (N) & \multicolumn{4}{|c|}{80} \\
\hline
\end{tabular}




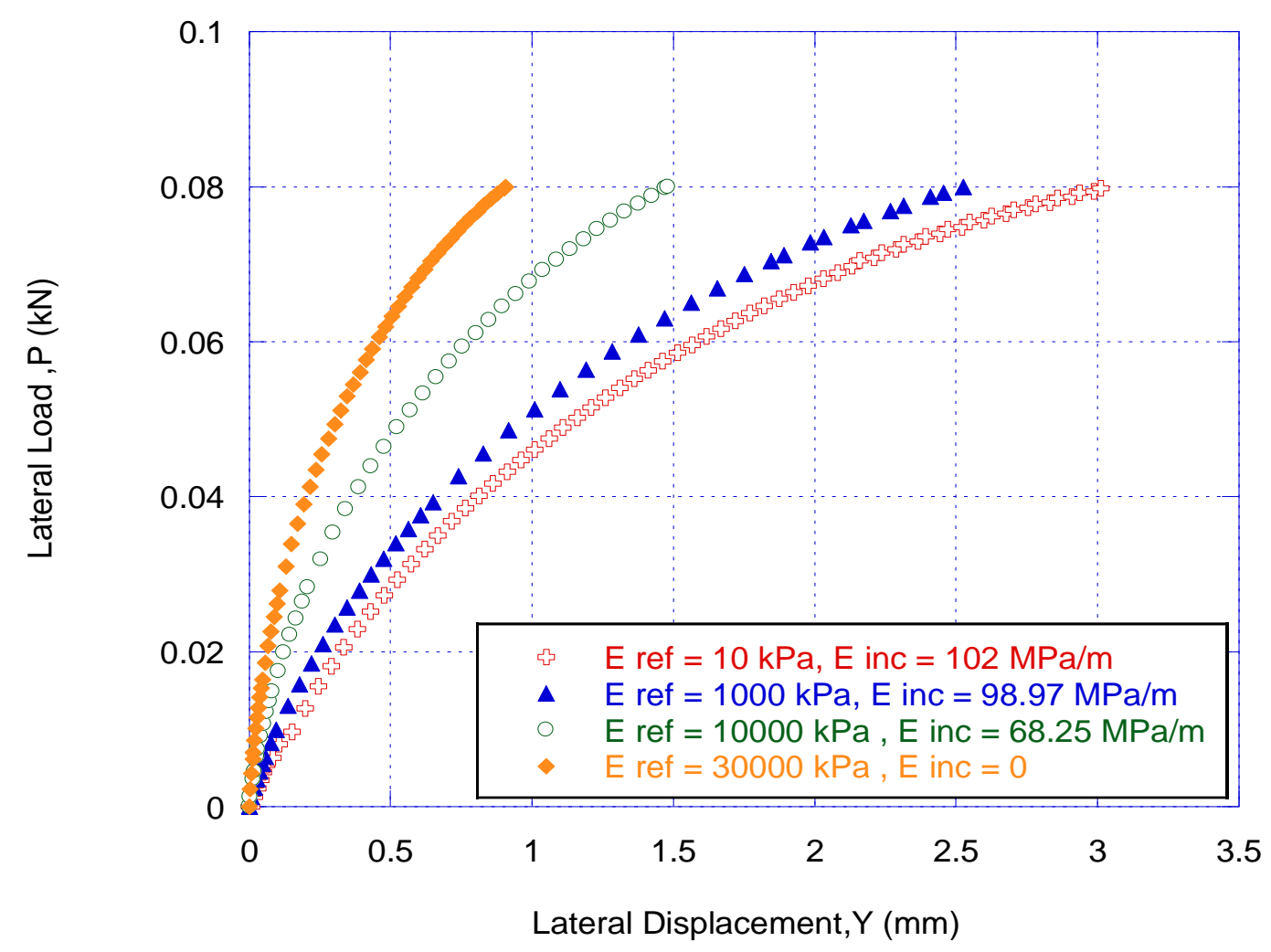

Figure 5.3 Influence on load-deformation curve from elasticity modulus

According to the analyses results, the lateral displacements observed at the pile head decrease with an increasing value of $E_{\text {reference. }}$ Furthermore, the rotation depth is moved towards the sand surface with an increasing value of $E_{\text {reference. }}$ It is also observed that the value of the lateral displacement at the pile head in the case of $E_{\text {reference }}=30 \mathrm{MPa}$ is around $71 \%$ lesser than in the case of $E_{\text {reference }}=10 \mathrm{kPa}$. However, when the same lateral displacement is considered, the lateral load capacity in the case of $E_{\text {reference }}=10 \mathrm{kPa}$ is nearly $56 \%$ smaller than that of the case of $\mathrm{E}_{\text {reference }}=30 \mathrm{MPa}$.

The Plaxis 3D Foundation results for the each cases are also given in Table 5.4 to compare with the results from the Plaxis 3D embedded pile. 


\subsubsection{EFFECT OF SAND DILATANCY}

The conventional theories use internal friction angle $(\phi)$ as the principal parameter to predict the behavior of a laterally loaded pile embedded in sand. Nevertheless, in these methods the effect of the volume change characteristics of sands based on the dilatancy of the pile's response have been ignored. The sand dilatancy plays an important role in the lateral load capacity of the pile (Fan and Long, 2005). A series of non-linear FE analyses are carried out to explore the effect of dilatancy on the behavior of a laterally loaded short rigid shaft. The following formula is used to obtain the values of the dilatancy angle.

$$
\phi=\phi_{\text {critical }}+\psi
$$

Bolton (1986) proposed the value of $\phi$ critical for quartz sand as $33^{\circ}$. Plaxis suggests this value as $30^{\circ}$. Both cases are considered in this study. The friction angle is taken constant as $44^{\circ}$ for the sand in the analyses. The input parameters and numerical results are presented in Table 5.5.

With the dilatancy angle is increased from $11^{\circ}$ to $14^{\circ}$, the lateral displacement at the pile head decreases by approximately $15 \%$. However, the variation of the dilatancy angle does not affect the depth of the rotation point greatly. With the use of a higher dilatation value, the volume of the sand mass mobilized due to lateral loading will be more. Consequently, a greater lateral load capacity is obtained with a higher dilatation value.

The effect of sand dilatancy on the load and deformation curve of a laterally loaded shaft is shown in Fig. 5.4. At smaller lateral displacement values, the effect of dilatancy is minimal with two curves almost overlapped. When the lateral displacement is increased, the influence from dilatancy becomes more with a higher ultimate lateral capacity and corresponding deformation. 
Table 5.5 The influence of the dilatancy angle in sand

\begin{tabular}{|c|c|c|}
\hline Dilatancy Angle $\psi\left({ }^{\circ}\right)$ & 11 & 14 \\
\hline \multicolumn{3}{|c|}{ Lateral displacement $u_{x=0}(\mathrm{~mm})$ - Plaxis 3D Embedded pile } \\
\hline - Medium mesh density & 2.810 & 2.519 \\
\hline - $\quad$ Fine mesh density & 3.236 & 2.828 \\
\hline - Very fine mesh density & 3.838 & 3.273 \\
\hline Depth of rotation point $\mathrm{R}_{\mathrm{D}}(\%)$ & 77.5 & 77 \\
\hline Rotation angle $\mathrm{R}\left({ }^{\circ}\right)$ & 1.418 & 1.209 \\
\hline $\begin{array}{l}\text { Lateral displacement } u_{x=0}(\mathrm{~mm}) \text { - Plaxis } \\
\text { 3D Foundation }\end{array}$ & 2.84 & 2.41 \\
\hline $\mathrm{E}_{\text {reference }}\left(\mathrm{kN} / \mathrm{m}^{2)}\right.$ & \multicolumn{2}{|c|}{10} \\
\hline $\mathrm{E}_{\text {increment }}\left(\mathrm{kN} / \mathrm{m}^{2} / \mathrm{m}\right)$ & \multicolumn{2}{|c|}{102000} \\
\hline Friction angle $\left({ }^{\circ}\right)$ & \multicolumn{2}{|c|}{44} \\
\hline Strength-reduction factor, $R_{\text {inter }}$ & \multicolumn{2}{|c|}{0.7} \\
\hline Dry unit weight of soil $\left(\mathrm{kN} / \mathrm{m}^{3)}\right.$ & \multicolumn{2}{|c|}{17.06} \\
\hline Unit weight of soil $\left(\mathrm{kN} / \mathrm{m}^{3)}\right.$ & \multicolumn{2}{|c|}{20.33} \\
\hline Lateral load P (N) & \multicolumn{2}{|c|}{80} \\
\hline
\end{tabular}




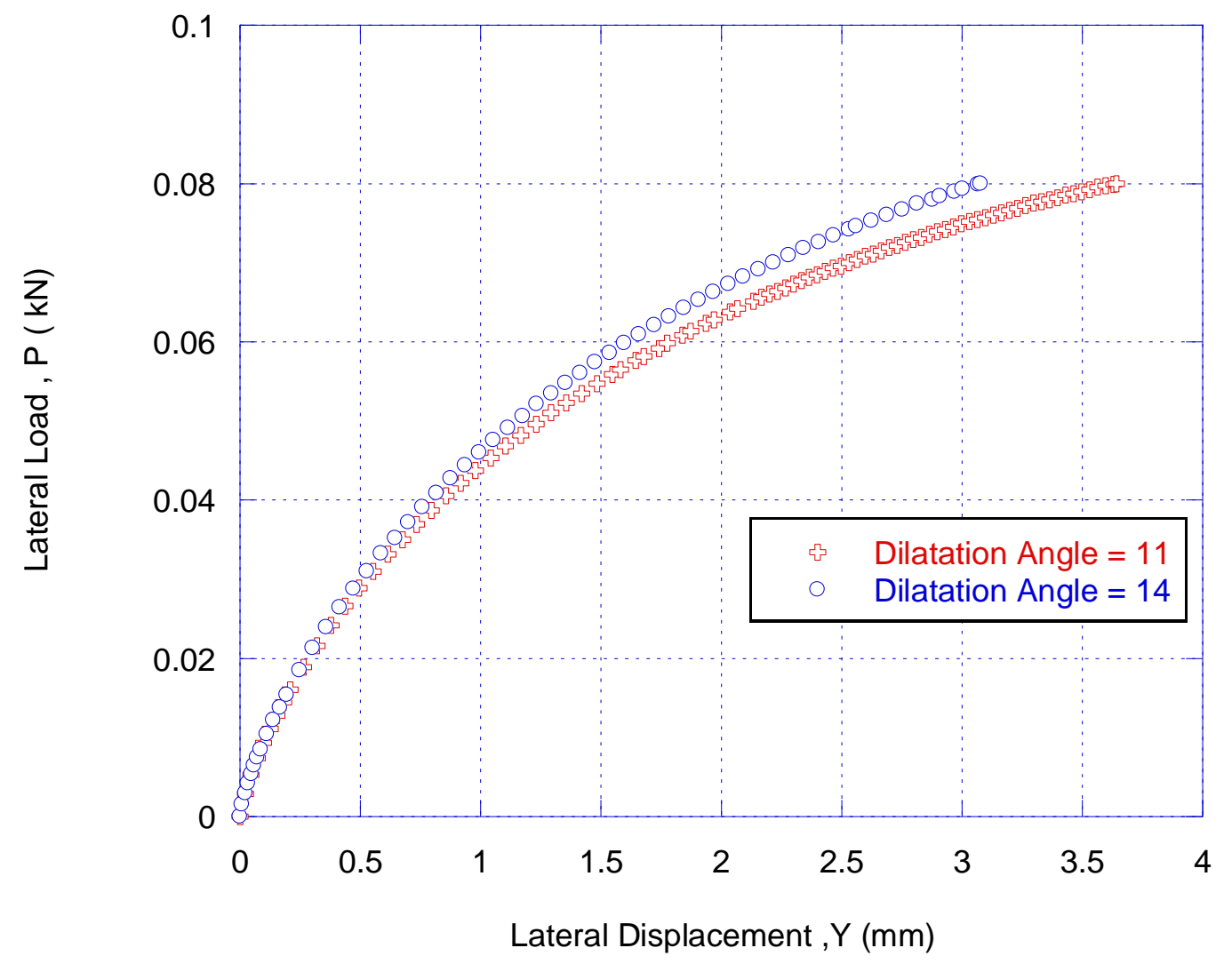

Figure 5.4 Influence on load - deformation curve from dilatation angle

The Plaxis 3D Foundation results for each cases on the dilatancy angle are also given in Table 5.5 to compare the results from the Plaxis 3D embedded pile. 


\subsubsection{INTERFACE BEHAVIOR}

The main parameter represented the interface behavior is the strength-reduction factor $\left(R_{\text {inter }}\right)$, which relates the property of the interface around the volume pile to the property of the surrounding soil. A suitable value for $R_{\text {inter }}$ can be chosen to model the side friction between the pile and the soil.

The following rules are applied to calculate the interface properties from the soil properties in the related data set and value of $R_{\text {inter }}$.

$$
\begin{aligned}
& c_{i}=R_{\text {inter }} c_{\text {soil }} \\
& \text { tan } \phi_{i}=R_{\text {inter }} \text { tan } \phi_{\text {soil }} \\
& \Psi i=0^{\circ} \text { for } R_{\text {inter }}<1, \text { otherwise } \Psi i=\Psi_{\text {soil }}
\end{aligned}
$$

Where

$$
\begin{aligned}
& c_{i} \text { - Cohesion of the interface } \\
& c_{\text {soil }} \text { - Cohesion of the soil } \\
& \phi_{i} \text { - Interface friction angle } \\
& \phi_{\text {soil }} \text {-Soil friction angle } \\
& \Psi_{i} \text {-Dilatancy angle of the interface } \\
& \Psi_{\text {soil }} \text {-Dilatancy angle of the soil }
\end{aligned}
$$

Generally, if the interface is considered weaker and more flexible than the associated soil layer, the value of $R_{\text {inter }}$ will be less than 1 . The behaviour of the interface element is affected by some factors, such as the pile installation method, the relative density of the sand, the roughness of the pile surface and pile material. Therefore, these factors should be considered to decide the value of $R_{\text {inter }}$. Due to this reason, a trial-and-error approach is needed to be used to determine the value of $R_{\text {inter }}$ in the analyses performed. 
The results of the analyses are summarized in Table 5.6. The results of the analyses in terms of lateral load-displacement relationships at the pile head with different $R_{\text {inter }}$ values are shown in Fig. 5.5.

Based on Fig. 5.5, it can be found that the lateral displacement at the pile head has not changed much with increasing $R_{\text {inter }}$ values. The depth of the rotation point also does not change noticeably. The reason for this behaviour is due to the limitation of the embedded pile model for a soil-pile interface modelling.

Table 5.6 The influence of the interface behaviour in sand

\begin{tabular}{|c|c|c|c|}
\hline Strength-reduction factor, $R_{\text {inter }}$ & 0.13 & 0.35 & 0.7 \\
\hline \multicolumn{4}{|c|}{ Lateral displacement $\mathrm{u}_{\mathrm{x}=0}(\mathrm{~mm})$-Plaxis 3D Embedded pile } \\
\hline - Medium mesh density & 2.810 & 2.704 & 2.704 \\
\hline - Fine mesh density & 3.236 & 2.998 & 2.998 \\
\hline - Very fine mesh density & 3.838 & 3.709 & 3.709 \\
\hline Depth of rotation point $\mathrm{R}_{\mathrm{D}}(\%)$ & 75 & 76.5 & 75.5 \\
\hline Rotation angle $\mathrm{R}\left({ }^{\circ}\right)$ & 1.427 & 1.379 & 1.388 \\
\hline $\begin{array}{l}\text { Lateral displacement } u_{x=0}(\mathrm{~mm})- \\
\text { Plaxis 3D Foundation }\end{array}$ & 5.85 & 4.17 & 2.84 \\
\hline Dry unit weight of soil $\left(\mathrm{kN} / \mathrm{m}^{3}\right)$ & \multicolumn{3}{|c|}{17.06} \\
\hline Unit weight of soil $\left(\mathrm{kN} / \mathrm{m}^{3}\right)$ & \multicolumn{3}{|c|}{20.33} \\
\hline Lateral load $P(\mathrm{~N})$ & \multicolumn{3}{|c|}{80} \\
\hline$E_{\text {reference }}\left(\mathrm{kN} / \mathrm{m}^{2}\right)$ & \multicolumn{3}{|c|}{10} \\
\hline$E_{\text {increment }}\left(\mathrm{kN} / \mathrm{m}^{2} / \mathrm{m}\right)$ & \multicolumn{3}{|c|}{102000} \\
\hline Dilatancy angle $\psi\left({ }^{\circ}\right)$ & \multicolumn{3}{|c|}{11} \\
\hline Friction angle $\left(^{\circ}\right)$ & \multicolumn{3}{|c|}{44} \\
\hline
\end{tabular}


According to the results provided in Table 5.6, there are large variations between the results of the Plaxis 3D embedded pile, and Plaxis 3D Foundation. The reason for these variations is also due to the limitation of the embedded pile model for a soil-pile interface modelling. However, in Plaxis 3D Foundation program the pile is modeled as a solid pile using volume elements which take into account the soil-pile interface behaviour.

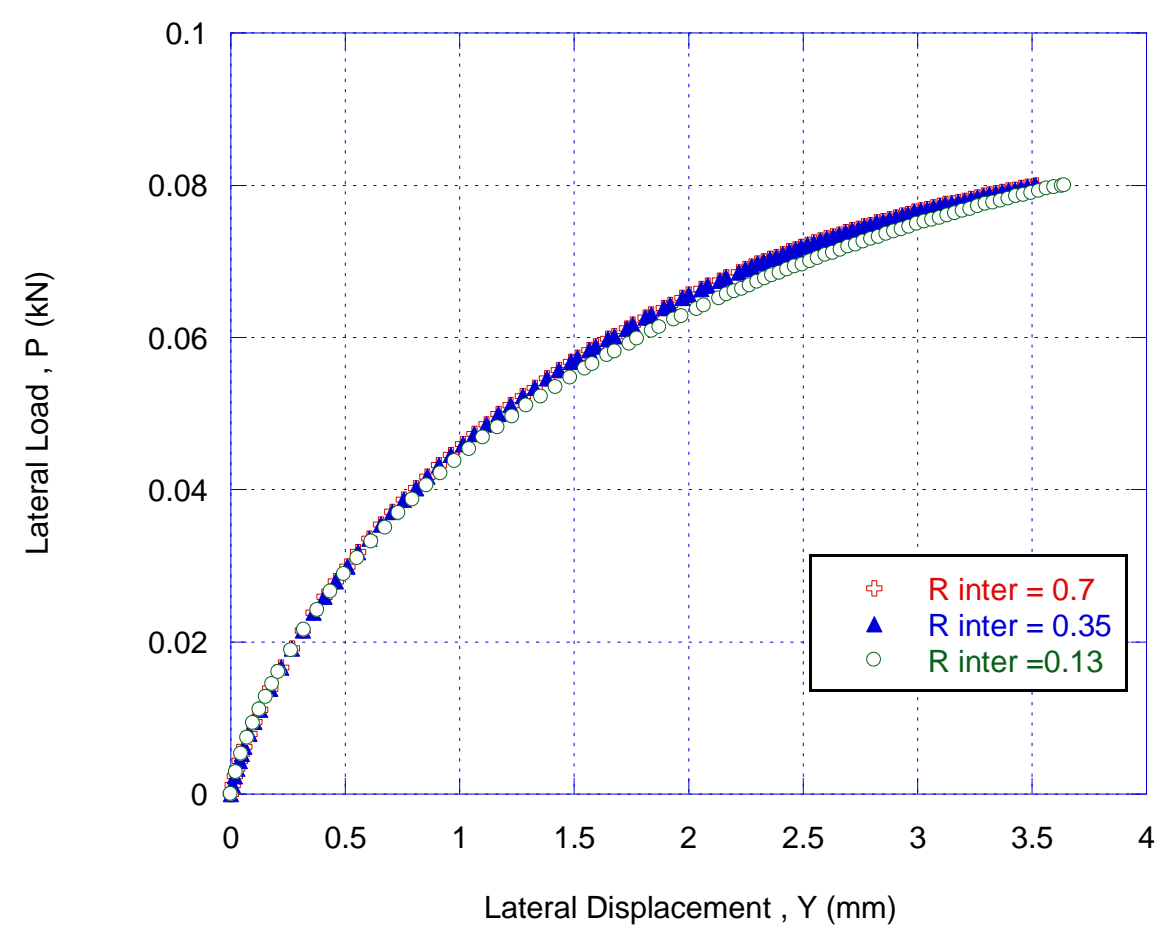

Figure 5.5 Influence on load-deformation curve from soil-shaft interface 


\subsubsection{SOIL FRICTION ANGLE}

This is a shear strength parameter of soil. The definition of friction angle can be derived from the M-C failure criterion, i.e. the angle on the Mohr's Circle of the shear stress and normal effective stresses at which shear failure occurs. Direct shear test or the triaxial stress test can be used to determine the soil friction angle in the laboratory. The friction angles used for parametric study are $47^{\circ}, 44^{\circ}$, and $41^{\circ}$. When soil friction angle increases, the lateral displacement on the pile head decreases and ultimate lateral load increases, as shown in Fig. 5.6.

The Plaxis embedded pile results are not compared with the Plaxis 3D Foundation results in the case of friction angle since they are not available in the Uncuoglu \& Laman study.

Table 5.7 The influence of the friction angle in sand

\begin{tabular}{|c|c|c|c|}
\hline Friction angle $\left({ }^{\circ}\right)$ & 47 & 44 & 41 \\
\hline \multicolumn{4}{|l|}{$\begin{array}{l}\text { Lateral displacement } \mathrm{u}_{\mathrm{x}=0}(\mathrm{~mm})- \\
\text { Plaxis 3D Embedded pile }\end{array}$} \\
\hline - Medium mesh density & 2.314 & 2.810 & 3.735 \\
\hline - Fine mesh density & 2.555 & 3.236 & 4.676 \\
\hline - Very fine mesh density & 2.869 & 3.838 & 7.079 \\
\hline Depth of rotation point $\mathrm{R}_{\mathrm{D}}(\%)$ & 77 & 75 & 77 \\
\hline Rotation angle $\mathrm{R}\left({ }^{\circ}\right)$ & 1.060 & 1.427 & 2.632 \\
\hline $\mathrm{E}_{\text {reference }}\left(\mathrm{kN} / \mathrm{m}^{2}\right)$ & \multicolumn{3}{|c|}{10} \\
\hline $\mathrm{E}_{\text {increment }}\left(\mathrm{kN} / \mathrm{m}^{2} / \mathrm{m}\right)$ & \multicolumn{3}{|c|}{102000} \\
\hline Dilatancy angle $\psi\left({ }^{\circ}\right)$ & \multicolumn{3}{|c|}{11} \\
\hline Strength-reduction factor, $R_{\text {inter }}$ & \multicolumn{3}{|c|}{0.7} \\
\hline Dry unit weight of soil $\left(\mathrm{kN} / \mathrm{m}^{3}\right)$ & \multicolumn{3}{|c|}{17.06} \\
\hline Unit weight of soil $\left(\mathrm{kN} / \mathrm{m}^{3}\right)$ & \multicolumn{3}{|c|}{20.33} \\
\hline Lateral Load P (N) & \multicolumn{3}{|c|}{80} \\
\hline
\end{tabular}




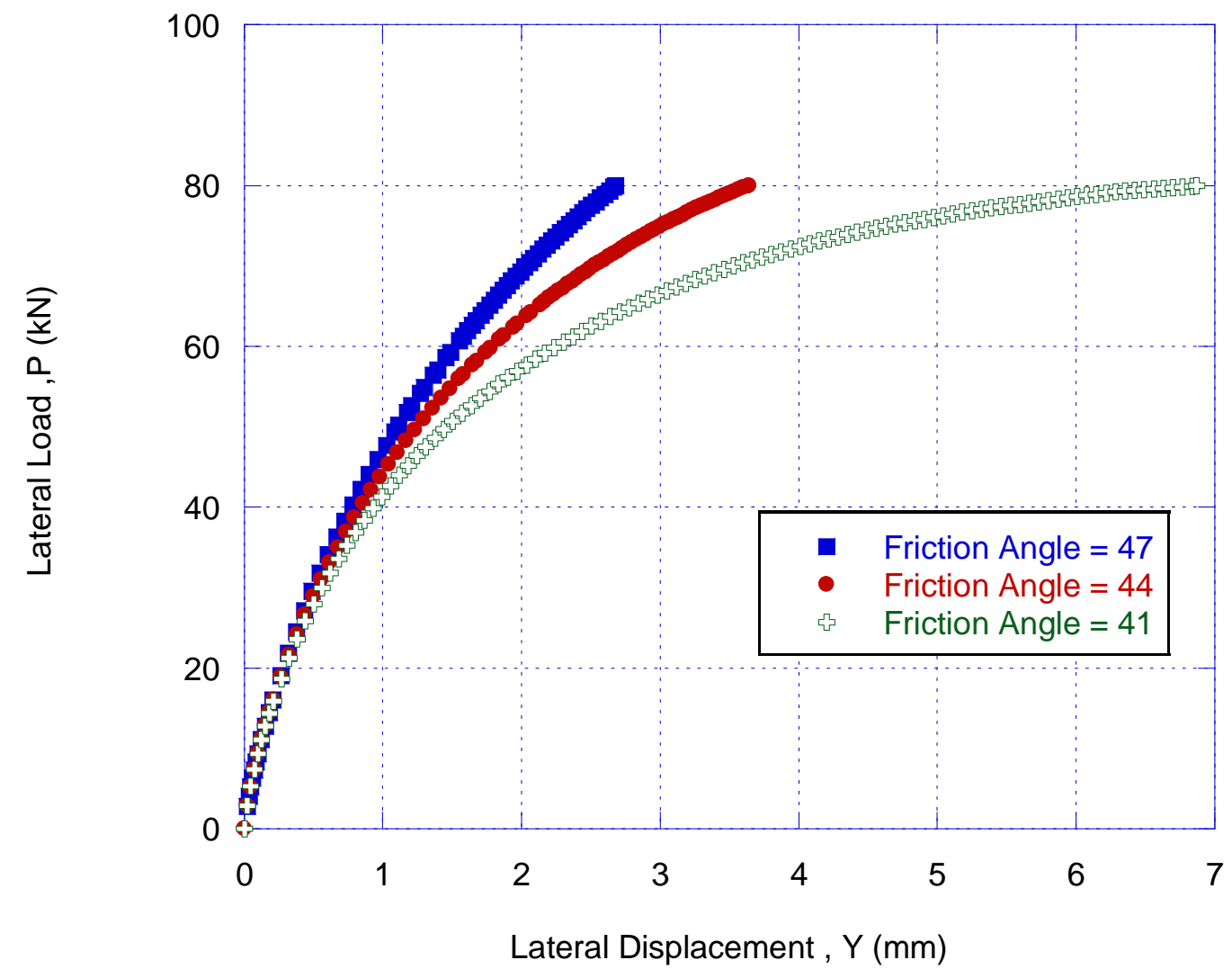

Figure 5.6 Influence of load-deformation curve from friction angle 


\subsection{COMPARISON WITH LAB TEST RESULTS}

In this case, the ultimate lateral load capacity of the model pile was determined using the Plaxis $3 \mathrm{D}$ embedded pile so as to get $5 \mathrm{~mm}$ lateral displacement at the pile head in $\mathrm{x}$ direction. The soil properties in Table 5.8 are used for this analysis. These numerical results are compared with model test results, and the Plaxis 3D Foundation results (Fig. 5.7). The lateral load capacities were $56.6 \mathrm{~N}, 51.0 \mathrm{~N}$, and $85.5 \mathrm{~N}$ for the model test, Plaxis 3D Foundation, and Plaxis 3D embedded pile, respectively. The numerical result from the Plaxis 3D embedded pile has overestimated the lateral load capacity than the model test, because, this laterally loaded pile case has a "smoother" surface. The pile is modeled as a solid pile using volume elements in the case of Plaxis 3D Foundation program. It shows again the Plaxis 3D embedded pile model has a limitation in modelling a pile with a smooth surface. Though it works perfect for a pile with a rough surface.

Table 5.8 Soil properties used for comparison study - Uncuoglu \& Laman case

\begin{tabular}{|l|c|}
\hline$E_{\text {reference }}\left(\mathrm{kN} / \mathrm{m}^{2}\right)$ & 10 \\
\hline$E_{\text {increment }}\left(\mathrm{kN} / \mathrm{m}^{2} / \mathrm{m}\right)$ & 102000 \\
\hline Dilatancy angle $\psi\left({ }^{\circ}\right)$ & 11 \\
\hline Friction angle $\left(^{\circ}\right)$ & 44 \\
\hline Strength-reduction factor, $R_{\text {inter }}$ & 0.13 \\
\hline Dry unit weight of soil $\left(\mathrm{kN} / \mathrm{m}^{3}\right)$ & 17.06 \\
\hline Unit weight of soil $\left(\mathrm{kN} / \mathrm{m}^{3}\right)$ & 20.33 \\
\hline
\end{tabular}




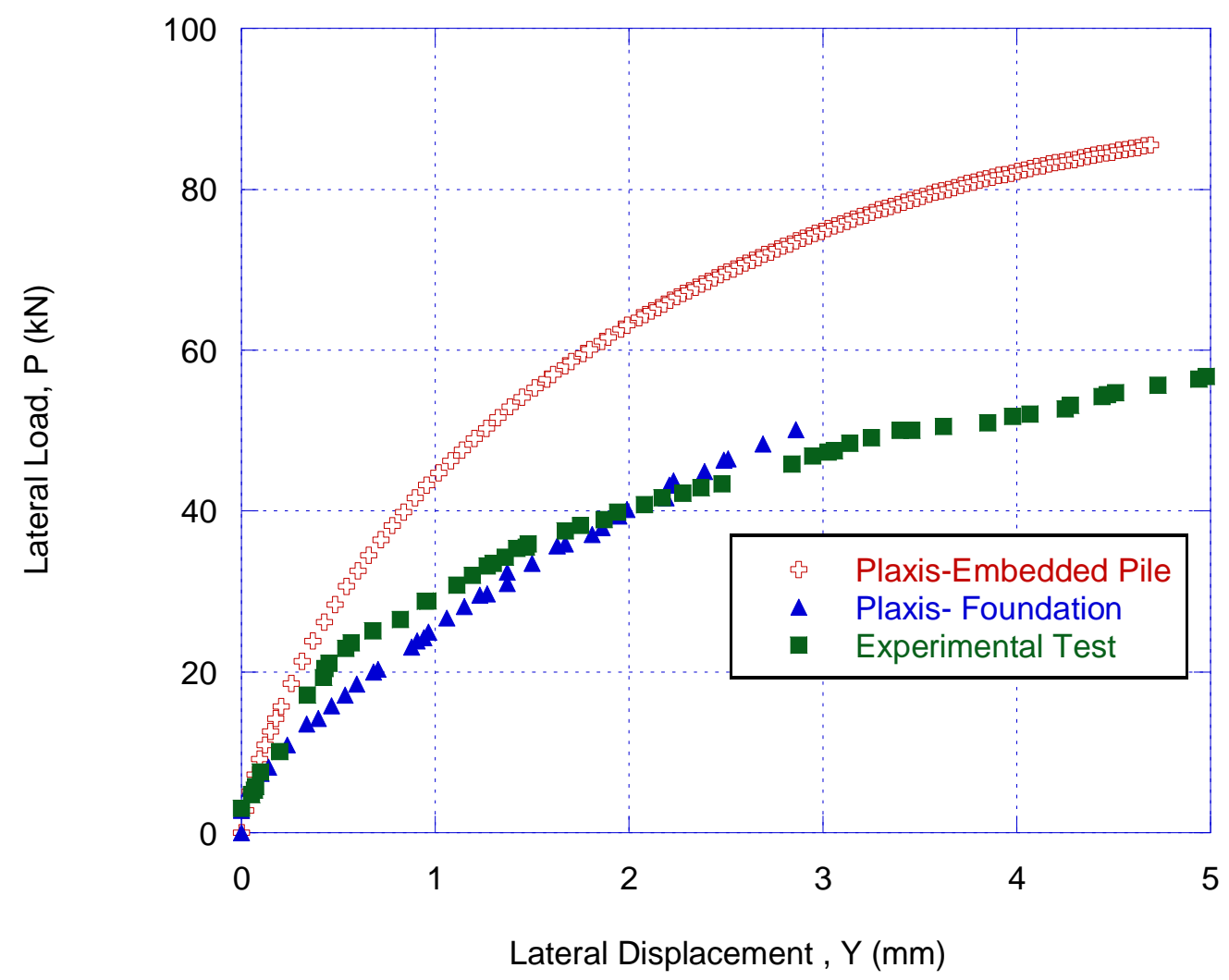

Figure 5.7 Comparison between FEM results and laboratory measurement

Table 5.9 Comparison of the results - Uncuoglu \& Laman case

\begin{tabular}{|l|l|l|l|}
\hline Method & Model test & $\begin{array}{l}\text { Plaxis 3D } \\
\text { Foundation }\end{array}$ & $\begin{array}{l}\text { Plaxis 3D } \\
\text { Embedded pile }\end{array}$ \\
\hline Lateral displacement, $\mathrm{U}_{\mathrm{x}}(\mathrm{mm})$ & 5 & 3 & 4.9 \\
\hline Ultimate lateral load $(\mathrm{N})$ & 56.6 & 51 & 85.5 \\
\hline
\end{tabular}




\section{6 SUMMARY}

In this Chapter, a parametric study is performed to investigate the influence on a laterally loaded shaft in sand from soil parameters. The following conclusions can be drawn:

- The friction angle is the most significant influence factor for the ultimate load capacity. According to the results, when soil friction angle increases, the lateral displacement on the pile head decreases and ultimate lateral capacity increases.

- The lateral displacements observed at the pile head decrease with an increasing value of $E_{\text {reference. }}$ Furthermore, the rotation depth is moved towards the sand surface with an increasing value of $E_{\text {reference. }}$

- It is also observed that the lateral displacement at the pile head decreases when the dilatancy angle is increased.

- The Plaxis 3D embedded pile has overestimated the lateral load capacity than the model test results, and the Plaxis 3D Foundation results. The embedded pile model has a tendency to overestimate the lateral capacity of a pile with a "smooth" surface. 


\section{CHAPTER 6: CONCLUSION AND DISCUSSION}

\subsection{SUMMARY}

In this research, Plaxis 3D embedded pile model, the published case studies from Helmers (1997) and Uncuoglu \& Laman (2011), the theories proposed by Broms and Birch-Hansen to estimate lateral load capacity of short shafts, have been analyzed to achieve the main findings.

In the case of Helmers (1997), the results obtained from numerical analyses are compared with the field load tests and the empirical theories. The FEM program, Plaxis 3D, has shown itself very reliable for lateral load capacity estimation by producing the satisfactory results.

The Broms's (1964b) theory for cohesionless soils, has underestimated the lateral load capacities when compared with the field results at all five test sites. This is because this theory doesn't calculate the cohesion of soils. It considers only the values of internal friction angle.

$>$ On average, an accurate measure of estimating shaft capacities has been provided by Brinch-Hansen's (1961) theory, which considers both cohesion and friction parts in the calculations. The shaft capacities have been slightly overestimated for the Price's Fork and Salem sites by this theory.

In the case of Uncuoglu \& Laman (2011), the effects of the elasticity modulus, friction angle, dilatancy, and interface behavior of the sand on the lateral load capacity of short rigid piles are investigated numerically by performing parametric studies using the Plaxis 3D. According to the results, it has been proved that the modulus of elasticity, friction angle, and dilatancy angle had a considerable effect on the behavior of short rigid piles subjected to lateral loads. However, there is not much variations in the results noticed in 
the case of interface behavior. In addition, Plaxis 3D embedded pile has overestimated the lateral load capacity than the Plaxis 3D Foundation results for a smooth pile used in the laboratory.

$>$ The embedded pile shows a good performance in modelling the laterally loaded pile. It is perfect in modelling the pile having a "rough" surface. However, it has a tendency to overestimate the displacement-load behavior if the pile having "smoother" surface is modeled. The reason is that the "slide" in the horizontal directions which is used to model the soil- pile interaction is not taken into account by the embedded pile. The Plaxis setting uses the "slide" to model the soil-pile interaction in axial direction. As a consequence, $R_{\text {inter }}$ has not influenced the displacements in case of a laterally loaded pile. In the meantime, the pile is modeled as a solid pile using volume elements in Plaxis 3D Foundation program.

The lateral load capacity of a drilled shaft is a 3-D problem. When a horizontal load is applied to the pile, 3-D region of soil around the pile is mobilized. Therefore 3-D analysis can be considered closer to reality than the 2-D analysis.

The 3-D FEM showed itself a good way to evaluate both the ultimate load capacity and the load-deflection curves for horizontal loaded shafts and piles, although the pile capacity for bending moments and shear forces should be double-checked before applying it to avoid structural failure of the pile.

There are also many other reasons for the variations in the numerical results, for example, the real conditions of saturation of the field cannot be applied in Plaxis. Moreover, in the simulations, the soil is considered as a uniform block, which does not represent the reality in the field.

The properties of the soil are determined mostly from the laboratory experiments which don't provide the actual field values. This also might cause the variation in the results. 


\subsection{RECOMMENDATIONS FOR FURTHER RESEARCH}

The future research studies shall be proceeded by considering the following recommendations.

- The conclusions are presented in this report based on the data from the case studies conducted by Helmers (1997) and Uncuoglu \& Laman (2011). Consequently, although the 3-D FEM has shown itself a good method, its applicability to other soil sites such as the GTA needs to be investigated thoroughly and treated with an extra care.

- According to the results, the embedded pile model shows a good performance in modelling a laterally loaded pile or shaft. It is perfect in modelling the pile having a "rough" surface $\left(R_{\text {inter }}=1\right)$. However, it has a tendency to overestimate the displacementload behavior if the pile having a "smoother" surface $\left(R_{\text {inter }}<1\right)$ is modeled. Therefore, an efficient modelling method shall be investigated in modelling a smooth pile using Plaxis 3D. In addition, the embedded pile is modelled without any local mesh refinement around the pile. When very fine mesh is used in the simulation, it may be time consuming. The installation effect is also not taken into consideration by the embedded pile model.

- In this research, the dynamic behavior of the wind load applicable to noise barrier walls along highways is not taken into consideration. Therefore, future study is required to consider the dynamic wind load and its effect on the lateral capacity of shafts.

- The M-C material model has been used in this research. The results show a satisfactory result in capturing the behavior of shaft/pile in soils in Virginia, U.S. Even though more advanced material models shall be implemented to see the influence of a material model on the results. 
- Normally, the pile or shaft is designed based on their structural capacity against moment or shear forces. Currently, the comparison between structural software and Plaxis is not considered and shall be investigated in the future. 


\section{REFERENCES}

AASHTO (1989). Guide Specifications for Structural Design of Sound Barriers. AASHTO, Washington D.C., 38 p.

AASHTO (1992). 1992 Revisions to Guide Specifications for Structural Design of Sound Barriers. AASHTO, Washington D.C., 38 p.

Baker, C. L., Lahti, L. R., \& Roumbanis, D. C. (1998). Urban Geology of Toronto and Surrounding Area. Urban Geology of Canadian Cities, Edited by PF Karrow and OL White. Geological Association of Canada, GAC Special Paper, 42, 323-352.

Baker, C.L., Lahti, L.R., \& Roumbanis, D.C. (1998). Urban geology of Toronto and surrounding area. Urban Geology of Canadian Cities. Edited by: P.F. Karrow, 42, 323-352.

Bierschwale, M. W., Coyle, H. M., \& Bartoskewitz, R. E. (1981). Lateral load tests on drilled shafts founded in clay. In Drilled piers and caissons, ASCE, 98-113.

Bolton, M.D. (1986). The strength and dilatancy of sands. Geotechnique, 36(1), 65-78.

Brinch-Hansen, J., (1961), The Ultimate Resistance of Rigid Piles against Transversal Forces. Bulletin No. 12, Geoteknisk Institut (The Danish Geotechnical Institute), Copenhagen, pp. 5-9.

Broms, B. B. (1964a). Lateral resistance of piles in cohesive soils. Journal of the Soil Mechanics and Foundations Division, ASCE, 90(2), 27-64.

Broms, B. B. (1964b). Lateral resistance of piles in cohesionless soils. Journal of the Soil Mechanics and Foundations Division, 90(3), 123-158.

Canadian National Model Construction Code Documents (2010): National Building Code of Canada. Retrieved from the web site: http://www.nationalcodes.nrc.gc.ca/eng/nbc/.

Czerniak, E. (1957). Resistance to overturning of single, short piles. Journal of the Structural Division, 83(2), 1-25.

Dao, T. P. T. (2011). Validation of PLAXIS embedded piles for lateral loading. Ph.D. Dissertation, TU Delft, Delft University of Technology.

Dickin, E.A. and Nazir, R. (1999). Moment-carrying capacity of short pile foundations in cohesionless soil. Journal of Geotechnical and Geoenvironmental Engineering, ASCE, 125 (1), 1-10. 
Dreimanis, A. (1989). Tills: their genetic terminology and classification. RP GOLDWAITH ET CL MATSCl-l (éd): Genetic classification of glacige-nic deposits, 17-83.

Duncan, J. M., Evans Jr, L. T., \& Ooi, P. S. (1994). Lateral load analysis of single piles and drilled shafts. Journal of geotechnical engineering, 120(6), 1018-1033.

El Naggar, M.H. and Wei, J.Q.(1999). Response of tapered piles subjected to lateral loading. Canadian Geotechnical Journal, 36, 52-71.

Fan, C. C., \& Long, J. H. (2005). Assessment of existing methods for predicting soil response of laterally loaded piles in sand. Computers and Geotechnics, 32(4), 274-289.

Halton Region Regional Municipality (2011). Region of Halton Noise Abatment Policy. Retrieved from Halton Region website: http://www.halton.ca/living_in_halton/roads_transportation/development_impacts/

Helmers, M. J. (1997). Use of ultimate load theories for design of drilled shaft sound wall foundations (Doctoral dissertation, Virginia Polytechnic Institute and State University).

Hendriks, R. (1998). Technical Noise Supplement: TeNS: a Technical Supplement to the Traffic Noise Analysis Protocol. California Department of Transportation, Environmental Program, Environmental Engineering-Noise, Air Quality, and Hazardous Waste Management Office.

Hu, Z., McVay, M., Bloomquist, D., Herrera, R. and Lai, P. (2006). Influence of torque on lateral capacity of drilled shafts in sands. Journal of Geotechnical and Geoenvironmental Engineering, ASCE, 132 (4), 456-464.

Jaky, J. (1944). The coefficient of earth pressure at rest. Journal of the Society of Hungarian Architects and Engineers, 78(22), 355-358.

Kézdi, Á., \& Rétháti, L. (1974). Handbook of Soil Mechanics. Vol. 1. Elsevier.

Knight Sr, L. E. (1997). Concrete post usable with a sound barrier fence. U.S. Patent No. 5,689,927. Washington, DC: U.S. Patent and Trademark Office.

Laman, M., King, G. J. W., \& Dickin, E. A. (1999). Three-dimensional finite element studies of the moment-carrying capacity of short pier foundations in cohesionless soil. Computers and Geotechnics, 25(3), 141-155.

Matlock, H., \& Reese, L. C. (1960). Generalized solutions for laterally loaded piles. Journal of the Soil Mechanics and Foundations Division, ASCE, 86(5), 63-94. 
Mayne, P. W., Kulhawy, F. H., Trautmann, C. H., \& Kulhawy, F. H. (1992). Experimental study of undrained lateral and moment behavior of drilled shafts during static and cyclic loading (No. EPRI-TR-100221). Electric Power Research Inst., Palo Alto, CA (United States); Cornell Univ., Ithaca, NY (United States). Geotechnical Engineering Group.

Plaxis, B. V. (2013). Netherlands User Manuals. Plaxis 3D.

Ports, D. M., \& Zdravkovic, L. (2001). Finite element analysis in Geotechnical engineering. Thomas Telford, London.

Poulos, H. G., \& Davis, E. H. (1980). Pile Foundation Analysis and Design. No. Monograph 1980.

Prat, M., Bisch, P., Millard, A., Mestat, P., \& Pijaudier-Calot, G. (1995). La modélisation des ouvrages.

Randolph, M. F., \& Houlsby, G. T. (1984). The limiting pressure on a circular pile loaded laterally in cohesive soil. Geotechnique, 34(4), 613-623.

Sawwaf, M.E. (2006). Lateral resistance of single pile located near geosynthetic reinforced slope. Journal of Geotechnical and Geoenvironmental Engineering, ASCE, 132 (10), 1336-1345.

Skempton, A. W. (1986). Standard penetration test procedures and the effects in sands of overburden pressure, relative density, particle size, ageing and overconsolidation. Geotechnique, 36(3), 425-447.

Strang, G., \& Fix, G. J. (1973). An Analysis of the Finite Element Method. Englewood Cliffs, NJ: Prentice-Hall.

Sun, K. (1994). Laterally loaded piles in elastic media. Journal of Geotechnical Engineering. ASCE, 120(8), 1324-1344.

Terzaghi, K. (1955). Evalution of conefficients of subgrade reaction. Geotechnique, 5(4), 297326.

Timoshenko S \& Goodier J.N. (1951). Theory of Elasticity. McGraw Hill, New York

Tomlinson M. and Woodward, J. (2008) Pile Design and Construction Practice, $5^{\text {th }}$ ed. Taylor \& Francis, New York.

Uncuoğlu, E., \& Laman, M. (2011). Lateral resistance of a short rigid pile in a two-layer cohesionless soil. 
Yang, K., \& Liang, R. (2006). Numerical solution for laterally loaded piles in a two-layer soil profile. Journal of Geotechnical and Geoenvironmental Engineering, ASCE, 132(11), 1436-1443. 